\title{
Advanced CIDI Emission Control System Development
}

\section{Final Technical Progress Report}

Reporting Period 07/01/2001-12/31/2005

\author{
Principal Author: \\ Christine Lambert \\ June 30, 2006 \\ (DE-FC26-01NT41103)
}

Ford Research \& Advanced Engineering

P.O. Box 2053, MD 3179, RIC Dearborn, MI 48121

\section{Subcontractors:}

FEV Engine Technology, Inc., Auburn Hills, Michigan

ExxonMobil Research and Engineering Company, Paulsboro, New Jersey 


\section{DISCLAIMER}

This report was prepared as an account of work sponsored by an agency of the United States Government. Neither the United States Government nor any agency thereof, nor any of their employees, makes any warranty, express or implied, or assumes any legal liability or responsibility for the accuracy, completeness, or usefulness of any information, apparatus, product, or process disclosed, or represents that its use would not infringe privately owned rights. Reference herein to any specific commercial product, process, or service by trade name, trademark, manufacturer, or otherwise does not necessarily constitute or imply its endorsement, recommendation, or favoring by the United States Government or any agency thereof. The views and opinions of authors expressed herein do not necessarily state or reflect those of the United States Government or any agency thereof. 


\section{ABSTRACT}

Ford Motor Company, with ExxonMobil and FEV, participated in the Department of Energy's (DOE) Ultra-Clean Transportation Fuels Program with the goal to develop an innovative emission control system for light-duty diesel vehicles. The focus on diesel engine emissions was a direct result of the improved volumetric fuel economy (up to $50 \%$ ) and lower $\mathrm{CO}_{2}$ emissions (up to $25 \%$ ) over comparable gasoline engines shown in Europe. Selective Catalytic Reduction (SCR) with aqueous urea as the NOx reductant and a Catalyzed Diesel Particulate Filter (CDPF) were chosen as the primary emission control system components. The program expected to demonstrate more than $90 \%$ durable reduction in particulate matter (PM) and NOx emissions on a lightduty truck application, based on the FTP-75 drive cycle. Very low sulfur diesel fuel $(<15$ ppm-wt) enabled lower PM emissions, reduced fuel economy penalty due to the emission control system and improved long-term system durability.

Significant progress was made toward a durable system to meet Tier 2 Bin 5 emission standards on a $6000 \mathrm{lbs}$ light-duty truck. A $40 \%$ reduction in engine-out NOx emissions was achieved with a mid-size prototype diesel engine through engine recalibration and increased exhaust gas recirculation. Use of a rapid warm-up strategy and urea SCR provided over $90 \%$ further NOx reduction while the CDPF reduced tailpipe PM to gasoline vehicle levels. Development work was conducted to separately improve urea SCR and CDPF system durability, as well as improved oxidation catalyst function. Exhaust gas NOx and ammonia sensors were also developed further. While the final emission control system did not meet Tier 2 Bin 5 NOx after 120k mi of aging on the dynamometer, it did meet the standards for HC, NMOG, and PM, and an improved SCR catalyst was shown to have potential to meet the NOx standard, assuming the DOC durability could be improved further. Models of DOC and SCR function were developed to guide the study of several key design factors for SCR systems and aid in the development of urea control strategy for maximum NOx reduction with minimum $\mathrm{NH}_{3}$ slip. A durable co-fueling system was successfully built and tested, with the help of service station nozzle and dispenser manufacturers, for simultaneous delivery of diesel fuel and aqueous urea to the vehicle. The business case for an aqueous urea infrastructure in the US for light-duty vehicles was explored. 


\section{TABLE OF CONTENTS}

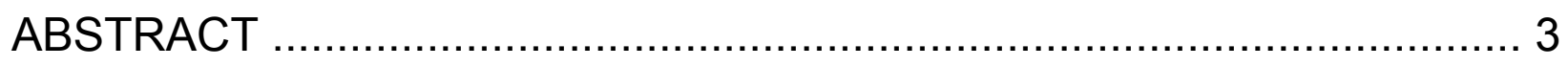

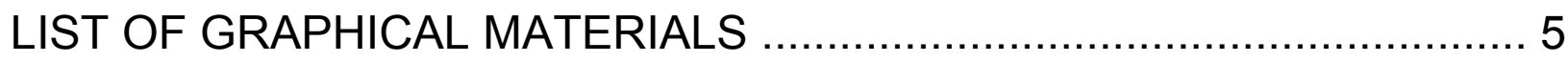

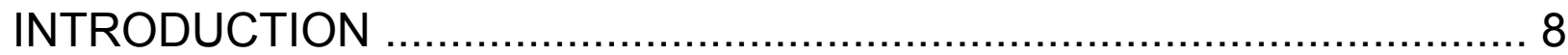

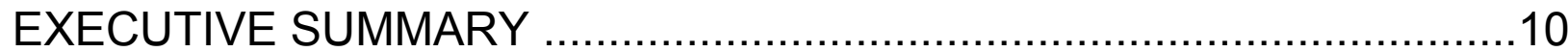

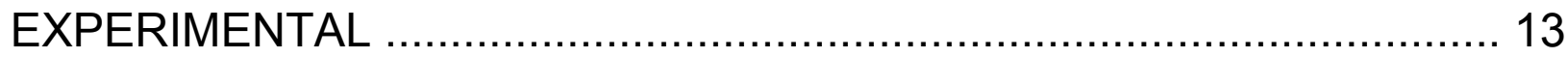

RESULTS AND DISCUSSION .................................................... 18

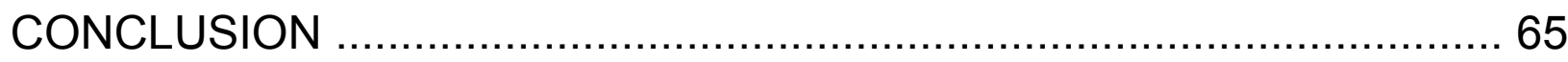

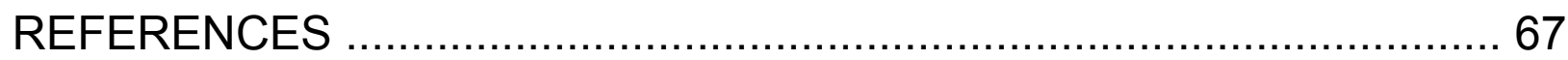

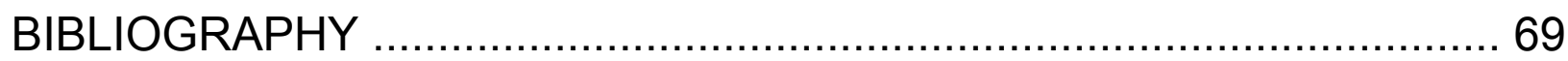

LIST OF ACRONYMS AND ABBREVIATIONS .................................. 71 


\section{LIST OF GRAPHICAL MATERIALS}

\section{TABLES:}

Table 1: FTP-75 emission standards* (passenger cars and light-duty vehicles).

Table 2: Composition of simulated diesel exhaust gas for DOC activity measurement.

Table 3: Composition of simulated diesel exhaust gas for SCR activity measurement.

Table 4: Composition of simulated diesel exhaust gas for LNT-SCR system activity measurement.

Table 5: Program fuel properties.

Table 6: Ash removed from CDPF.

Table 7: Urea cost estimates for manufacture, distribution, storage and delivery.

Table 8: Estimated capital cost of a single co-fueling dispenser with complete heating.

Table 9: Estimated annual operating cost of single co-fueling dispenser.

Table 10: Estimated costs for bottled urea to the retail location.

\section{FIGURES:}

Figure 1. Exhaust system configuration onboard the $6000 \mathrm{lbs}$ LDT (Light Duty Truck).

Figure 2. Vehicle speed trace for Ford High Speed Cycle, a corporate standard aging cycle. Urea SCR and CDPF system was aged on FEV's engine dynamometer $24 \mathrm{~h}$ per day, 5 to 6 days per week using this cycle.

Figure 3. Typical operating window for ammonia SCR with base metal/zeolite catalyst at $30 \mathrm{k} \mathrm{h}^{-1}$.

Figure 4. System A: Particulate filter placed closest to the engine.

Figure 5. System B: Oxidation and NOx reduction functions placed closest to the engine.

Figure 6. Predicted system efficiencies.

Figure 7. Summary of tailpipe emissions and system efficiencies over the cold-start FTP-75 with the LDT. The mixing of urea in the exhaust gas was improved and resulted in over $80 \%$ cycle NOx reduction.

Figure 8. Exhaust gas temperatures and space velocity (relative to the SCR catalyst volume) during the cold-start FTP-75 test with the LDT.

Figure 9. Performance of $120 \mathrm{k}$ mi aged DOC samples for oxidation of NO.

Figure 10. Performance of $120 \mathrm{k}$ mi aged DOC samples for oxidation of HC.

Figure 11. Effect of hydrocarbon concentration on DOC light-off.

Figure 12. Effect of hydrocarbon concentration on NO oxidation. 


\section{LIST OF GRAPHICAL MATERIALS (CON'T)}

Figure 13. NO oxidation comparison for fresh and aged DOC.

Figure 14. Initial SCR catalyst selection after $120 \mathrm{k} \mathrm{mi}$ of simulated hydrothermal aging $\left(670^{\circ} \mathrm{C}, 64 \mathrm{~h}\right)$. Evaluation was completed with $\mathrm{NO}$ and $\mathrm{NH} 3$ at a $1: 1$ ratio and an overall space velocity of $30 \mathrm{k} \mathrm{h}^{-1}$.

Figure 15. Effect of hydrocarbons on NOx conversion for a typical base metal/zeolite SCR catalyst.

Figure 16. Thermally aged SCR catalyst laboratory performance for catalyst sample A3. A feedgas $\mathrm{NO}_{x}$ of $80 \% \mathrm{NO}$ and $20 \% \mathrm{NO}_{2}$ was used. The $\mathrm{NH}_{3} / \mathrm{NO}_{x}$ ratio was equal to one.

Figure 17 . Thermally aged SCR catalyst (A3) laboratory performance. A feedgas $\mathrm{NO}_{\mathrm{X}}$ of $20 \% \mathrm{NO}$ and $80 \% \mathrm{NO}_{2}$ was used. The $\mathrm{NH}_{3} / \mathrm{NO}_{x}$ ratio was equal to one.

Figure 18. Performance of $120 \mathrm{k}$ mi aged SCR samples for reduction of $\mathrm{NO}$ with $\mathrm{NH}_{3}$ at $30 \mathrm{k} \mathrm{h}^{-1}$.

Figure 19. Performance of $120 \mathrm{k}$ mi aged SCR samples for reduction of $\mathrm{NO}$ with $\mathrm{NH}_{3}$ at $30 \mathrm{k}$ and $100 \mathrm{k} \mathrm{h}^{-1}$.

Figure 20. Effect of aging on amount of ammonia stored on SCR catalysts.

Figure 21. Example of LNT-SCR concept. LNT generates ammonia during reduction of NOx that is stored by the SCR for further NOx reduction.

Figure 22. Performance comparison of LNT-SCR concept in a laboratory flow reactor. All cores were aged for the equivalent of $120 \mathrm{k} \mathrm{mi}$.

Figure 23. Sensitivity of supplier ammonia sensor in the laboratory.

Figure 24. Sensitivity of supplier ammonia sensor on the LDT.

Figure 25. Average tailpipe emissions and system efficiencies from four cold-start FTP75 simulations with fresh catalysts on the engine dynamometer. Enhanced mixing of reductant in the exhaust gas and additional EGR resulted in a low mileage TP NOx level below Tier 2 Bin 5. THC (Total Hydrocarbon) results are shown while the emission standard does not include methane (NMOG Non-Methane Organic Gases).

Figure 26. Cold-start FTP-75 performance results on FEV's engine dynamometer.

Figure 27. FTP-75 performance of the $50 \mathrm{k}$ mi aged catalyst system on the $6000 \mathrm{lbs}$ LDT.

Figure 28. Downpipe DOC performance at $25 \mathrm{k}$ and $50 \mathrm{k}$ mi of durability.

Figure 29. Predicted FTP-75 performance of the $50 \mathrm{k} \mathrm{mi}$ aged catalyst system on the LDT with rapid warm-up during cold-start.

Figure 30 . FTP-75 performance of the $120 \mathrm{k} \mathrm{mi}$ aged catalyst system on the $6000 \mathrm{lbs}$ LDT.

Figure 31. FTP-75 performance with $4 \mathrm{k}$ DOC and $120 \mathrm{k}$ mi aged SCR catalyst on the $6000 \mathrm{lbs}$ LDT. 


\section{LIST OF GRAPHICAL MATERIALS (CON'T)}

Figure 32. FTP-75 performance with $4 \mathrm{k} \mathrm{mi} \mathrm{DOC}$ and improved SCR catalyst $\mathrm{B}$ on the $6000 \mathrm{lbs}$ LDT.

Figure 33. FTP-75 performance with $120 \mathrm{k} \mathrm{mi} \mathrm{DOC} \mathrm{and} \mathrm{improved} \mathrm{SCR} \mathrm{catalyst} \mathrm{B} \mathrm{on} \mathrm{the}$ $6000 \mathrm{lbs}$ LDT.

Figure 34. Schematic of the SIMTWC based DOC model.

Figure 35. A typical pulsator generated $D O C$ reaction map.

Figure 36. Model data match in a typical HC light-off experiment.

Figure 37. DOC model prediction and data showing DOC out $\mathrm{NO}_{2}$ over an FTP-75 test. The $\mathrm{DOC}$ out $\mathrm{NO}_{2}$ during the first 200 s is negligible.

Figure 38. Inhibition effect of $\mathrm{HCs}$ on the $\mathrm{DOC}$ generation of $\mathrm{NO}_{2}$.

Figure 39. Semi-empirical model of the DOC+SCR system.

Figure 40. Representative SCR reaction map showing the effect of $\mathrm{NO}_{2}$ on SCR performance.

Figure 41. Amount of $\mathrm{NO}_{2}$ generated from three different $\mathrm{DOC}$ formulations - (1) no $\mathrm{NO}_{2}$, (2) $50 \% \mathrm{NO}_{2} / \mathrm{NOx}$ and (3) $20 \% \mathrm{NO}_{2} / \mathrm{NOx}$ - to study the effect of $\mathrm{NO}_{2}$ on SCR performance.

Figure 42. Model predictions over an FTP-75 test showing that SCR performance is better when a DOC that produces $50 \% \mathrm{NO}_{2} / \mathrm{NO}_{\mathrm{X}}$ is placed upstream of the SCR as compared to that the DOC that produces no $\mathrm{NO}_{2}$.

Figure 43. Trade-off between using a larger $\mathrm{DOC}$ to produce more $\mathrm{NO}_{2}$ and reduced SCR performance due to lower SCR input temperatures.

Figure 44. Comparison of the predicted and measured data for $\mathrm{NH}_{3}$ adsorption/desorption at a beginning temperature of $150^{\circ} \mathrm{C}$ (Sample B).

Figure 45. Comparison of the measured data for $\mathrm{NH}_{3}$ oxidation $\left(\mathrm{NH}_{3}=350 \mathrm{ppm}\right.$, space velocity $=30 \mathrm{k} \mathrm{h}^{-1}, \mathrm{O}_{2}=14 \%$ ).

Figure 46. Comparison of the measured data $\left(\mathrm{NH}_{3}=350 \mathrm{ppm}\right.$ and $\mathrm{NO}=350 \mathrm{ppm}$, space velocity $=30 \mathrm{k} \mathrm{h}^{-1}, \mathrm{O}_{2}=14 \%$ ).

Figure 47. Comparison of the measured data $\left(\mathrm{NH}_{3}=350 \mathrm{ppm}, \mathrm{NO}=280 \mathrm{ppm}\right.$ and $\mathrm{NO}_{2}=$ 70ppm, space velocity $=30 \mathrm{k} \mathrm{h}^{-1}, \mathrm{O}_{2}=14 \%$ ).

Figure 48. Comparison of the measured data $\left(\mathrm{NH}_{3}=350 \mathrm{ppm}\right.$ and $\mathrm{NO}=350 \mathrm{ppm}$, space velocity $\left.=30 \mathrm{k} \mathrm{h}^{-1}\right)$.

Figure 49. SCR outlet gas temperature prediction during the FTP-75.

Figure 50. Cumulative NOx comparison of the model prediction with measured data during the FTP-75.

Figure 51. Comparison of $\mathrm{NH}_{3}$ slip prediction with measured data during the FTP-75.

Figure 52. Comparison of $\mathrm{N}_{2} \mathrm{O}$ prediction vs measured data during the FTP-75.

Figure 53. Prototype co-fueling dispenser. 


\section{INTRODUCTION}

Reducing particulate matter (PM) and NOx emissions are primary concerns for diesel vehicles required to meet 2007 Federal Tier 2 and California LEVII emission standards (Table 1). These standards represent a 90-95\% reduction from current Federal Tier 1 diesel standards.

Table 1: FTP-75 emission standards* (passenger cars and light-duty vehicles).

\begin{tabular}{|l|c|c|c|c|}
\hline & \multicolumn{2}{|c|}{$50 k$ mi } & \multicolumn{2}{c|}{ 120k mi } \\
\hline $\begin{array}{l}\text { Standard } \\
\text { (g/mi) }\end{array}$ & NOx & PM & NOx & PM \\
\hline LEVII & 0.05 & ---- & 0.07 & 0.01 \\
\hline Tier 2, Bin 5 & 0.05 & ---- & 0.07 & 0.01 \\
\hline
\end{tabular}

${ }^{*}$ SFTP standards not included.

The high oxygen content of diesel exhaust makes onboard NOx control complicated. The available technologies for high NOx reduction in lean environments include Selective Catalytic Reduction (SCR), in which NOx is continuously removed through active reductant injection over a catalyst; and Lean NOx Traps (LNT), which are materials that adsorb NOx under lean conditions and require periodic regeneration under rich conditions to reduce $\mathrm{NOx}$ to $\mathrm{N}_{2}$. The technology with the most potential to achieve $90+\%$ NOx conversion with minimal or no fuel economy penalty is SCR with an ammonia-based reductant such as aqueous urea. Ammonia-SCR has been used extensively for stationary source NOx control [1]. Its high selectivity and reactivity with NOx in high $\mathrm{O}_{2}$ environments makes SCR attractive for diesel vehicle use. The main reactions are shown below:

urea decomposition:

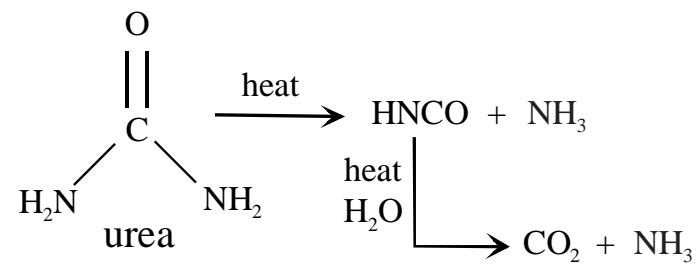

$N O_{x}$ reduction:

$$
\begin{aligned}
& 4 \mathrm{NO}+4 \mathrm{NH}_{3}+\mathrm{O}_{2} \longrightarrow 4 \mathrm{~N}_{2}+6 \mathrm{H}_{2} \mathrm{O} \\
& 6 \mathrm{NO}_{2}+8 \mathrm{NH}_{3} \longrightarrow 7 \mathrm{~N}_{2}+12 \mathrm{H}_{2} \mathrm{O} \\
& 2 \mathrm{NH}_{3}+\mathrm{NO}+\mathrm{NO}_{2} \longrightarrow 2 \mathrm{~N}_{2}+3 \mathrm{H}_{2} \mathrm{O}
\end{aligned}
$$

Compared to ammonia, aqueous urea is much safer for onboard vehicle use. Feasibility has been proven by past work at Ford [2,3], Volkswagen [4], Mack Truck [5] and DaimlerChrysler [6]. 


\section{INTRODUCTION (CON'T)}

Control of diesel PM is accomplished with a periodically regenerated wall-flow ceramic filter. The filter may be washcoated with precious metal to help oxidize $\mathrm{HC}$ and collected soot, commonly referred to as a Catalyzed Diesel Particulate Filter (CDPF). A diesel oxidation catalyst (DOC) may also be placed upstream of the filter to further aid in filter regeneration. The DOC also provides reduction in hydrocarbon $(\mathrm{HC})$ and carbon monoxide (CO) emissions, as well as NO oxidation for more durable SCR function.

Alternative catalyst systems for high NOx conversion on light-duty vehicles that do not require urea include a Lean NOx Trap (LNT) that generates ammonia during reduction of NOx, followed by an SCR catalyst that adsorbs the ammonia and provides further NOx reduction to $\mathrm{N}_{2}$. The main advantage of the concept, besides not requiring urea, is to replace a portion of the LNT volume with base metal/zeolite SCR catalyst, saving cost by reducing precious metal in the system. 


\section{EXECUTIVE SUMMARY}

The goal of Ford Motor Company's participation in the Ultra-Clean Transportation Fuels Program was to develop an exhaust emission control system that provides high efficiency particulate matter (PM) and NOx reduction to meet Tier 2 Bin 5 emission standards $(0.01 \mathrm{~g} / \mathrm{mi} \mathrm{PM}, 0.07 \mathrm{~g} / \mathrm{mi} \mathrm{NOx})$. The high efficiency was obtained through the use of a Catalyzed Diesel Particulate Filter (CDPF) and the most advanced NOx control available. Very low sulfur diesel fuel enabled low PM emissions, reduced the fuel economy penalty associated with the emission control system, and increased the longterm durability of the system.

With Ford as the prime contractor, the project team included an emission control technology developer and CIDI engine manufacturer (Ford), a fuel and catalyst technology developer (ExxonMobil Research \& Engineering), catalyst suppliers, and an outside research facility (FEV). The program recently was completed with a variety of associated accomplishments from the Ford, EMRE and FEV team members.

An initial systems analysis was completed and Selective Catalytic Reduction (SCR) using aqueous urea was chosen due to its potential for very high NOx reduction with minimal fuel economy penalty across a wide range of driving conditions. Modeling of the proposed aftertreatment system revealed that the SCR catalyst should be placed upstream of the particulate filter in order to achieve Tier 2 Bin 5 emission levels for $\mathrm{NO}_{\mathrm{x}}$. This was attributed to the faster warm-up of the SCR catalyst during cold-start if it is placed upstream of the filter. A mid-sized diesel engine, installed on a dynamometer at FEV, achieved steady-state NOx conversions of up to $98 \%$ with the SCR system. Engine-out emissions data were collected on a $6000 \mathrm{lb}$ Ford light-duty truck (LDT) equipped with a similar mid-sized diesel engine. Over $80 \%$ cycle NOx conversion on the cold-start FTP-75 was achieved, approaching the Tier 2 Bin 8 NOx standard with fresh catalysts. The SCR system consisted of a NOx sensor, oxidation catalyst, aqueous urea injection and base metal/zeolite catalyst. Mixing devices were used to enhance the distribution of urea in the exhaust gas. An ammonia sensor, believed to be the most reliable to date, was tested downstream of the SCR system with favorable results.

Later the fresh system was improved to achieve over $90 \%$ NOx conversion on the coldstart FTP-75. Tailpipe emissions were below Tier 2 Bin 5 levels at $0.041 \mathrm{~g} / \mathrm{mi}$ NOx and $0.001 \mathrm{~g} / \mathrm{mi}$ PM. A rapid warm-up strategy and an improved exhaust gas recirculation (EGR) system were used. $\mathrm{HC}$ and $\mathrm{CO}$ emissions were also below Tier 2 Bin 5 levels. The SCR system consisted of a NOx sensor, oxidation catalyst, aqueous urea injection and base metal/zeolite SCR catalyst. A spray target, developed by FEV for this program, was used to enhance the distribution of reductant in the exhaust gas. The CDPF was located downstream of the SCR catalyst. The fuel economy penalty for NOx control was less than $1 \%$ for rapidly warming the catalysts during cold-start. 


\section{EXECUTIVE SUMMARY (CON'T)}

Laboratory work on catalyst improvements was an ongoing part of the program. DOC sample $A B$ had the highest $\mathrm{NO}_{2}$ production after aging, although it was not the best catalyst for low temperature $\mathrm{HC}$ conversion. Long-chain $\mathrm{HC}$ such as those present in diesel fuel were found to suppress NO oxidation. Base metal/zeolite type SCR catalysts were selected for their wide temperature window of operation. The importance of an upstream oxidation catalyst for more durable SCR performance was demonstrated in the laboratory using a feedgas mixture containing both $\mathrm{NO}$ and $\mathrm{NO}_{2}$. The negative impact of $\mathrm{HC}$ and sulfur on SCR NO$\times$ conversion and the conditions required to regain high NOx conversion were quantified. SCR catalysts were improved for greater thermal durability to withstand filter regeneration conditions. A new SCR catalyst exhibited over $80 \%$ NO conversion at key conditions for the FTP- $75\left(200^{\circ} \mathrm{C}\right.$ and $\left.30 \mathrm{k} \mathrm{h}^{-1}\right)$ after hydrothermal aging, whereas the previous best catalyst had about $50 \%$ NO conversion at those conditions. Two other new SCR catalysts, designed for high temperature NOx conversion, showed almost $100 \%$ NO conversion in the range of 350 to $550^{\circ} \mathrm{C}$ at $30 \mathrm{k} \mathrm{h}^{-1}$, and over $80 \%$ conversion at $100 \mathrm{k} \mathrm{h}^{-1}$. These catalysts were thought to be appropriate for test cycles with high speeds and loads such as those for engines that are certified on an engine dynamometer.

Laboratory and vehicle testing of pre-production $\mathrm{NOx}$ and prototype $\mathrm{NH}_{3}$ sensors was successful. The NOx sensor behavior in diesel exhaust and its cross-sensitivity with $\mathrm{NH}_{3}$ was understood, and initial results with a prototype $\mathrm{NH}_{3}$ sensor onboard the vehicle were favorable. Nearly complete regeneration of a CDPF was achieved within ten minutes, or less time than one FTP-75 cycle.

Alternative catalyst systems for high NOx conversion on light-duty vehicles that do not require urea were explored. These systems included a Lean $\mathrm{NO}_{x}$ Trap (LNT) that generated ammonia during reduction of NOx, followed by an SCR catalyst that adsorbed the ammonia and provided further NOx reduction to $N_{2}$. Laboratory results with aged catalyst cores showed the potential to replace a portion of the LNT volume with base metal/zeolite SCR catalyst, saving cost by reducing precious metal in the system. However, the fuel penalty and cost of the LNT-SCR system was estimated to be higher than for a comparable urea SCR system, and also the LNT-SCR system proved to be too complex to be studied any further as part of this program.

The improved Urea SCR and CDPF system was aged to $50 \mathrm{k} \mathrm{mi}$ on the engine dynamometer using an accelerated aging cycle that mimicked both city and highway driving modes. Over 300 CDPF regenerations occurred. FTP-75 performance at 50k $\mathrm{mi}$ was lower than expected due to lack of rapid warm-up during cold-start due to difficulties with the prototype diesel engine. Tailpipe emission levels on the FTP-75 were $0.091 \mathrm{~g} / \mathrm{mi}$ NOx, $0.002-0.005 \mathrm{~g} / \mathrm{mi} P M, 0.021 \mathrm{~g} / \mathrm{mi} \mathrm{NMOG}$, and $1.78 \mathrm{~g} / \mathrm{mi} \mathrm{CO}$. These are below Tier 2 Bin 5 except for NOx, which was projected to be $0.05 \mathrm{~g} / \mathrm{mi}$ if the rapid warm-up procedure had been working. 


\section{EXECUTIVE SUMMARY (CON'T)}

The improved Urea SCR and CPDF system was aged successfully for another 70k mi on the engine dynamometer using the same aging cycle, bringing the total aging time to about 2500 engine hours or an equivalent total mileage of $120 \mathrm{k} \mathrm{mi}$. The CDPF was regenerated a total of 643 times, with each regeneration typically lasting ten minutes, including six minutes with the SCR at high temperature (over $600^{\circ} \mathrm{C}$ ). In all, the SCR spent approximately $64 \mathrm{~h}$ at high temperature during the durability phase, similar to the lab aging time. PM, NMOG and CO emissions were within Tier 2 Bin 5 limits, but the Bag 1 NOx emissions were higher than expected due to the lack of a reliable rapid warm-up strategy during cold start. Overall FTP-75 NOx conversion was $74 \%$ conversion with $0.128 \mathrm{~g} / \mathrm{mi}$ at the tailpipe, exceeding the Tier 2 Bin 5 standard at $120 \mathrm{k}$ $\mathrm{mi}$ of $0.07 \mathrm{~g} / \mathrm{mi}$ NOx. This result was improved by using a fresh DOC upstream of the $120 \mathrm{k} \mathrm{mi} \mathrm{SCR}(0.091 \mathrm{~g} / \mathrm{mi})$; therefore, the durability of the DOC had a significant impact on SCR performance. A further improved SCR catalyst was oven-aged and tested with the $120 \mathrm{k} \mathrm{mi} \mathrm{DOC} \mathrm{resulting} \mathrm{in} 0.08 \mathrm{~g} / \mathrm{mi} \mathrm{NOx}$, and $0.06 \mathrm{~g} / \mathrm{mi}$ NOx with a fresh DOC. Again the importance of DOC durability for long-term NOx reduction was shown.

A semi-empirical DOC model was developed based on the SIMTWC framework. The model was calibrated using the pulsator reactor data and was used to predict $\mathrm{NO}_{2}$ generated by the DOC. The model was able to explain the inhibition effect of HCs on $\mathrm{NO}_{2}$ production. The DOC model was used along with an SCR model to explain (1) the importance of $\mathrm{NO}_{2}$ generated in the DOC for the increased SCR performance, and (2) the trade-off between increasing the size of the catalyst to generate more $\mathrm{NO}_{2}$ and the reduction of SCR performance due to the reduced SCR input temperatures.

A more detailed SCR model was developed that considered energy and mass balances with the description of $\mathrm{NH}_{3}$ algorithms, $\mathrm{NH}_{3}$ oxidation as well as several selective $\mathrm{NH}_{3}$ reactions with NOx. Overall the model prediction results agreed well with the measured data. The successful development of the SCR model will guide the study of several key design factors for SCR systems and aid in the development of urea control strategy for maximum NOx reduction with minimum $\mathrm{NH}_{3}$ slip.

Discussions with a major nozzle supplier were successful regarding modifications to the Ford-designed diesel/urea co-fueling nozzle for improved durability and reliability. Additionally a major dispenser manufacture provided EMRE with equipment for a cofueling demonstration. A co-fueling dispenser for urea and diesel fuel was tested successfully to minus $20^{\circ} \mathrm{F}$. Heaters were used in the urea tank and delivery system to prevent freeze. A potential nozzle durability issue was discovered that caused leakage of aqueous urea into the diesel fuel line. Cross contamination of urea into diesel remained a concern for co-axial design due to urea line connection within the diesel refueling stream. A second-generation nozzle had a reduced leak rate. The economics of an aqueous urea infrastructure for light-duty (LD) service stations in the US were studied. The cost of co-fueled urea in 2007 was estimated to be high in the short-term during introduction, and was greatly dependent on the number of LD diesel vehicles that required urea. 


\section{EXPERIMENTAL}

\section{GENERAL APPROACH}

At Ford, improved supplier catalysts were tested in laboratory flow reactors for aged conversion levels. Technologies included Diesel Oxidation Catalysts (DOCs), Selective Catalytic Reduction (SCR) catalysts, and Lean NOx Traps (LNTs). A full-size system of DOC, SCR catalyst, and CDPF was aged and tested on an engine dynamometer at FEV. Interim tests of the aged system were performed on a light-duty truck (LDT). Appropriate exhaust gas sensors and control strategies were tested for durable system function. System modeling played an important role in design. Hardware for delivery of aqueous urea to light-duty diesel vehicles was completed.

\section{LABORATORY TESTING \& AGING CONDITIONS: DOC}

Fundamental catalyst activity data were obtained using a laboratory-scale flow reactor system. A round sample core of 1" diameter was taken from a washcoated monolith obtained from a supplier. All DOC catalyst formulations were aged for the equivalent of $120 \mathrm{k} \mathrm{mi}$ before activity testing. Simulated diesel exhaust gas was flowed through the sample core at a range of space velocities, with a typical composition as shown in Table 2. Very low sulfur diesel fuel was assumed so sulfur was not added to the gas mix. Activity tests included $\mathrm{HC}, \mathrm{CO}$ and $\mathrm{NO}$ oxidation.

Table 2: Composition of simulated diesel exhaust gas for DOC activity measurement.

\begin{tabular}{|c|c|}
\hline Component & Concentration \\
\hline $\mathrm{O}_{2}$ & $8-10 \%$ \\
\hline $\mathrm{H}_{2} \mathrm{O}$ & $10 \%$ \\
\hline $\mathrm{CO}_{2}$ & $12 \%$ \\
\hline $\mathrm{NO}_{x}$ & $350-450 \mathrm{ppm}$ \\
\hline $\mathrm{HC}$ & $1500-3000 \mathrm{ppmC} 1$ \\
\hline $\mathrm{CO}$ & $2500-3000 \mathrm{ppm}$ \\
\hline $\mathrm{N}_{2}$ & Balance \\
\hline
\end{tabular}

\section{LABORATORY TESTING \& AGING CONDITIONS: UREA SCR}

Fundamental catalyst activity data were obtained using a laboratory-scale flow reactor system. A round sample core of 1" diameter was taken from a washcoated monolith obtained from a supplier. All SCR catalyst formulations tested were base metal/zeolite and did not contain vanadium. Simulated diesel exhaust gas was flowed through the sample core at space velocities of $30 \mathrm{k}$ and $100 \mathrm{k} \mathrm{h}^{-1}$, with a composition as shown in 


\section{EXPERIMENTAL (CON'T)}

Table 3. Very low sulfur diesel fuel was assumed so sulfur was not added to the gas mix. Cores were aged for the equivalent of $120 \mathrm{k}$ mi before evaluation.

Table 3: Composition of simulated diesel exhaust gas for SCR activity measurement.

\begin{tabular}{|c|c|}
\hline Component & Concentration \\
\hline $\mathrm{O}_{2}$ & $14 \%$ \\
\hline $\mathrm{H}_{2} \mathrm{O}$ & $4.5 \%$ \\
\hline $\mathrm{CO}_{2}$ & $5 \%$ \\
\hline $\mathrm{NOx}$ & $350 \mathrm{ppm}$ \\
\hline $\mathrm{NH}_{3}$ & $350 \mathrm{ppm}$ \\
\hline $\mathrm{N}_{2}$ & Balance \\
\hline
\end{tabular}

The catalyst temperature was maintained with a tube furnace. An FTIR instrument from MIDAC Corporation with a heated sample cell was used at the outlet of the reactor to measure $\mathrm{NOx}$ and ammonia $\left(\mathrm{NH}_{3}\right)$ levels. Data were taken at catalyst temperatures from approximately $170^{\circ} \mathrm{C}$ to $550^{\circ} \mathrm{C}$ in $30-50^{\circ} \mathrm{C}$ steps in order to cover the normal operating range expected on a diesel vehicle. NOx conversion was allowed to equilibrate before raising the catalyst temperature to the next level. The amount of ammonia stored on the catalyst core was measured via ammonia adsorption followed by a NOx titration technique.

\section{LABORATORY TESTING \& AGING CONDITIONS: LNT-SCR}

Fundamental catalyst activity data were obtained using a laboratory-scale flow reactor system similar to that described above. Various Lean NOx Trap (LNT) formulations were tested with various SCR catalysts located downstream. All sample cores were aged for the equivalent of $120 \mathrm{k} \mathrm{mi}$ in a separate pulsating reactor that burned isooctane doped with an organosulfur compound at a concentration calculated to give sulfur exposure to the catalysts equivalent to $120 \mathrm{k}$ mi of on-vehicle exposure. Both deSOx and CDPF regeneration modes were included in the aging. Combinations of one LNT core and one SCR core were aged and tested as pairs in series. Simulated diesel exhaust gas was flowed through the sample cores at overall space velocities of $15 \mathrm{k}$ and $30 \mathrm{k} \mathrm{h}^{-1}$, with a particular composition (Table 4). 


\section{EXPERIMENTAL (CON'T)}

Table 4: Composition of simulated diesel exhaust gas for LNT-SCR system activity measurement.

\begin{tabular}{|c|c|c|}
\hline Component & Lean Conc. & Rich Conc. \\
\hline $\mathrm{CO}$ & $0 \mathrm{ppm}$ & $4 \%$ \\
\hline $\mathrm{H}_{2}$ & $0 \mathrm{ppm}$ & $1.3 \%$ \\
\hline $\mathrm{C}_{3} \mathrm{H}_{6}$ & $0 \mathrm{ppmC}_{1}$ & $5000 \mathrm{ppmC}_{1}$ \\
\hline $\mathrm{O}_{2}$ & $10 \%$ & $1 \%$ \\
\hline $\mathrm{NO}$ & $500 \mathrm{ppm}$ & $500 \mathrm{ppm}$ \\
\hline $\mathrm{CO}_{2}$ & $5 \%$ & $5 \%$ \\
\hline $\mathrm{H}_{2} \mathrm{O}$ & $5 \%$ & $5 \%$ \\
\hline Lambda & 1.96 & 0.90 \\
\hline $\mathrm{N}_{2}$ & Balance & Balance \\
\hline
\end{tabular}

\section{LOW SULFUR DIESEL FUEL}

Ultra low sulfur (<15 ppm S) diesel fuel was used in both the engine dynamometer and vehicle as an enabler for the high efficiency emission control system. The program fuel, manufactured by ExxonMobil, was for use in the optimization and long-term durability portions of the program. The fuel properties, shown in Table 5, approximated the product quality anticipated in the 2006 market. The resultant fuel also met the EPA certification fuel standards for 2007.

Table 5: Program fuel properties.

\begin{tabular}{|c|c|c|c|}
\hline & $\begin{array}{l}\text { Est. Avg. } \\
\text { '06 Diesel } \\
\text { Properties }\end{array}$ & Program Fuel & 2007 Cert. Fuel \\
\hline Sulfur, ppm & $15^{*}$ & 12.5 & $7 / 15$ \\
\hline Density, $\mathrm{kg} / \mathrm{m}^{3}$ & 850 & 841.1 & 839 / 865 \\
\hline Aromatics, vol\% & 32 & 29.5 & $27 \mathrm{~min}$ \\
\hline Polyaromatics, wt\% & 10 & 11.0 & no spec \\
\hline Cetane number & 46 & 44.9 & $40 / 50$ \\
\hline $\mathrm{T} 50,{ }^{\circ} \mathrm{C}$ & 267 & 249 & $243 / 282$ \\
\hline $\mathrm{T} 90,{ }^{\circ} \mathrm{C}$ & 306 & 307 & $293 / 332$ \\
\hline
\end{tabular}

* As delivered to the vehicle. 


\section{EXPERIMENTAL (CON'T)}

\section{ENGINE DYNAMOMETER TESTING}

At FEV's Technical Center in Auburn Hills, Ml, a mid-sized diesel engine similar to the one in the program vehicle was installed in a transient dynamometer cell. The test cell was equipped for full raw emissions capability with dedicated emission benches for $\mathrm{HC}, \mathrm{CO}, \mathrm{CO}_{2}, \mathrm{O}_{2}, \mathrm{NOx}$ and diesel smoke analysis; FTIR analyzer for specific (nonregulated) emission measurements; single operator control console for all test cell operations and data display; FEV proprietary mini-dilution tunnel for particulate measurements; and precision engine coolant, oil, and air conditioning equipment for precise test condition control. A machine shop, welding area, and vehicle laboratory were present to support development programs.

\section{VEHICLE TESTING}

A light-duty truck (LDT) with a mid-size prototype diesel engine, tested at $6000 \mathrm{lbs}$, was equipped with an oxidation catalyst, aqueous urea injection system, base metal/zeolite SCR catalyst, CDPF, and a low pressure exhaust gas recirculation (EGR) loop, as shown in Figure 1. The oxidation catalyst converted engine-out $\mathrm{HC}$ and $\mathrm{CO}$ and also converted a portion of the $\mathrm{NO}$ to $\mathrm{NO}_{2}$. Aqueous urea was injected upstream of the SCR catalyst. The flow rate of urea was controlled based on fuel flow and information from a catalyst inlet temperature sensor, an air meter, and a $\mathrm{NO}_{x}$ sensor. A solution of 32.5 wt $\%$ urea in water was used with atomizing air.

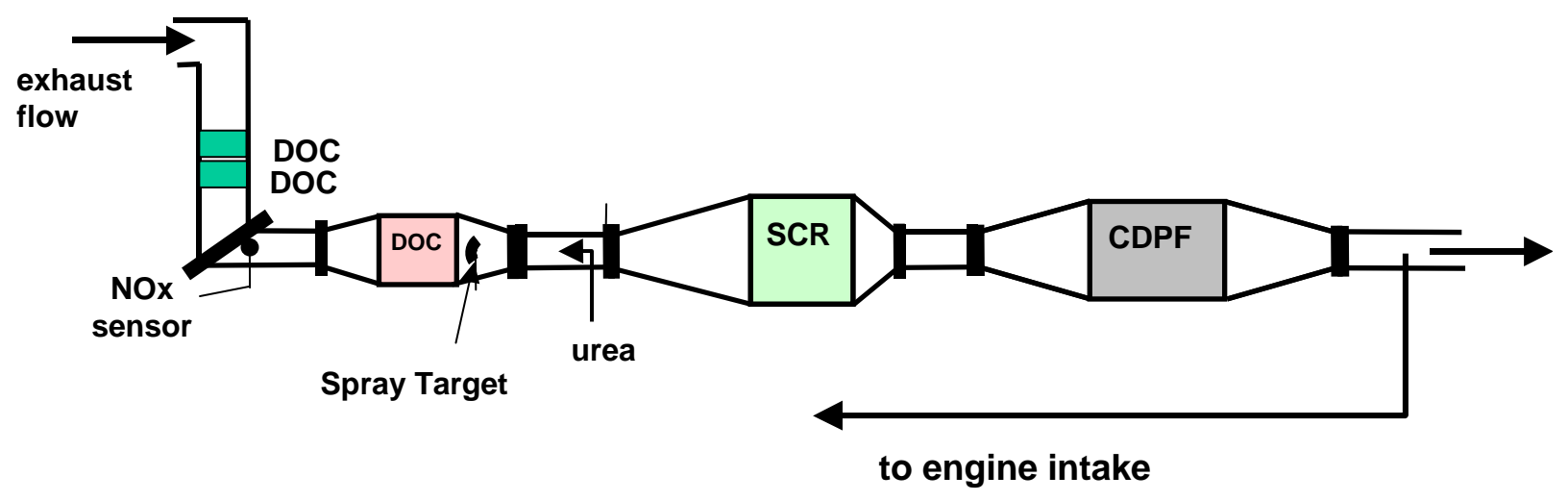

Figure 1. Exhaust system configuration onboard the 6000 lbs LDT (Light Duty Truck).

The vehicle was tested at the Vehicle Emissions Research Laboratory (VERL) located within Ford Research \& Advanced Engineering. Four bench/analyzer systems (HC, $\mathrm{CO}$, NOx, and $\mathrm{CO}_{2}$ ) were available, as well as a mass spectrometer and two FTIR instruments for real-time emissions analysis, a gas chromatograph for off-line analysis, and balance equipment for particulate filter weighing. The FTIR instruments were used 


\section{EXPERIMENTAL (CON'T)}

to measure non-regulated emissions such as $\mathrm{NH}_{3}$ and $\mathrm{N}_{2} \mathrm{O}$. VERL also had a temperature and humidity controlled soak area for vehicle preconditioning nearby.

\section{DURABILITY TESTING}

The final Urea SCR and CDPF system was aged for $120 \mathrm{k}$ mi by simulating the Ford High Speed Cycle, the corporate standard aging cycle, on the engine dynamometer. The vehicle speeds used for this cycle are shown in Figure 2. The average vehicle speed was $47 \mathrm{mph}$, with a peak speed of $75 \mathrm{mph}$, and incorporated both city and highway driving modes.

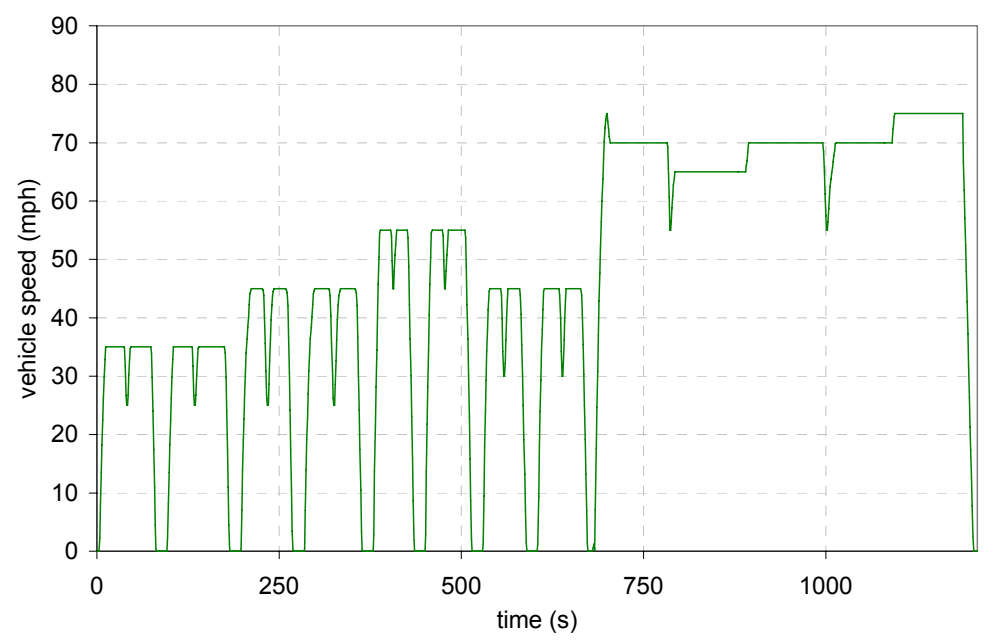

Figure 2. Vehicle speed trace for Ford High Speed Cycle, a corporate standard aging cycle. Urea SCR and CDPF system was aged on FEV's engine dynamometer 24h per day, 5 to 6 days per week using this cycle.

\section{MODELING TOOLS}

The Ford proprietary computer simulation tool, SIMTWC, is used to evaluate and compare the expected performance of aftertreatment configurations, saving experimental time and effort [7]. SIMTWC is integrated into the Matlab®/Simulink® environment to provide a flexible means to build and configure a wide variety of simulated exhaust aftertreatment systems. It includes a library of exhaust system components that range from thermocouples and flanges to pipes (single and dual wall) and catalysts. Inputs to the model include geometric specifications of the exhaust system components, performance characteristics of the catalysts, exhaust flow rate, temperature and emission species levels. 


\section{RESULTS AND DISCUSSION}

\section{EMISSION CONTROL SYSTEM SELECTION}

In general, the two leading technologies for very high NOx conversion are Lean NOx Traps (LNTs) and Selective Catalytic Reduction of NOx using aqueous urea (Urea SCR). LNTs contain an oxidative component such as Pt that oxidizes engine-out NO to $\mathrm{NO}_{2}$ and a storage component (typically an alkali metal salt) that forms a nitrate compound during lean (excess oxygen) conditions. During rich (low oxygen) conditions, the nitrate compound releases NOx that is then reduced to $N_{2}$. SCR catalysts typically contain base metals supported on a zeolite and can continuously convert NOx under lean conditions while ammonia is present. The technical advantages of Urea SCR over LNT include wider temperature window for very high NOx conversion, higher resistance to sulfur poisoning, better thermal durability, lower fuel economy penalty, lower system $\mathrm{HC}$ emissions, lower greenhouse gas emissions, and lower system cost [8].

A typical conversion curve for reduction of $\mathrm{NOx}$ with $\mathrm{NH}_{3}$, using a base metal/zeolite catalyst, was determined as shown in Figure 3. Using NO-only feedgas for NOx, over $90 \%$ conversion was achieved at a catalyst temperature of $250^{\circ} \mathrm{C}$ and was maintained until $550^{\circ} \mathrm{C}$ at a space velocity of $30 \mathrm{k} \mathrm{h}^{-1}$. With $50 \%$ of the $\mathrm{NO}$ replaced by $\mathrm{NO}_{2}$, known as "fast SCR" [9], the $90 \%$ conversion window began at less than $200^{\circ} \mathrm{C}$.

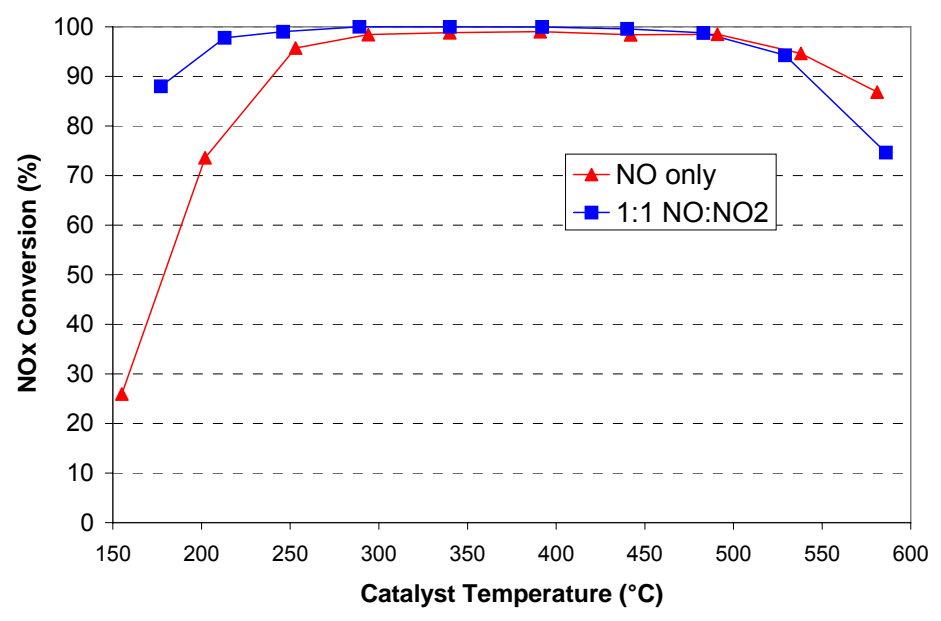

Figure 3. Typical operating window for ammonia SCR with base metal/zeolite catalyst at $30 \mathrm{k} \mathrm{h}^{-1}$.

Two options were considered for system configurations as shown in Figure 4 and Figure 5. In System A (Figure 4), the particulate filter was located upstream of the SCR catalyst to take full advantage of heat produced by the engine to oxidize $\mathrm{HC}, \mathrm{CO}$ and soot. However, the SCR catalyst took longer to heat up and was more susceptible to damage by large exotherms generated in the filter in this configuration. It was 


\section{RESULTS AND DISCUSSION (CON'T)}

advantageous to reverse the order of the components to achieve higher SCR catalyst temperatures and convert more $\mathrm{NO}_{x}$ earlier in the test cycle, as shown by System B (Figure 5). An oxidation catalyst close to the engine was required to oxidize $\mathrm{HC}$ and $\mathrm{CO}$, followed by urea injection and SCR. The downstream particulate filter could trap soot at any operating temperature and could also oxidize ammonia that slipped past the SCR catalyst. System B, however, required additional heat to regenerate the filter, resulting in a potentially higher fuel economy penalty.

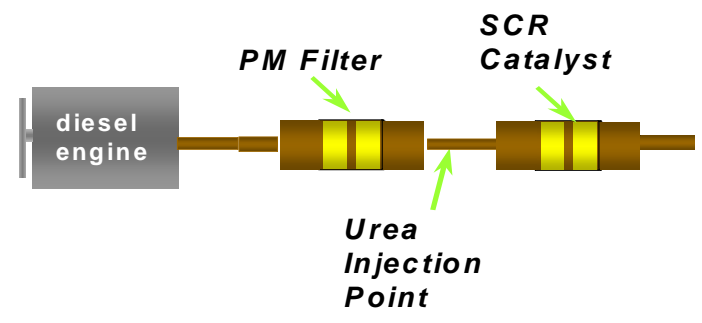

Figure 4. System A: Particulate filter placed closest to the engine.

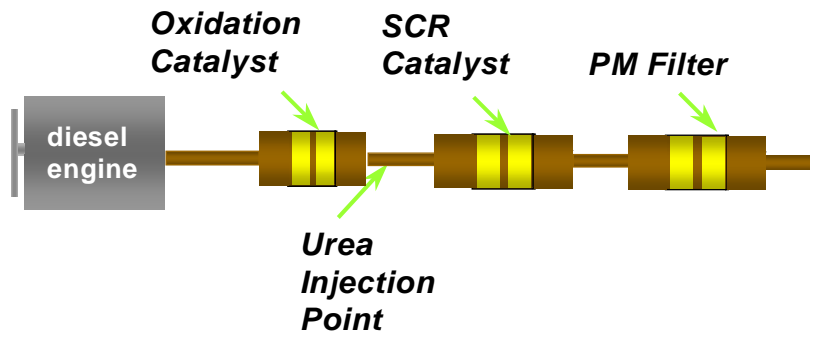

Figure 5. System B: Oxidation and NOx reduction functions placed closest to the engine.

FTP-75 cycle $\mathrm{NO}_{x}$ conversions for Systems $\mathrm{A}$ and $\mathrm{B}$ were estimated as shown in Figure 6. Neither system by itself was predicted to meet the $90 \%$ NOx conversion target to meet Tier 2 standards. More rapid heating of the SCR catalyst was needed to reach higher activity sooner. It was assumed an extra $50^{\circ} \mathrm{C}$ could be added to the system during the first 30 seconds of the cycle. 


\section{RESULTS AND DISCUSSION (CON'T)}

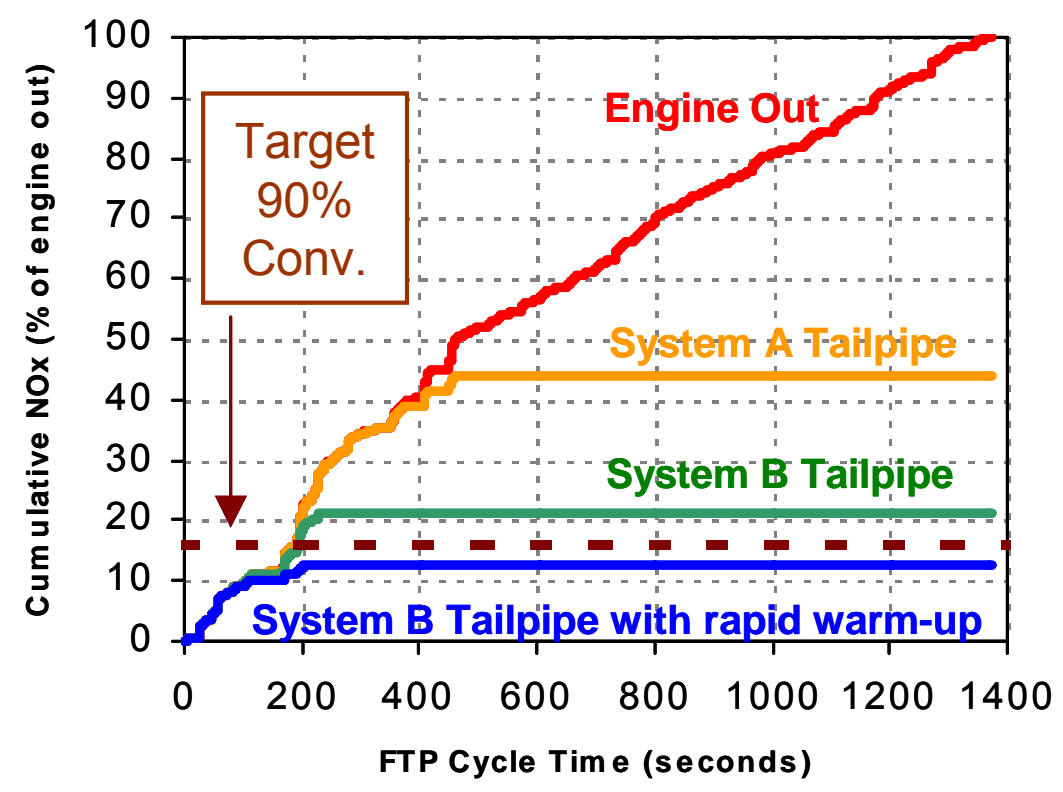

Figure 6. Predicted system efficiencies.

\section{BASELINE FRESH SYSTEM DEVELOPMENT ON LIGHT-DUTY TRUCK}

A maximum NOx conversion over the FTP-75 of about $65 \%$ was achieved using a baseline aqueous urea injection strategy in conjunction with a NOx sensor on the program vehicle. Results indicated that the injection system needed to more effectively distribute the reductant over the entire SCR catalyst. Mixing devices were added to the exhaust system that improved cycle NOx conversion to over $80 \%$. Reducing the angle of the entrance cone to the SCR catalyst was also found to be beneficial. The oxidation catalyst upstream of the SCR catalyst on the program vehicle was enlarged and the precious metal loading was increased. Tailpipe emissions and catalyst efficiencies were collected for several tests and are shown in Figure 7. 


\section{RESULTS AND DISCUSSION (CON'T)}

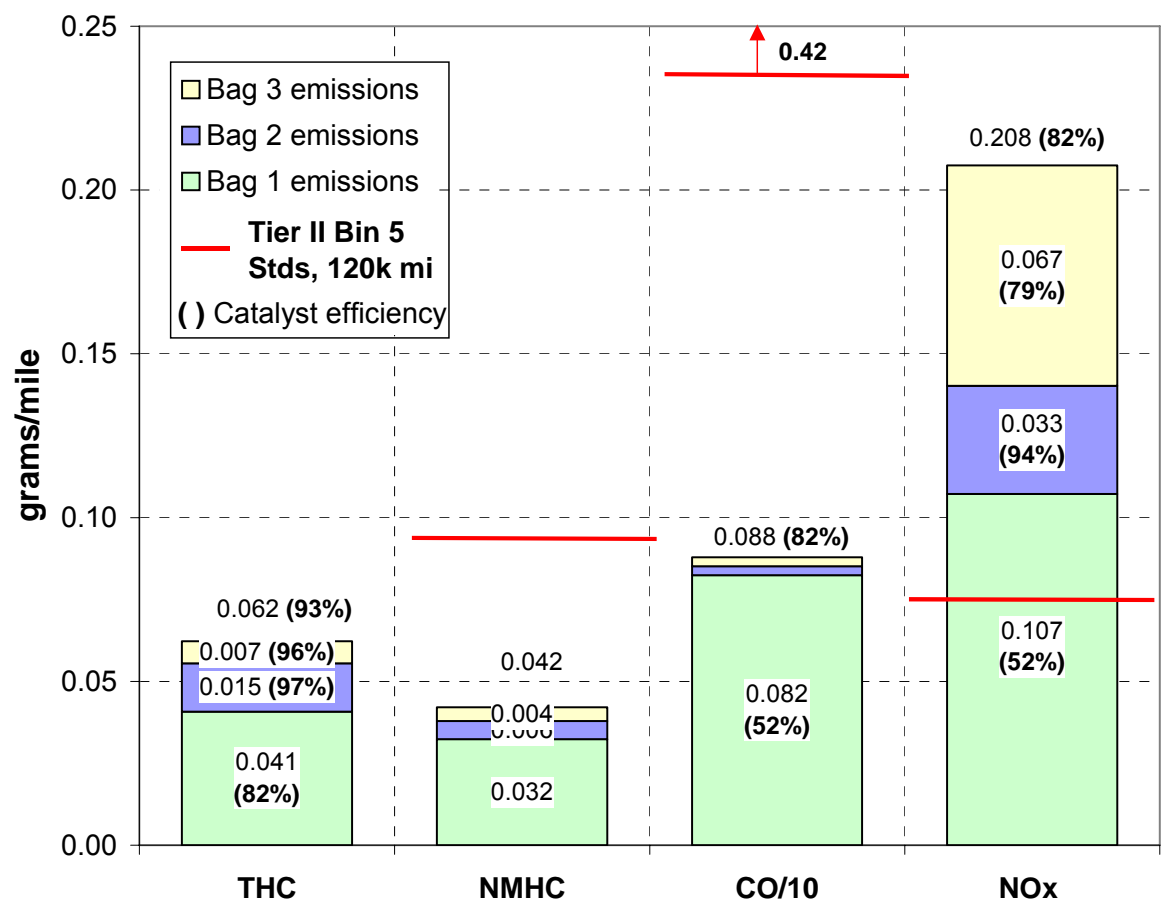

Figure 7. Summary of tailpipe emissions and system efficiencies over the cold-start FTP-75 with the LDT. The mixing of urea in the exhaust gas was improved and resulted in over $80 \%$ cycle NOx reduction.

Efficiencies were lowest for Bag 1 due to the cold-start, limiting the overall NOx conversion over the FTP-75 to $82 \%$. The SCR catalyst did not reach its temperature window for high efficiency $\left(>150^{\circ} \mathrm{C}\right)$ until over $200 \mathrm{~s}$ into the test, as shown in Figure 8. In order to improve the cycle NOx reduction up to $90 \%$ and meet the Tier 2 Bin 5 NOx standard, it was evident that the SCR catalyst needed to be heated to $200^{\circ} \mathrm{C}$ more quickly and the engine-out NOx emissions needed to be reduced. Component development was also considered, including the DOC and SCR catalyst formulations, exhaust gas sensors, and CDPF strategy. 


\section{RESULTS AND DISCUSSION (CON'T)}

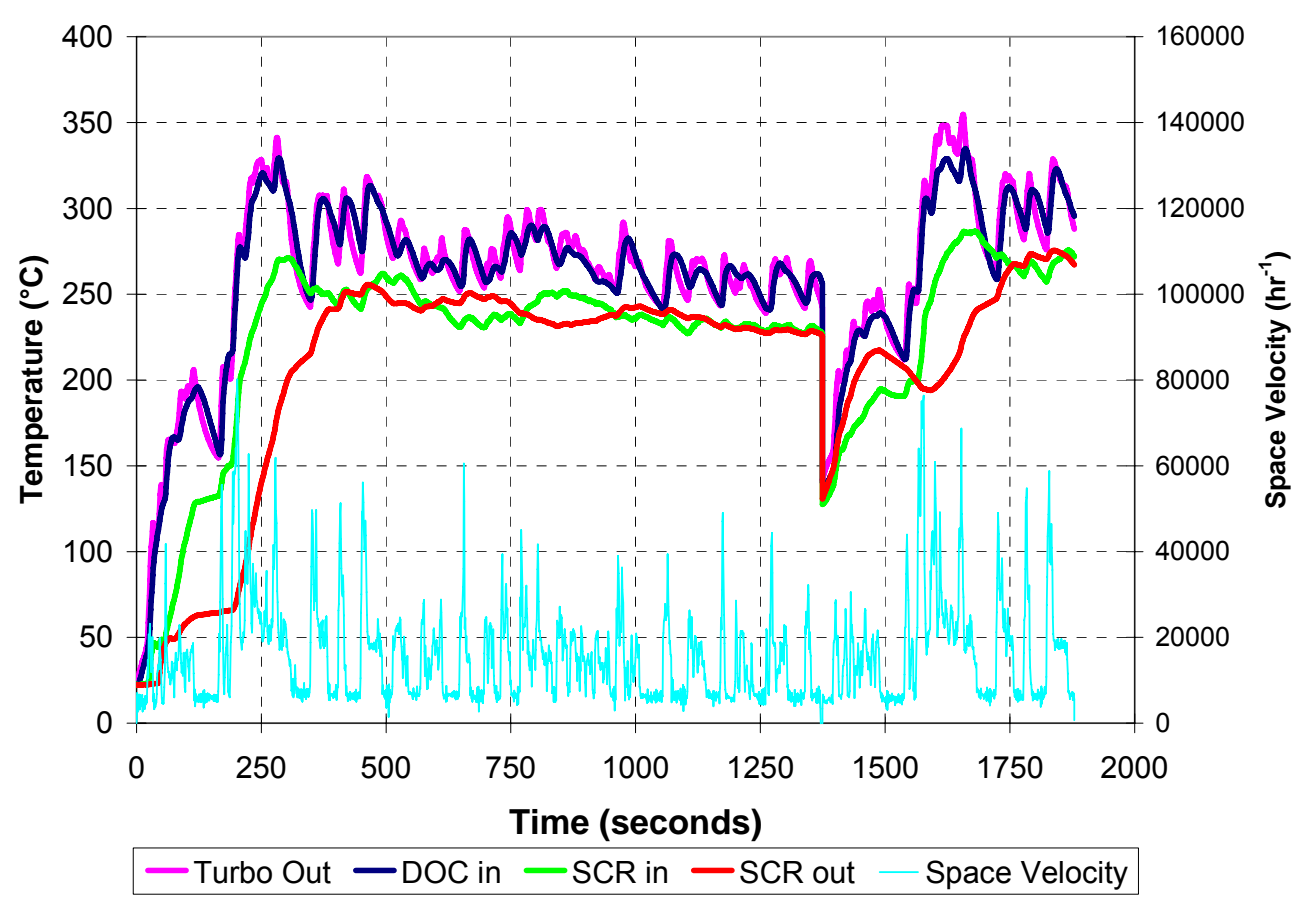

Figure 8. Exhaust gas temperatures and space velocity (relative to the SCR catalyst volume) during the cold-start FTP-75 test with the LDT.

\section{IMPROVED COMPONENT DEVELOPMENT}

\section{IMPROVED DIESEL OXIDATION CATALYSTS}

The DOC provided several functions for the Urea SCR and CDPF system: oxidation of $\mathrm{HC}$ and $\mathrm{CO}$ to meet tailpipe emissions, exotherm generation during cold-start and CDPF regeneration, and NO oxidation for improved, durable SCR performance. Peak NO oxidation was found to be about $20-40 \%$ in the laboratory flow reactor after $120 \mathrm{k} \mathrm{mi}$ equivalent aging as shown in Figure 9. Catalyst $A B$ was selected as the main underbody DOC for the full-size Urea SCR and CDPF system because of its superior NO oxidation performance. However, it was not the best DOC for HC conversion as shown in Figure 10. This tradeoff was deemed acceptable for long-term durability of the SCR system. 


\section{RESULTS AND DISCUSSION (CON'T)}

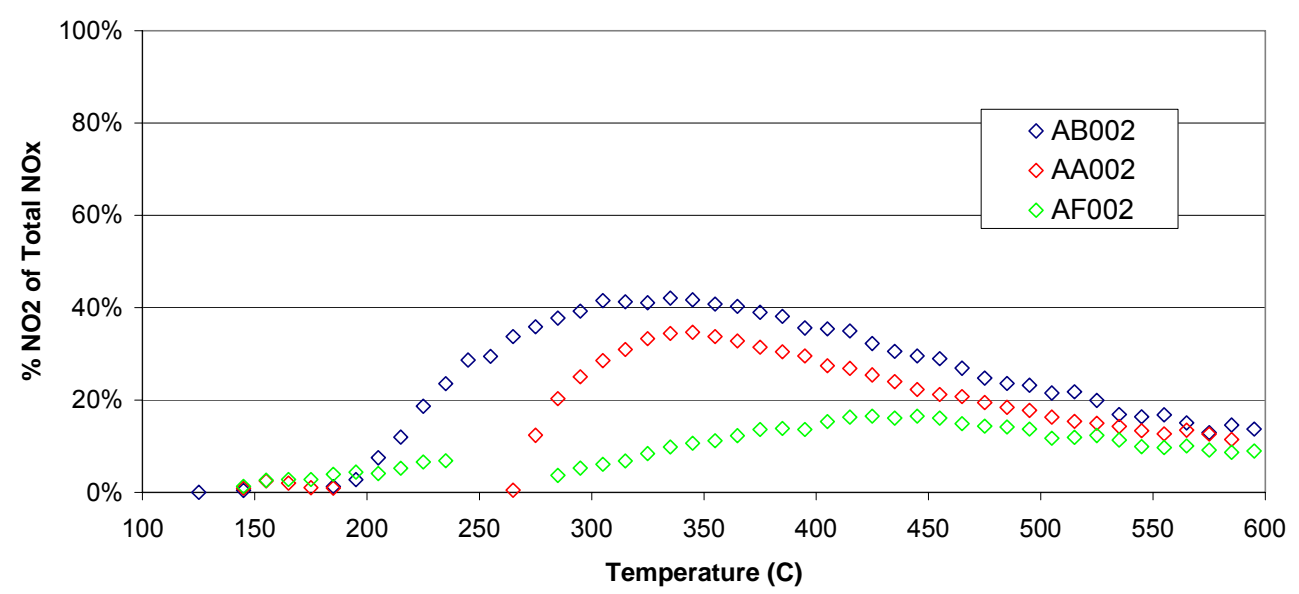

Figure 9. Performance of 120k mi aged DOC samples for oxidation of NO.

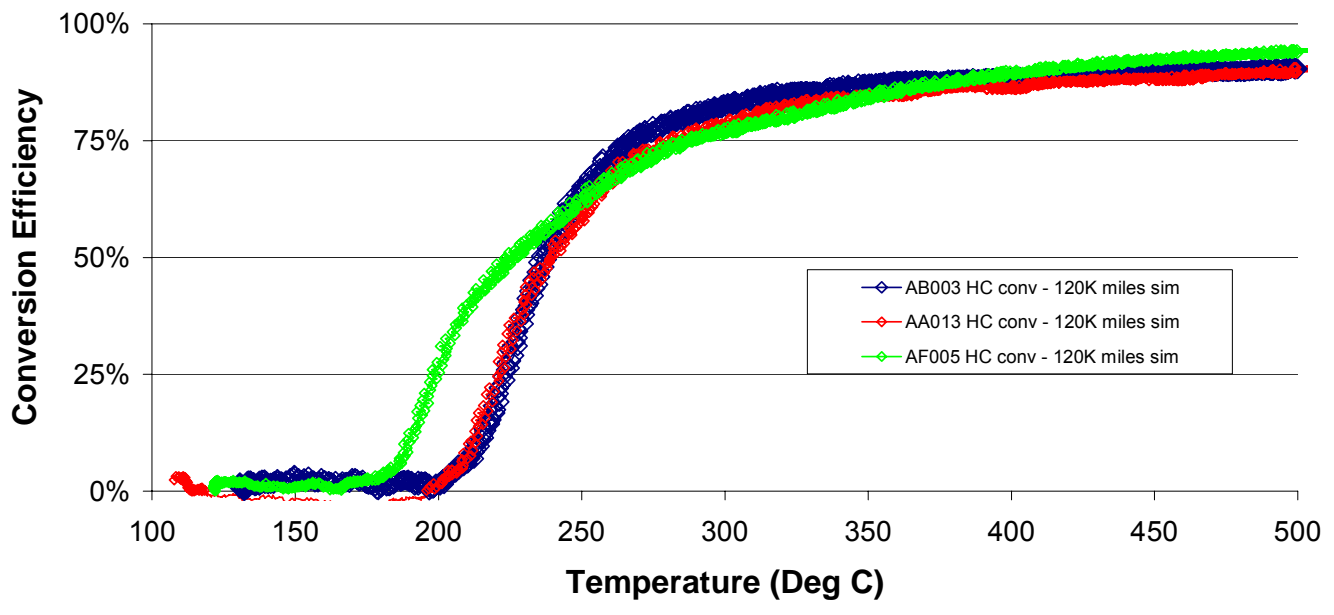

Figure 10. Performance of $120 \mathrm{k}$ mi aged DOC samples for oxidation of HC.

Further testing was conducted to study the effects of hydrocarbon concentration on catalyst light-off and NO oxidation. These parameters were important because strategies to warm the SCR catalyst or regenerate the CDPF could result in high levels of hydrocarbons entering the DOC. HC light-off conversion for the program DOC was measured with varying $\mathrm{HC}$ levels as shown in Figure 11. As the $\mathrm{HC}$ concentration was increased, the light-off temperature increased. The DOC was also less effective in oxidizing the long-chain hydrocarbons, so care must be used when injecting fuel into the exhaust for CDPF regeneration. It was also found that high $\mathrm{HC}$ levels, especially longchain $\mathrm{HC}$, also suppress the oxidation of $\mathrm{NO}$ to $\mathrm{NO}_{2}$ as shown in Figure 12. At 


\section{RESULTS AND DISCUSSION (CON'T)}

temperatures below $350^{\circ} \mathrm{C}$, where the impact on SCR performance is the most significant, the overall oxidation of NO decreased with catalyst age (Figure 13).

\section{HC Light-Off Conversion}

DOC: AB006

\section{Mode Aging: HC Effect}

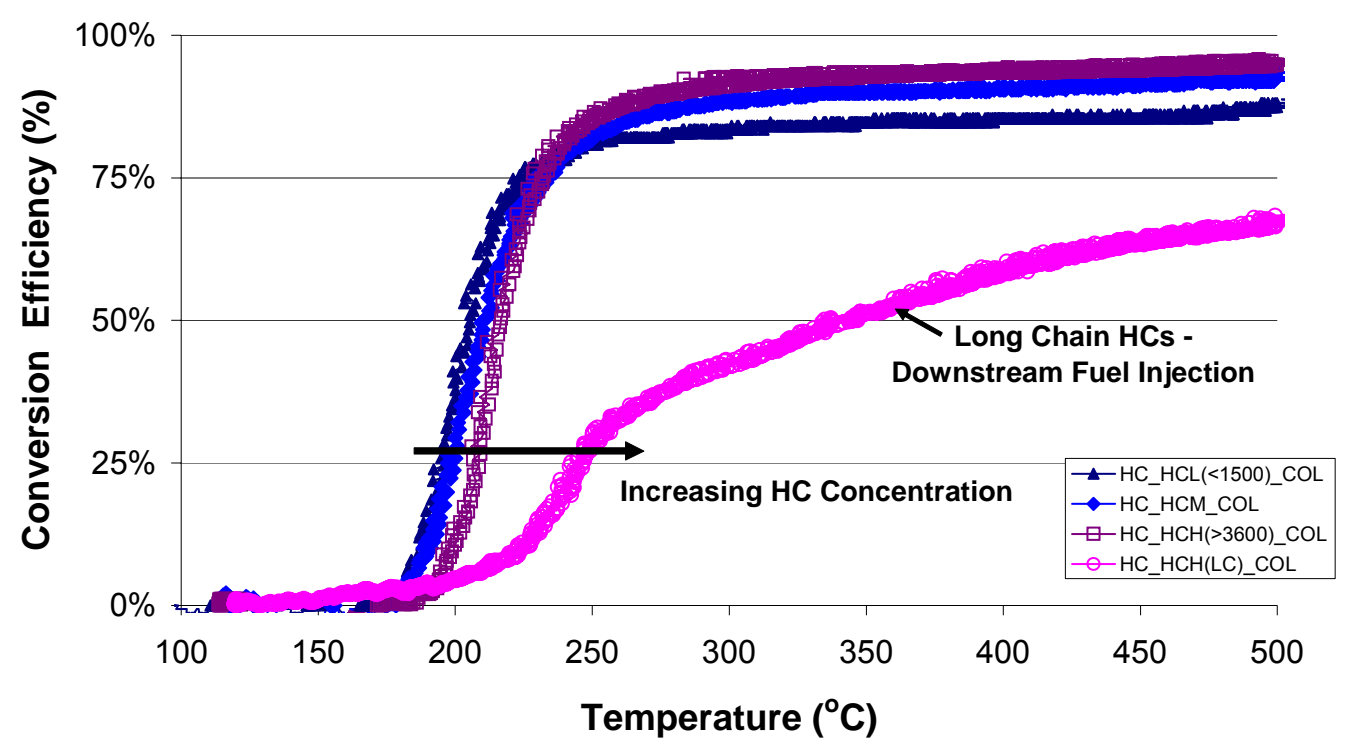

Figure 11. Effect of hydrocarbon concentration on DOC light-off.

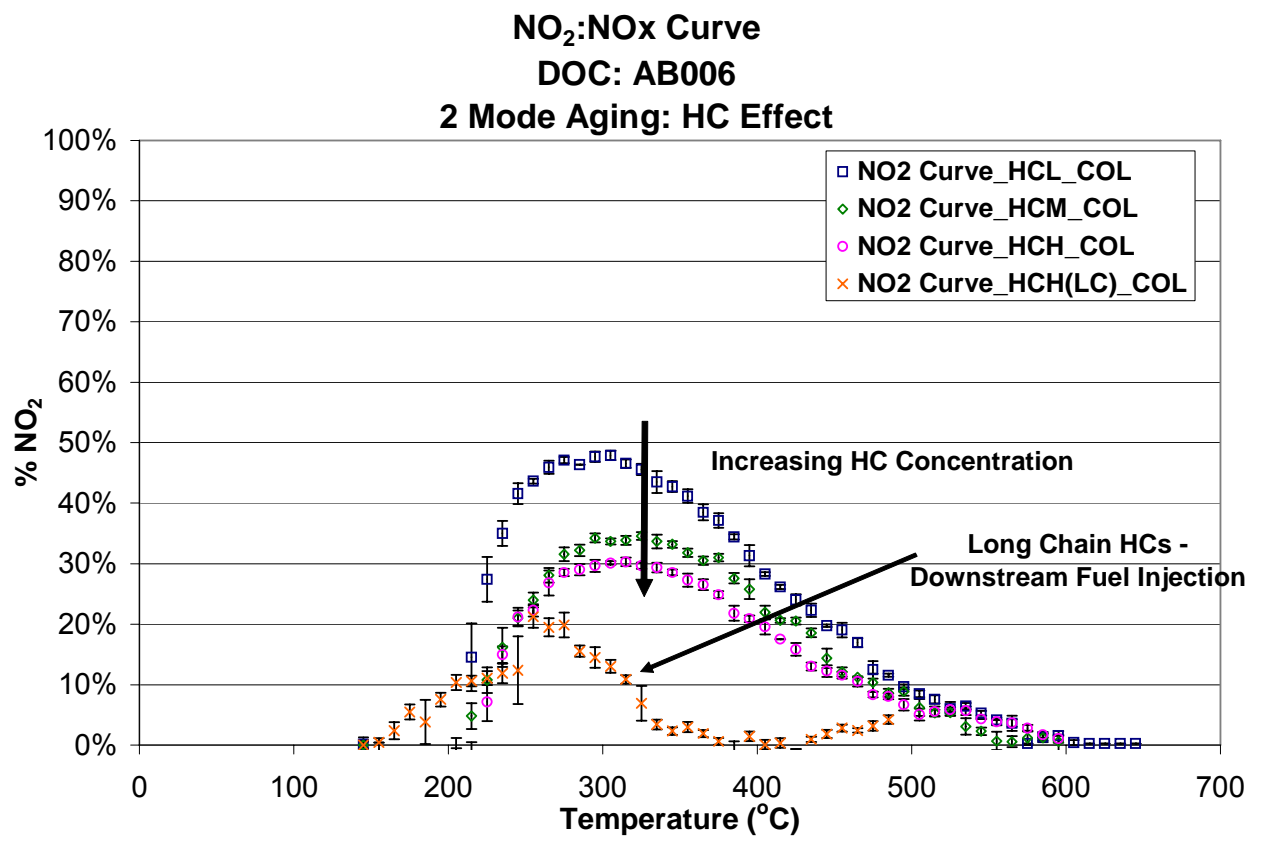

Figure 12. Effect of hydrocarbon concentration on NO oxidation. 


\section{RESULTS AND DISCUSSION (CON'T)}

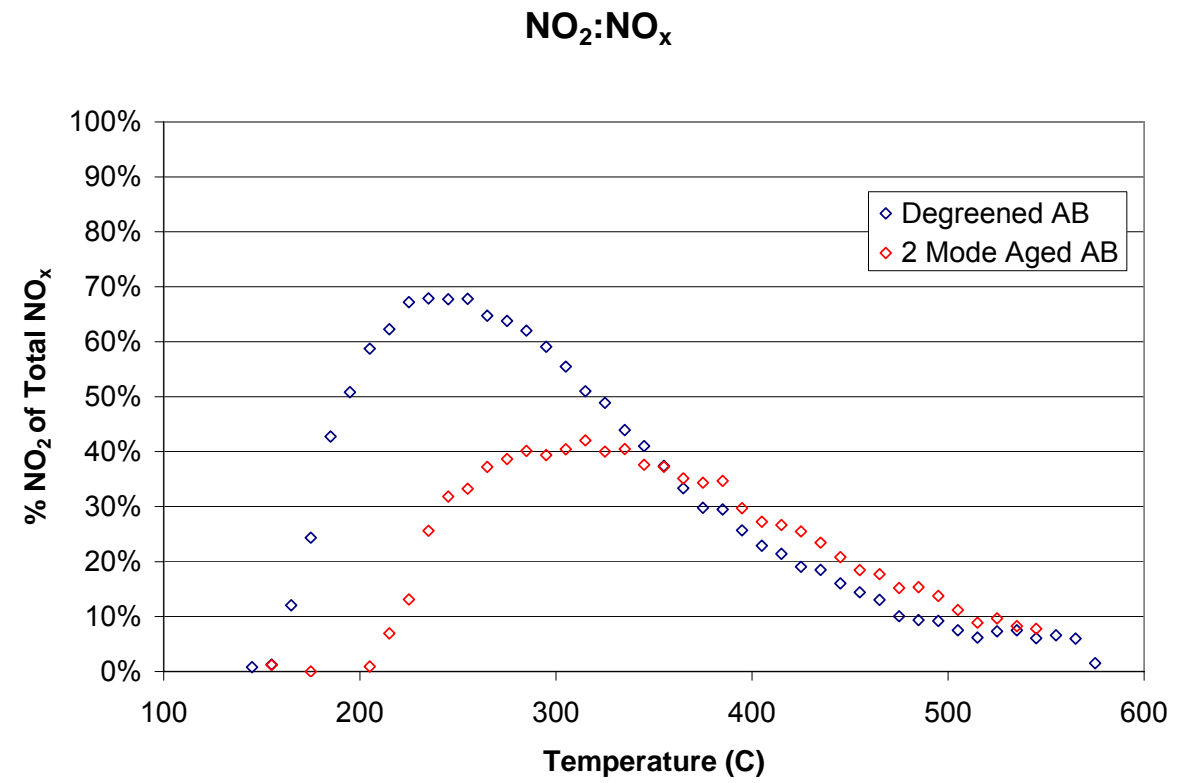

Figure 13. NO oxidation comparison for fresh and aged DOC.

\section{SCR CATALYST DEVELOPMENT}

An initial catalyst selection was completed using a simulated laboratory aging procedure $\left(670^{\circ} \mathrm{C}\right.$ for $64 \mathrm{~h}$, hydrothermal conditions). All catalysts tested were base metal/zeolite formulations that did not contain vanadium, and the selection was based on the reaction of $\mathrm{NO}$ and $\mathrm{NH}_{3}$ at a 1:1 molar ratio. Catalyst $\mathrm{A} 3$ was chosen as the leading catalyst in the temperature range of $200-300^{\circ} \mathrm{C}$, typical for the LD FTP-75 as shown in Figure 14. 


\section{RESULTS AND DISCUSSION (CON'T)}

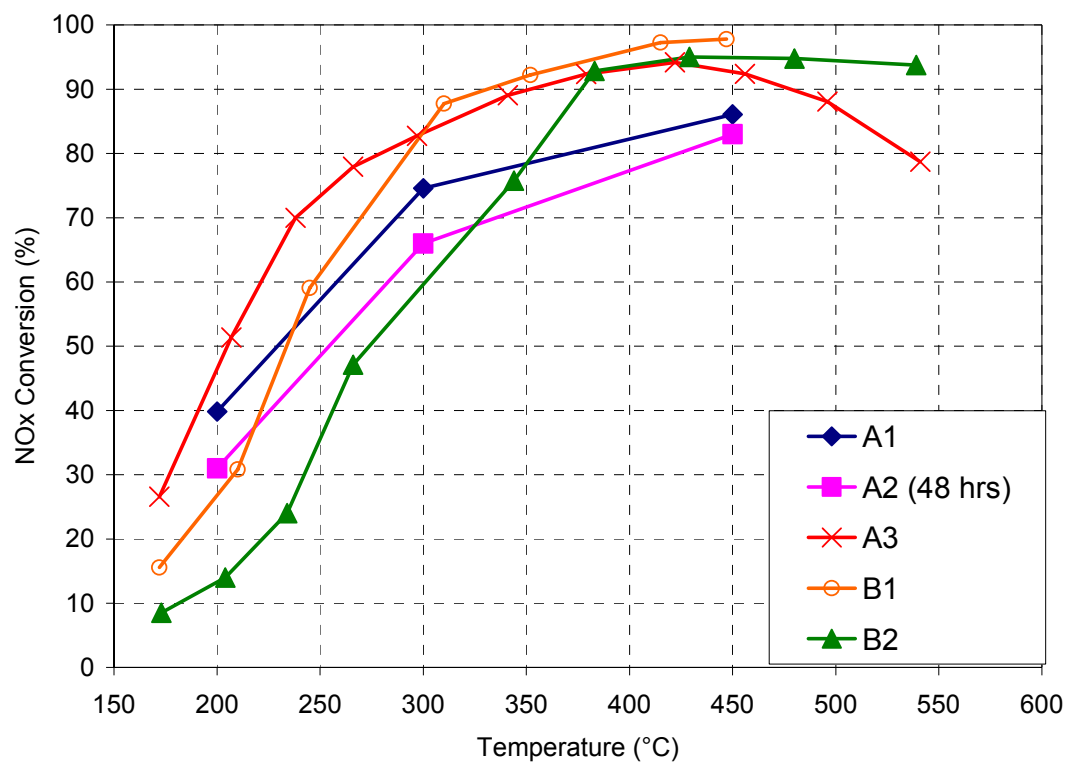

Figure 14. Initial SCR catalyst selection after $120 \mathrm{k}$ mi of simulated hydrothermal aging $\left(670^{\circ} \mathrm{C}\right.$, 64h). Evaluation was completed with $\mathrm{NO}$ and $\mathrm{NH} 3$ at a 1:1 ratio and an overall space velocity of $30 \mathrm{kh}^{-1}$.

The effect of poisons such as sulfur and $\mathrm{HC}$ were studied in the laboratory flow reactor on typical base metal/zeolite SCR catalysts. The negative impact of HC on SCR NOx performance was investigated in a laboratory flow reactor (Figure 15). A mixture containing an alkene, a long-chain alkane and an aromatic was fed into the flow reactor along with the usual levels of $\mathrm{O}_{2}, \mathrm{H}_{2} \mathrm{O}$, and $\mathrm{CO}_{2}$ while the catalyst was converting $\mathrm{NOx}$ with $\mathrm{NH}_{3}$. An inlet $\mathrm{NO}_{2} / \mathrm{NOx}$ ratio of $20 \%$ was used. The NOx conversion was allowed to degrade from $90+\%$ to $50 \%$ at $250^{\circ} \mathrm{C}$ and $30 \mathrm{k} \mathrm{h}^{-1}$, after which the temperature was raised. It was found that at least $425^{\circ} \mathrm{C}$ was required to regain $90 \%$ NOx conversion. 


\section{RESULTS AND DISCUSSION (CON'T)}

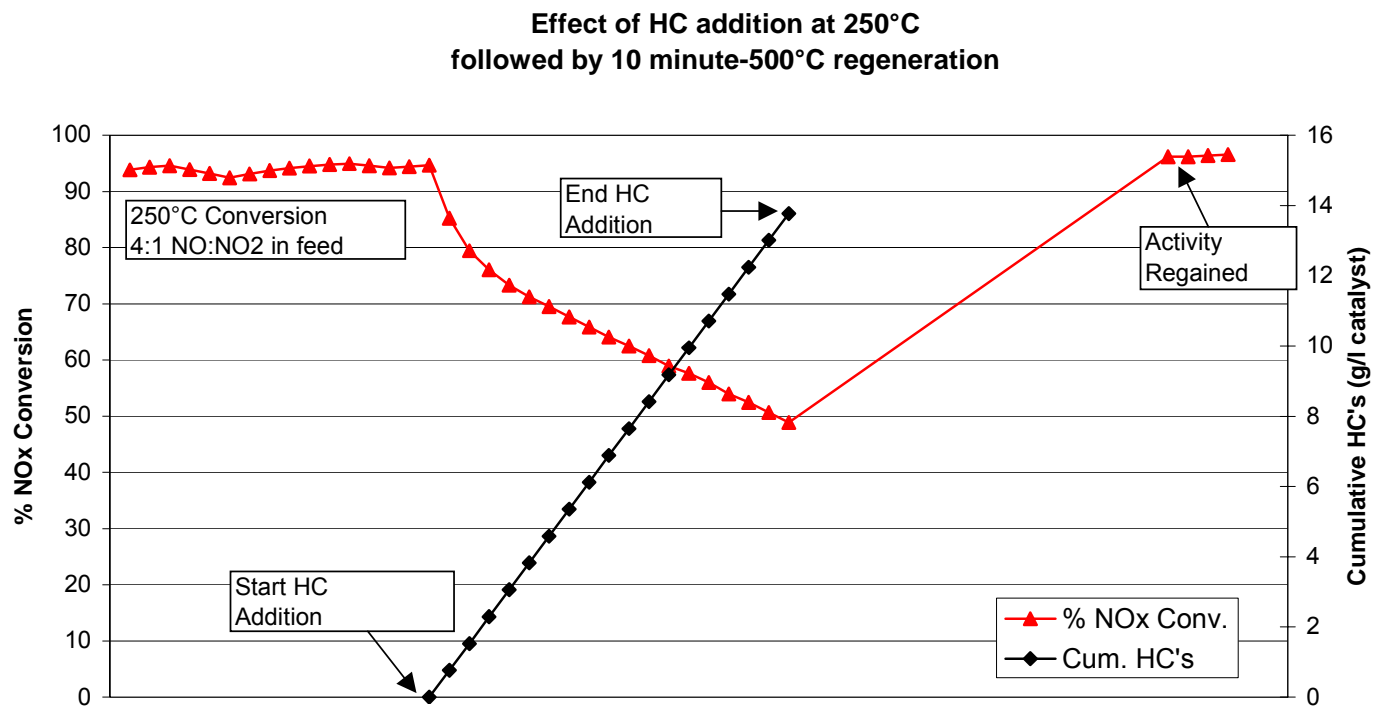

Figure 15. Effect of hydrocarbons on NOx conversion for a typical base metal/zeolite SCR catalyst.

The negative impact of sulfur on SCR NOx performance was investigated separately under similar test conditions to the $\mathrm{HC}$ experiments with SCR catalyst $\mathrm{A} 3$. A catalyst core at $350^{\circ} \mathrm{C}$ was exposed to enough flowing $\mathrm{SO}_{3}$ to represent $120 \mathrm{k}$ mi assuming a diesel fuel sulfur level of $10 \mathrm{ppm}$. Low temperature NOx conversion degraded significantly but could be completely regained by exposing the catalyst to $650^{\circ} \mathrm{C}$ under lean conditions.

The thermal durability of the leading SCR catalyst A3 was tested extensively in the laboratory in order to decide on the appropriate filter regeneration procedure for the emission control system. It was preferred to use the DOC to generate the exotherm for the filter through the SCR catalyst, exposing it to high in-use temperatures approaching $650-700^{\circ} \mathrm{C}$. This strategy had the added benefit of removing $\mathrm{HC}$ and sulfur from the $\mathrm{SCR}$ catalyst surface on a regular basis. Catalyst cores were aged at high temperature for $20 \mathrm{~h}$ in $14 \% \mathrm{O}_{2}, 4.5 \% \mathrm{H}_{2} \mathrm{O}, 5 \% \mathrm{CO}_{2}$, balance $\mathrm{N}_{2}$, at $30 \mathrm{k} \mathrm{h}^{-1}$, and NOx performance was tested with results as shown in Figure 16 . The feedgas contained $80 \%$ of the NOx as $\mathrm{NO}$ and $20 \%$ as $\mathrm{NO}_{2}$. The $\mathrm{NH}_{3} / \mathrm{NOx}$ feedgas ratio was equal to one. High $\mathrm{NOx}$ conversion was maintained over a wide window except after aging at $800^{\circ} \mathrm{C}$. Performance was also tested with $20 \% \mathrm{NO} / 80 \% \mathrm{NO}_{2}$ entering the catalyst (Figure 17). Here the effect of aging even at $800^{\circ} \mathrm{C}$ was small except between 150 and $200^{\circ} \mathrm{C}$. These results indicated that the SCR catalyst should be able to withstand exposure to high temperature of up to $750^{\circ} \mathrm{C}$ during filter regeneration, and up to $800^{\circ} \mathrm{C}$ if the oxidation catalyst remains highly active for NO oxidation. 


\section{RESULTS AND DISCUSSION (CON'T)}

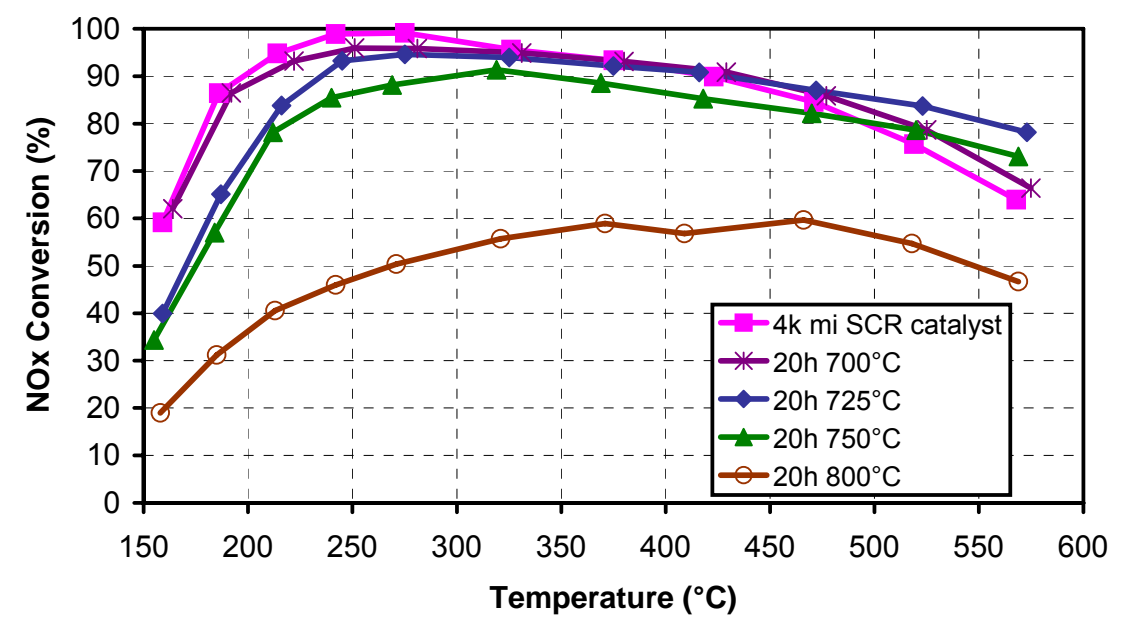

Figure 16. Thermally aged SCR catalyst laboratory performance for catalyst sample A3. A

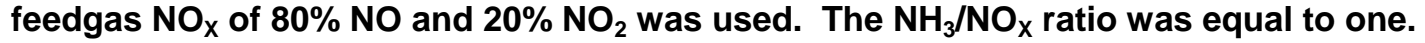

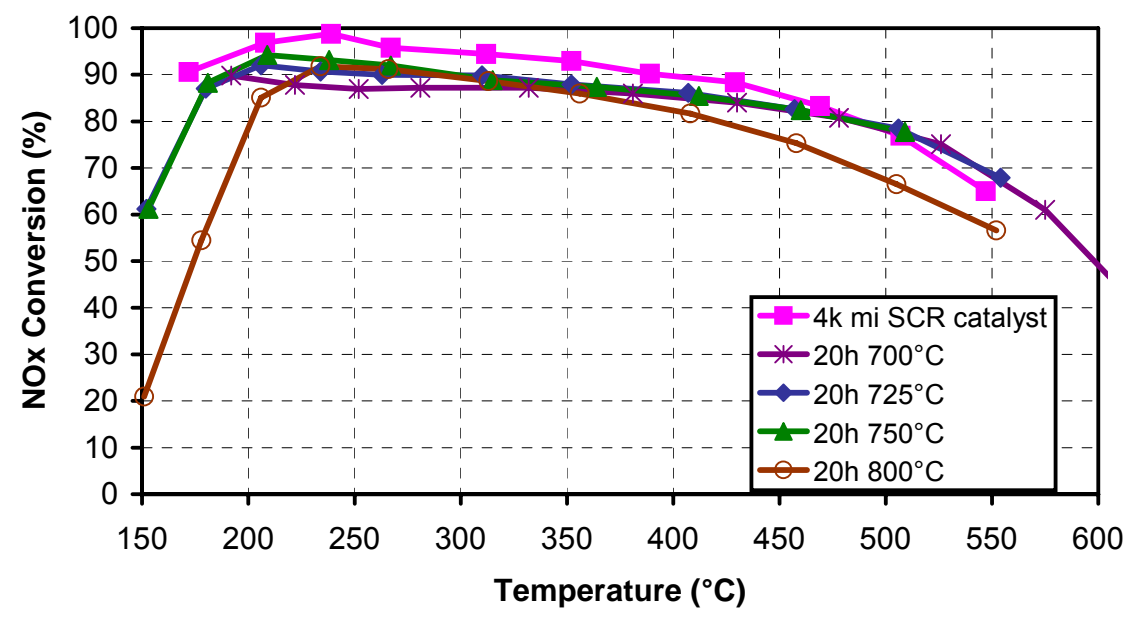

Figure 17. Thermally aged SCR catalyst (A3) laboratory performance. A feedgas $\mathrm{NO}_{\mathrm{x}}$ of $20 \% \mathrm{NO}$ and $80 \% \mathrm{NO}_{2}$ was used. The $\mathrm{NH}_{3} / \mathrm{NO}_{x}$ ratio was equal to one.

Later in the program, improved urea SCR catalysts continued to be aged and tested in the laboratory flow reactor to widen the temperature window for durable, high NOx conversion (Figure 18). The lab aged $\left(670^{\circ} \mathrm{C}, 64 \mathrm{~h}\right)$ performance of the program urea 


\section{RESULTS AND DISCUSSION (CON'T)}

SCR catalyst (A3) for NO conversion at $30 \mathrm{k} \mathrm{h}^{-1}$ was compared to a next-generation catalyst with greatly improved low temperature performance (B), and two with improved high temperature performance $(C$ and $D)$.

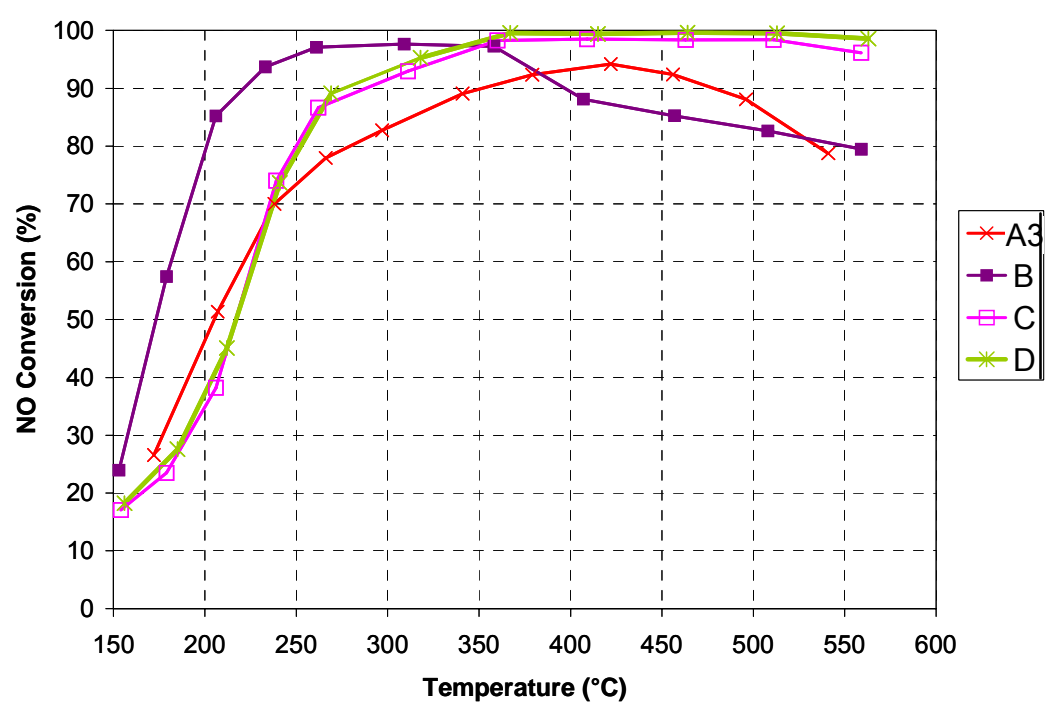

Figure 18. Performance of $120 \mathrm{k}$ mi aged SCR samples for reduction of $\mathrm{NO}$ with $\mathrm{NH}_{3}$ at $30 \mathrm{k} \mathrm{h}^{-1}$.

Further testing of catalysts $C$ and $D$ at higher space velocity (100k $\mathrm{h}^{-1}$, Figure 19) indicated that these catalysts were appropriate for higher speed test cycles such as those used in engine dynamometer certification of heavier weight vehicles. 


\section{RESULTS AND DISCUSSION (CON'T)}

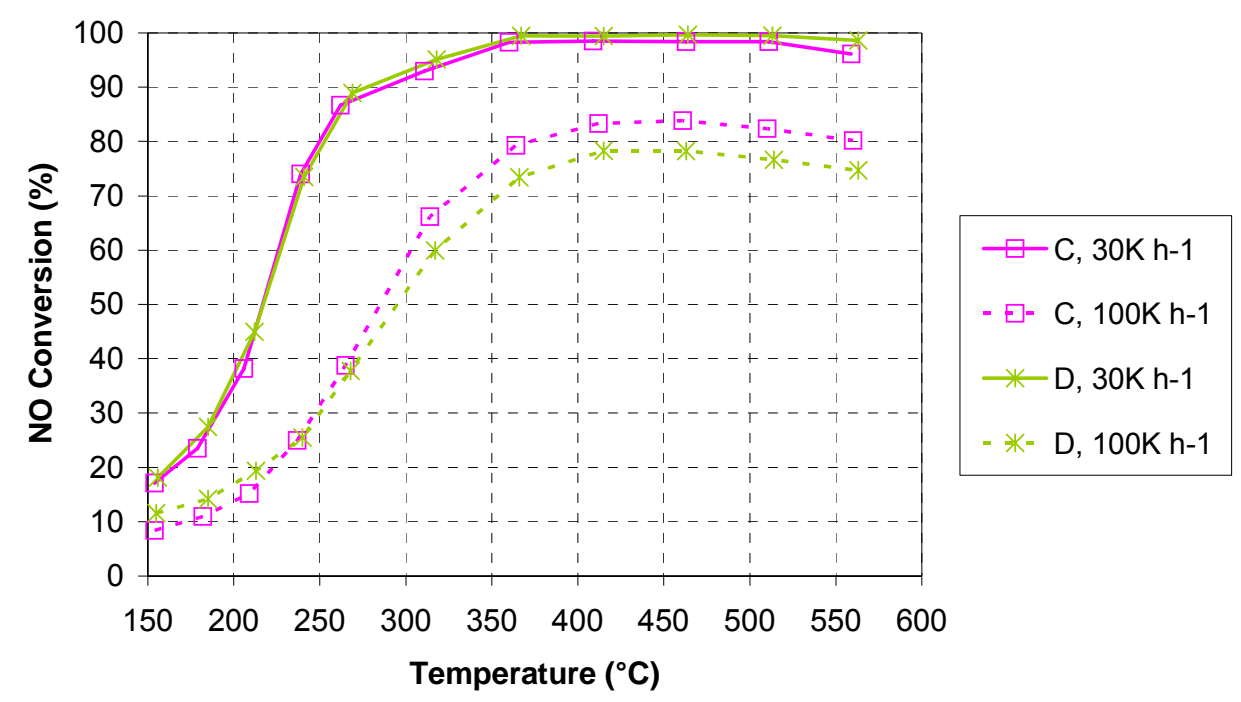

Figure 19. Performance of $120 \mathrm{k}$ mi aged SCR samples for reduction of $\mathrm{NO}$ with $\mathrm{NH}_{3}$ at $30 \mathrm{k}$ and $100 \mathrm{k} \mathrm{h}^{-1}$.

Another important property of SCR catalysts that was studied was their ability to store large quantities of ammonia, especially at lower temperatures. Ammonia storage, while important for high NOx reduction, was found to be detrimental during transient vehicle tests at times when the SCR catalyst temperature increased quickly, releasing stored ammonia that could be oxidized to NOx over the downstream CDPF. The effect of aging on storage ability was tested as shown in Figure 20, using the program SCR catalyst A3 and the improved low temperature catalyst B. It was found that after 120k mi of aging, catalyst A3 lost about two-thirds of its storage capacity, while catalyst B lost about one-third to one-half. While a lower amount of ammonia storage was desirable, catalyst B was seen as an improvement over A3 because it changed less during the course of aging, making the job of urea injection and ammonia slip control on the vehicle slightly easier. 


\section{RESULTS AND DISCUSSION (CON'T)}

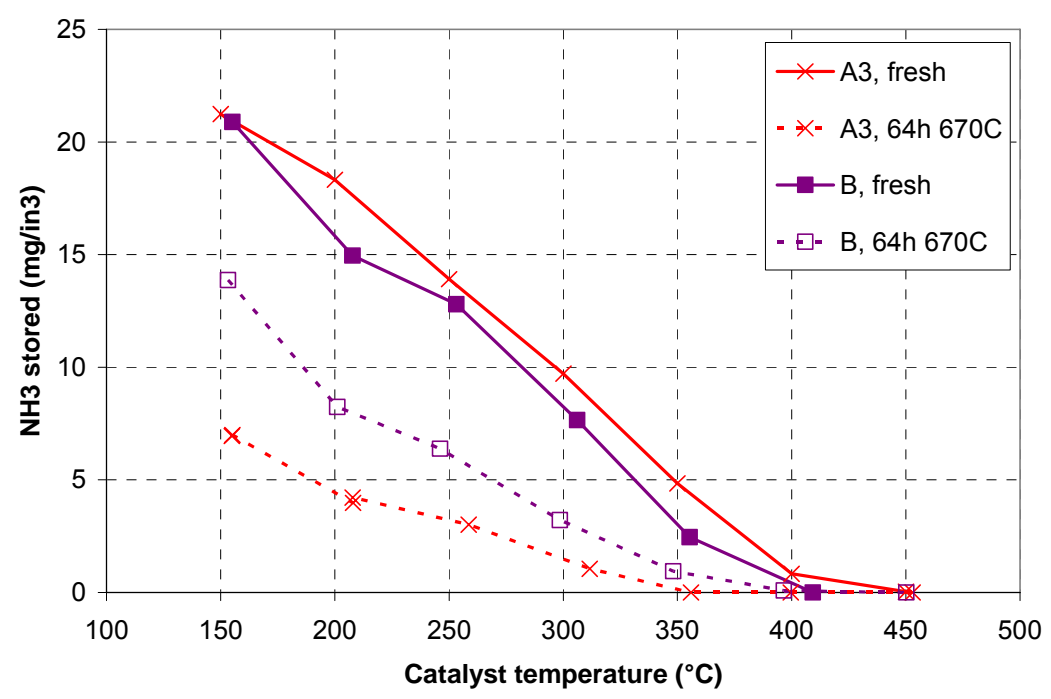

Figure 20. Effect of aging on amount of ammonia stored on SCR catalysts.

\section{DEVELOPMENT OF SCR TECHNOLOGY IF UREA IS NOT AVAILABLE (LNT-SCR)}

Due to the uncertainty of developing an infrastructure for aqueous urea delivery to lightduty vehicles in the US, it was decided to explore alternative catalyst systems that used SCR catalyst technology and did not require urea. Lean NOx Trap (LNT) catalysts, while capable of delivering high performance for NOx reduction, were known to generate large amounts of ammonia during the reduction process [10]. This property was used to advantage by locating an SCR catalyst downstream that can store the ammonia and use it for reduction of NOx slipping past the LNT, as described schematically in Figure 21.

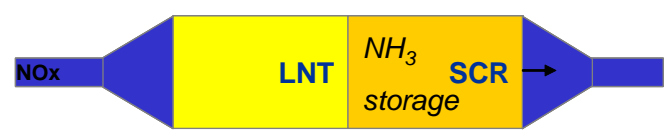

Figure 21. Example of LNT-SCR concept. LNT generates ammonia during reduction of NOx that is stored by the SCR for further NOx reduction.

The performance of aged cores of LNT and SCR were tested in the laboratory flow reactor as $120 \mathrm{k}$ mi aged pairs with a cycle of $40 \mathrm{~s}$ lean and $5 \mathrm{~s}$ rich. Performance of LNT A was improved greatly at low temperatures when the volume was doubled (Figure 


\section{RESULTS AND DISCUSSION (CON'T)}

22). The LNT A - SCR 1 pair had similar performance to the double LNT A system at temperatures below $300^{\circ} \mathrm{C}$, while LNT A - SCR 2 was similar to the double LNT A system at temperatures above $250^{\circ} \mathrm{C}$. These results established the potential of the LNT-SCR concept for diesel vehicles to have high $\mathrm{NO}_{x}$ reduction while saving cost and not requiring urea to be carried onboard. However, the fuel penalty and cost of the LNT-SCR system was estimated to be higher than for a comparable urea SCR system, and also the LNT-SCR system proved to be too complex to be studied any further as part of this program.

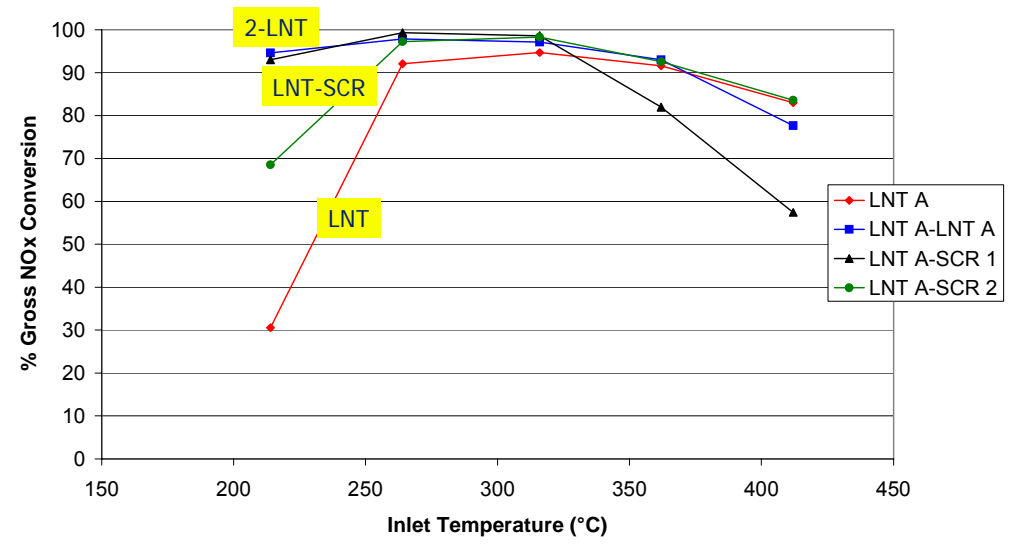

Figure 22. Performance comparison of LNT-SCR concept in a laboratory flow reactor. All cores were aged for the equivalent of $120 \mathrm{k} \mathrm{mi}$.

\section{EXHAUST GAS SENSOR DEVELOPMENT}

Both $\mathrm{NOx}$ and $\mathrm{NH}_{3}$ sensors were studied in the laboratory and on the program vehicle. A pre-production $\mathrm{NO}_{x}$ sensor was used upstream of the underbody oxidation catalyst to ensure that the correct amount of urea solution was injected during transient operation. NOx sensors used on the truck and engine dynamometer were modified to address thermal microcracking occurring during excessive diesel exhaust cooling. The modification increased response times slightly but were still within the usable range for this application. Research on a lower cost, less complex NOx sensor was initiated. Several different sensing technologies for selective detection of $\mathrm{NH}_{3}$ in the exhaust gas were investigated. These included resistive sensors based on thin film zeolites and molybdenum oxide $\left(\mathrm{MoO}_{3}\right)$, as well as silicon carbide-based ( $\mathrm{SiC}$ ) semiconducting devices and zirconia electrochemical elements. Although all of these technologies showed promise for selective $\mathrm{NH}_{3}$ detection, they each demonstrate severe limitations (drift, durability, reproducibility, etc.) and require further development. 


\section{RESULTS AND DISCUSSION (CON'T)}

Laboratory testing of multiple NOx sensors in dry conditions demonstrated that their sensitivity to ammonia was a complex function of temperature, gas constituents and gas concentration. However, the anomalous effects were greatly reduced when water was present. These tests also demonstrated that the sensitivity to NOx was lowered by roughly $10 \%$ in the presence of $100 \mathrm{ppm}$ of ammonia, and vice-versa. Vehicle testing of the NOx sensors demonstrated some small cross-sensitivity to oxygen.

Several prototype $\mathrm{NH}_{3}$ sensors were obtained from suppliers and tested for possible feedback control of urea dosing. Laboratory tests demonstrated good sensitivity to $\mathrm{NH}_{3}$

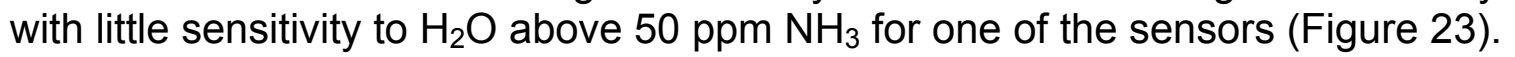

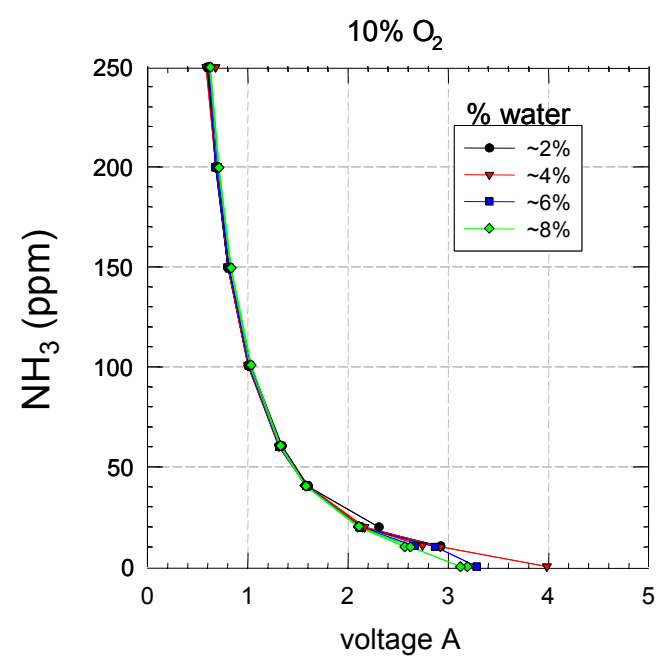

Figure 23. Sensitivity of supplier ammonia sensor in the laboratory.

One supplier ammonia sensor was successfully tested on the program vehicle when located between the SCR catalyst and CDPF. The sensor accurately indicated the amount of ammonia slipping past the SCR catalyst during Phase III of a FTP-75 cycle as shown in Figure 24 compared to FTIR in the same sample location. 


\section{RESULTS AND DISCUSSION (CON'T)}

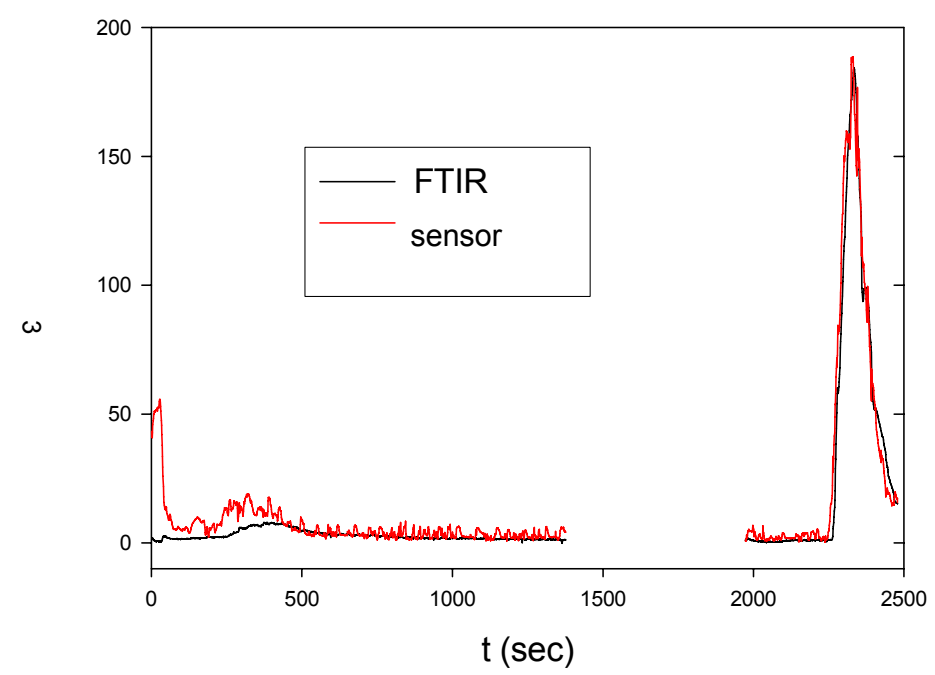

Figure 24. Sensitivity of supplier ammonia sensor on the LDT.

\section{CDPF STRATEGY DEVELOPMENT}

Work on the engine dynamometer included automated CDPF (Catalyzed Diesel Particulate Filter) regeneration. Oxidation catalyst volume to be used upstream of a CDPF was optimized. A CDPF was fully instrumented with thermocouples to determine internal temperature distribution during regeneration. The filter was weighed before and after regeneration. Automated regeneration was investigated under both city and highway driving conditions. A nearly complete regeneration was accomplished within ten minutes, or less than the time to complete one FTP-75 cycle.

\section{IMPROVED FRESH UREA SCR I CDPF SYSTEM PERFORMANCE}

Over $90 \%$ NOx conversion was achieved with fresh catalysts on a simulated FTP-75 on an engine dynamometer. This was an improvement over the $82 \%$ NOx cycle conversion achieved with the baseline SCR-CDPF system. The urea injector was pointed against the exhaust flow. A spray target, developed for this program at FEV, was added to the system resulting in enhanced mixing of reductant in the exhaust gas. Engine-out NOx was reduced approximately $40 \%$ through the use of higher levels of exhaust gas recirculation (EGR). A rapid warm-up procedure was used during the coldstart portion of the test cycle. Tailpipe emissions and system efficiencies from four simulated FTP-75 tests were averaged as shown in Figure 25. Emissions of THC (Total Hydrocarbon) were below the non-methane standard. Tailpipe NOx was below the Tier 2 Bin $5(120 \mathrm{k} \mathrm{mi}$ ) level of $0.07 \mathrm{~g} / \mathrm{mi} \mathrm{NOx}$, and PM levels were approximately $1 \mathrm{mg} / \mathrm{mi}$. 


\section{RESULTS AND DISCUSSION (CON'T)}

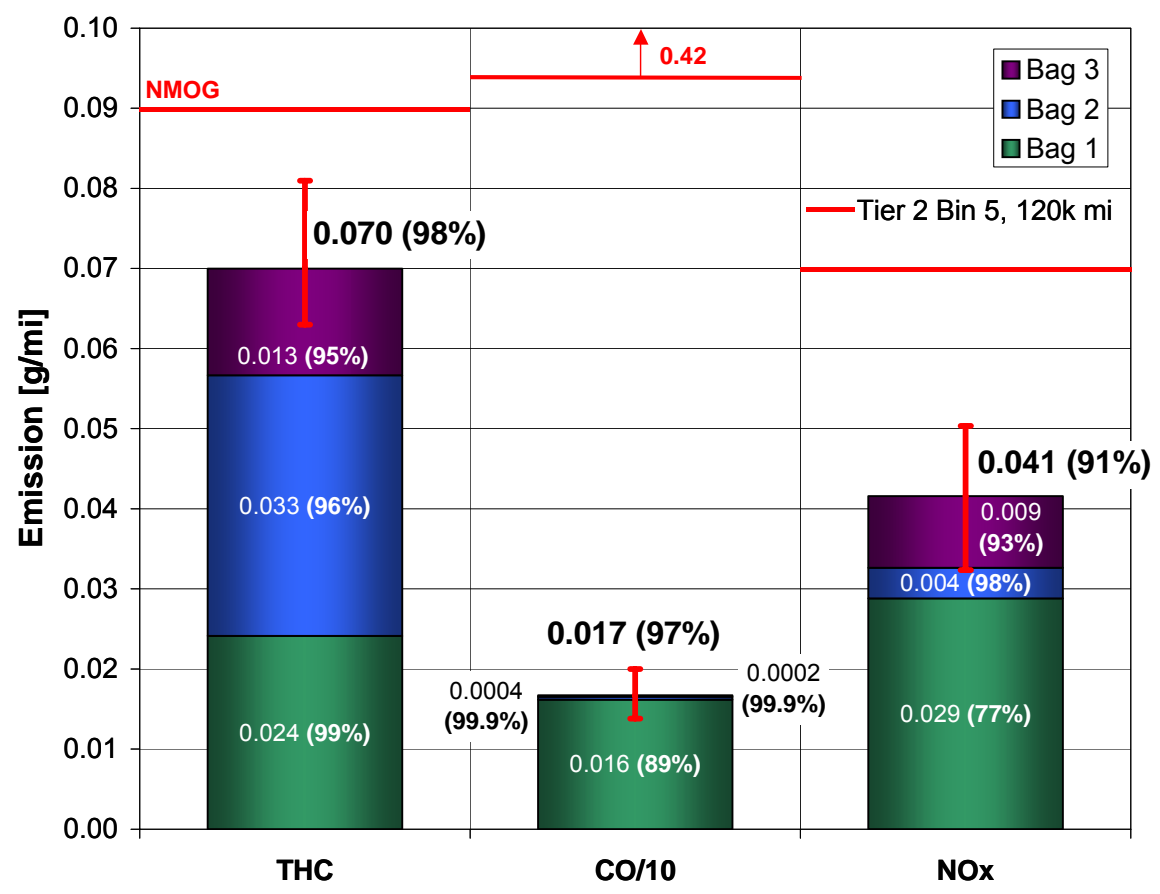

Figure 25. Average tailpipe emissions and system efficiencies from four cold-start FTP-75 simulations with fresh catalysts on the engine dynamometer. Enhanced mixing of reductant in the exhaust gas and additional EGR resulted in a low mileage TP NO level below Tier 2 Bin 5. THC (Total Hydrocarbon) results are shown while the emission standard does not include methane (NMOG - Non-Methane Organic Gases).

The key modifications to the cold-start engine strategy were close post injection for the first $60 \mathrm{~s}$ followed by far post injection for the following $120 \mathrm{~s}$. This allowed the underbody oxidation catalyst to warm up to its operating temperature about $154 \mathrm{~s}$ faster than with the baseline calibration, and create an exotherm with far post $\mathrm{HC}$. This resulted in an improvement of about one minute in SCR catalyst warm-up time. The average fuel economy penalty for the warm-up strategy, when combined with the previously mentioned engine-out NOx reduction, was calculated to be less than $1 \%$.

The urea dosing system on the vehicle clogged frequently due to collection of solid urea in the urea/air mixing chamber located downstream of the urea injector. A new design eliminated dead volume that might collect urea. The system was tested successfully for $10 \mathrm{k} \mathrm{mi}$ on a 2.4L European Ford Transit, with no need for interim cleaning of the mixing chamber, transfer tube or nozzle. This dosing system has been described in detail [11]. However, the new dosing system proved to be overly sensitive to pressure variations and was abandoned. The original air-assisted injection system was used for further durability testing. 


\section{RESULTS AND DISCUSSION (CON'T)}

\section{K MI UREA SCR I CDPF SYSTEM PERFORMANCE}

The durability cycle was repeated on the engine dynamometer at FEV for $24 \mathrm{~h}$ per day, 5 to 6 days per week, for $1065 \mathrm{~h}$. Over 300 CDPF regenerations were performed during $50 \mathrm{k} \mathrm{mi}$ of operation. The DOC was used to generate the exotherm required, regularly raising the SCR catalyst to temperatures in excess of $650^{\circ} \mathrm{C}$.

At the $50 \mathrm{k}$ mi mark, the system performance was tested on a simulated cold-start FTP75 on the engine dynamometer. Due to the prototype nature of the engine, it was not possible to consistently to control the post injection at a level that could warm the SCR without excessive HC slip past the DOC. This is critical to the function of the rapid warm-up strategy because hydrocarbons adsorbed on the SCR have been shown to temporarily depress NOx activity (Figure 15). Delayed SCR catalyst light-off resulted in tailpipe NOx emissions that exceeded the Tier 2 Bin 5 standard, as shown in Figure 26.

The large DOC, SCR, and CDPF catalysts were moved to the LDT, and similar tailpipe emissions were measured during vehicle testing (Figure 27). It was apparent that the Tier 2 Bin 5 standard was exceeded due to low NOx conversion during cold-start (Bag 1). However, the FTP-75 tailpipe NOx at 50k mi was similar to the fresh case without rapid warm-up $(0.091-0.14 \mathrm{~g} / \mathrm{mi}$ vs. 0.13$)$, indicating that the SCR catalyst had not significantly aged.
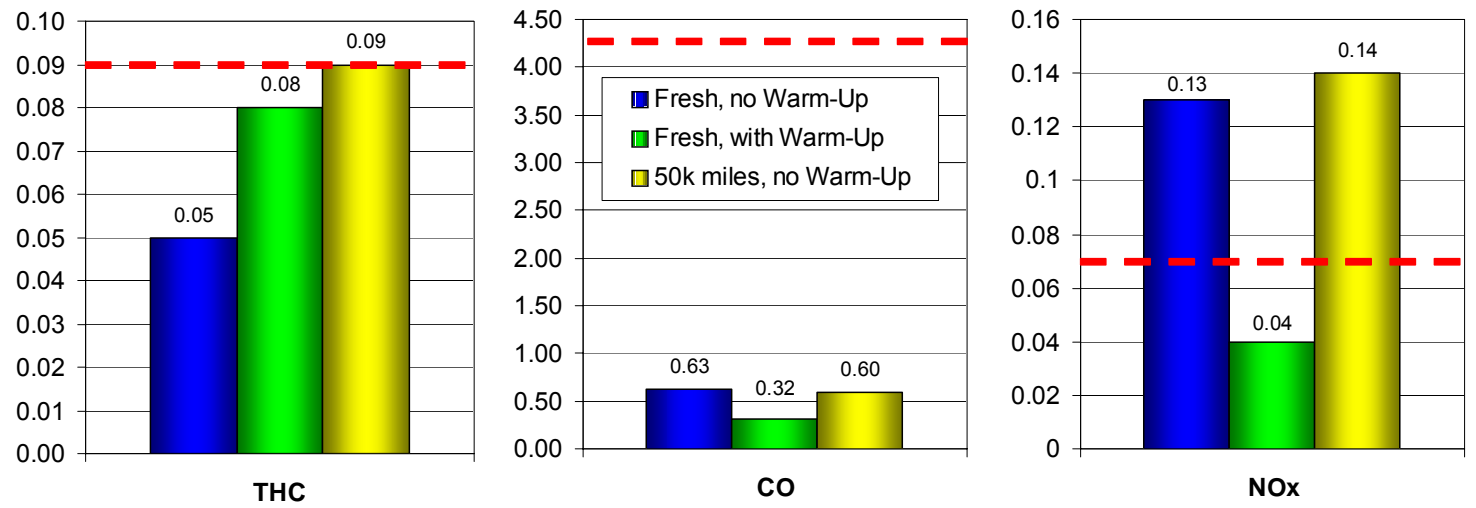

Figure 26. Cold-start FTP-75 performance results on FEV's engine dynamometer. 


\section{RESULTS AND DISCUSSION (CON'T)}

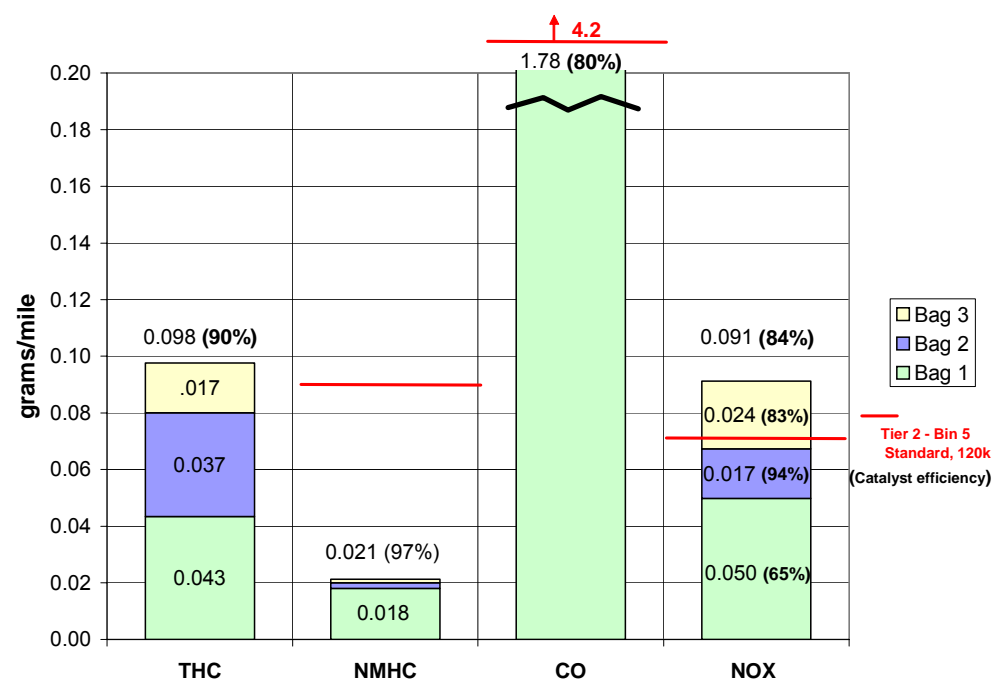

Figure 27. FTP-75 performance of the $50 \mathrm{k} \mathrm{mi} \mathrm{aged} \mathrm{catalyst} \mathrm{system} \mathrm{on} \mathrm{the} 6000 \mathrm{lbs}$ LDT.

The two small oxidation catalysts located in the downpipe upstream of the main underbody DOC were found to have significantly reduced activity after $50 \mathrm{k}$ mi of durability testing, producing little or no exotherm. Exhaust gas temperatures were measured during the cold-start as shown in Figure 28 . At $50 \mathrm{k} \mathrm{mi}$, these catalysts were producing no significant temperature increase. At low mileage, emission tests on the LDT showed that the close-coupled catalysts were only minimally effective in oxidizing $\mathrm{NO}$ to $\mathrm{NO}_{2}$. Although they were effective in oxidizing hydrocarbons, the total hydrocarbon (THC) level measured at the tailpipe was comparable between the vehicle (low-mileage catalysts) and the engine dynamometer (deactivated catalysts). Therefore, the aged downpipe catalysts were not installed on the LDT for testing the $50 \mathrm{k}$ and $120 \mathrm{k} \mathrm{mi}$. On the engine dynamometer, the deactivated catalysts were removed at $50 \mathrm{k} \mathrm{mi}$ and replaced with new ones, which were used through the final $70 \mathrm{k} \mathrm{mi}$. 


\section{RESULTS AND DISCUSSION (CON'T)}

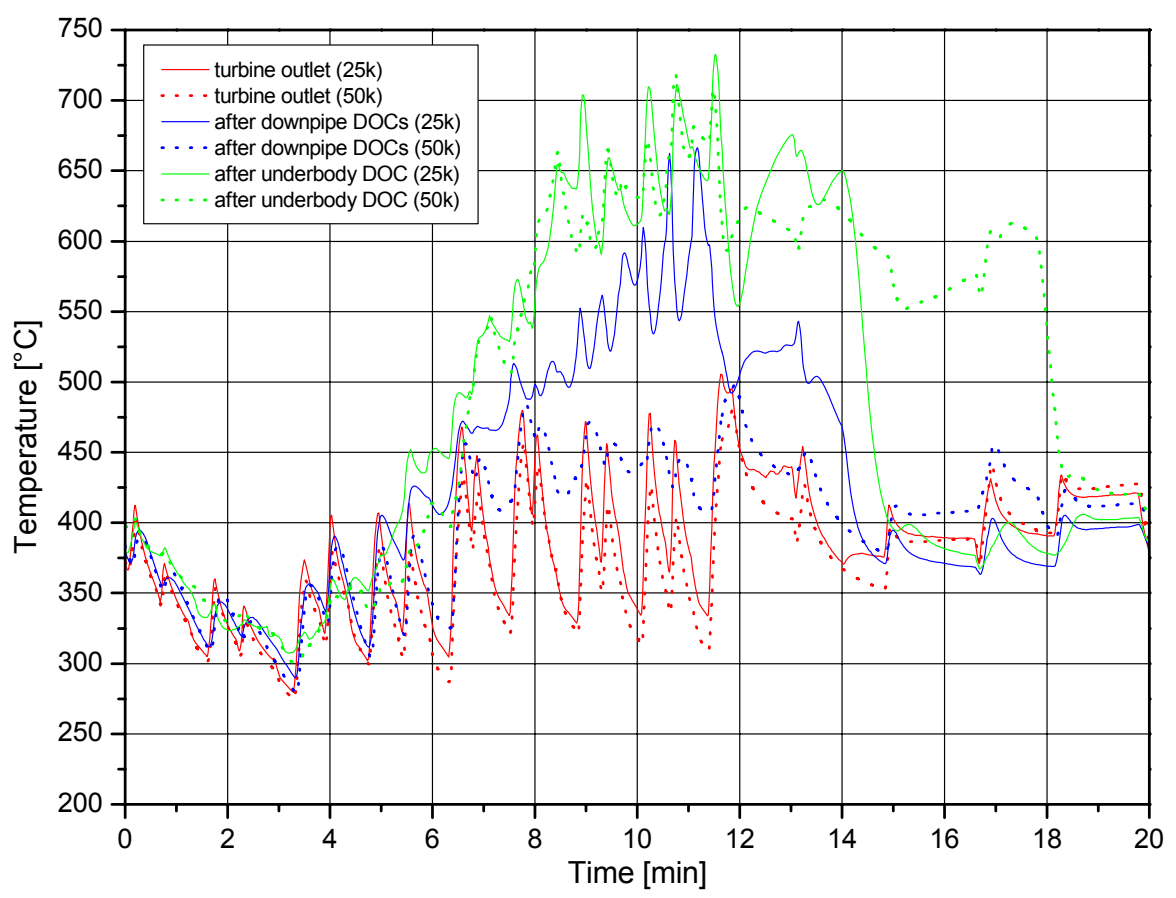

Figure 28. Downpipe DOC performance at $25 \mathrm{k}$ and $50 \mathrm{k}$ mi of durability.

Calculations were performed to predict what NOx emissions would have been at $50 \mathrm{k} \mathrm{mi}$ if rapid warm-up was functioning as it had been for the evaluation of the fresh catalyst performance. The inlet temperature to the SCR catalyst during the first phase (Bag 1) of the FTP-75 was much lower without rapid warm-up, as shown in Figure 29. This resulted in a higher level of tailpipe NOx $(0.076 \mathrm{~g} / \mathrm{mi})$ in the $50 \mathrm{k}$ mi test. An earlier test at $4 \mathrm{k}$ mi with warm-up resulted in less than $0.05 \mathrm{~g} / \mathrm{mi} \mathrm{NOx}$. It was predicted that if exhaust temperatures in the first $200 \mathrm{~s}$ of the $50 \mathrm{k} \mathrm{mi}$ test had been similar to the $0 \mathrm{~K} \mathrm{mi}$ test, the tailpipe $\mathrm{NO}_{x}$ would have been approximately $0.05 \mathrm{~g} / \mathrm{mi}$, meeting the Tier 2 Bin 5 standard. 


\section{RESULTS AND DISCUSSION (CON'T)}

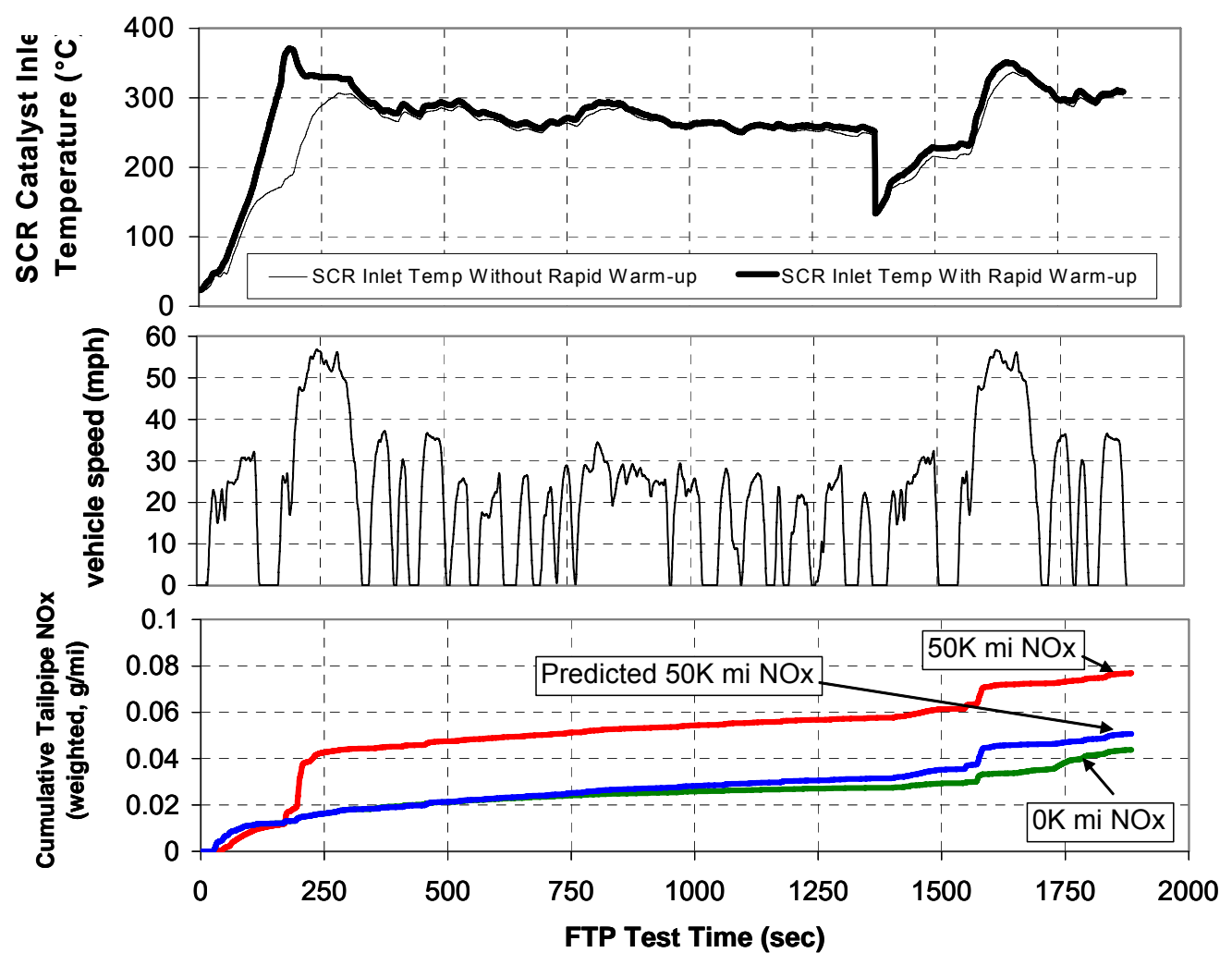

Figure 29. Predicted FTP-75 performance of the $50 \mathrm{k} \mathrm{mi}$ aged catalyst system on the LDT with rapid warm-up during cold-start.

\section{K MI UREA SCR I CDPF SYSTEM PERFORMANCE}

After $50 \mathrm{k}$ mi testing, the catalysts were returned to the dynamometer at FEV and aging was continued to the equivalent of $120 \mathrm{k} \mathrm{mi}$. Total time on the engine was 2544 hours. The CDPF was regenerated 643 times, with each regeneration typically lasting ten minutes, including six minutes with the SCR at high temperature (over $600^{\circ} \mathrm{C}$ ). In all, the SCR spent $64 \mathrm{~h}$ at high temperature during the durability phase. Emission evaluations were conducted on the dynamometer following accumulation of $75 \mathrm{k}$ and $120 \mathrm{k} \mathrm{mi}$, but problems with rapid warm-up and increased engine-out NOx prevented comparison with the earlier results.

After completion of the mileage accumulation, the catalysts were installed on the LDT. Issues with engine control again prevented using the rapid warm-up strategy that had proven effective with the fresh catalysts. FTP-75 emissions without rapid warm-up were collected and summarized (Figure 30). NMOG and CO emissions were within Tier 2 Bin 5 limits, but as expected the Bag 1 NOx emissions were higher than fresh and at 50k mi. Bag 2 and Bag 3 NOx emissions were also higher, resulting in 74\% conversion and 


\section{RESULTS AND DISCUSSION (CON'T)}

$0.128 \mathrm{~g} / \mathrm{mi}$ tailpipe NOx over the cycle. The CDPF continued to be effective at meeting the regulated level of PM with $0.0012 \mathrm{~g} / \mathrm{mi}$ at the tailpipe, and it effectively converted any $\mathrm{NH}_{3}$ slip past the SCR catalyst. Selectivity to $\mathrm{N}_{2} \mathrm{O}$ for the system was $15 \%$.

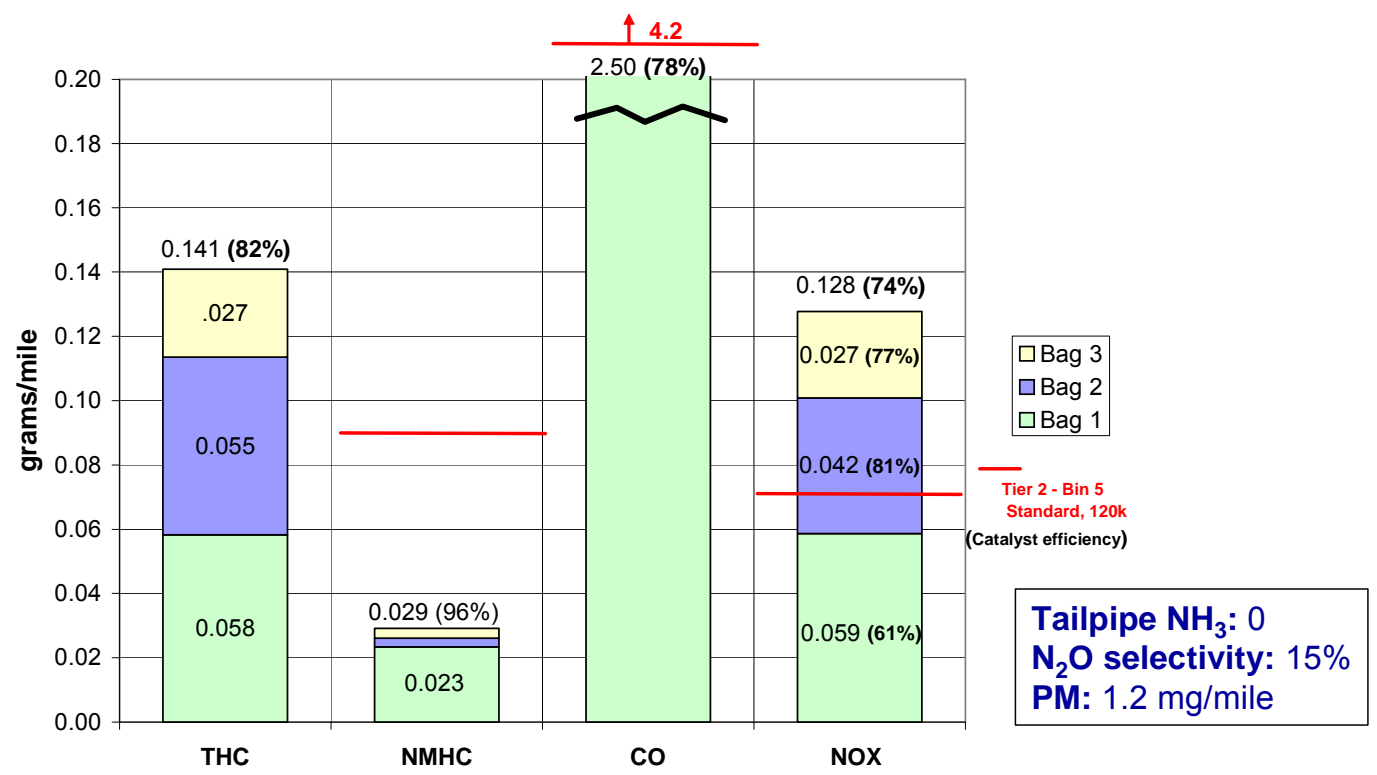

Figure 30. FTP-75 performance of the $120 \mathrm{k} \mathrm{mi}$ aged catalyst system on the $6000 \mathrm{lbs}$ LDT.

For regeneration of the CDPF, fuel was injected into the exhaust downstream from the turbo. Because post injection could not be controlled sufficiently to heat the catalysts rapidly during a cold start, the downstream injector was investigated as another means of using the DOC to produce an exotherm and heat the SCR catalyst. As with the post injection, complete conversion of the injected fuel over the DOC was an important limiting factor in order to avoid poisoning the SCR catalyst with adsorbed HC. With this limitation, the downstream injection was able to supply only half of the heating benefit that had been achieved during the successful tests with post injection, and the Bag 1 NOx conversion was not improved. The lack of success in speeding SCR catalyst lightoff using this technique could be largely explained by the laboratory results (Figure 11), where the DOC was shown to be much less effective in oxidizing the long-chain hydrocarbons that result from injecting fuel directly into the exhaust instead of incylinder. The lab results also showed that high $\mathrm{HC}$ levels suppress the production of $\mathrm{NO}_{2}$ (Figure 12), which was an especially important factor in the SCR performance during low-temperature cold-start conditions.

In order to determine the contribution of DOC aging and SCR aging to the overall emissions, additional combinations of fresh and aged catalysts were tested on the LDT. Replacing the $120 \mathrm{k}$ mi SCR with a low mileage catalyst improved the NOx conversion during the warmed-up stabilized phase (Bag 2) of the FTP-75 test to over $90 \%$, but did not improve the cold start phase (Bag 1) and had only a small benefit on the hot start 


\section{RESULTS AND DISCUSSION (CON'T)}

phase (Bag 3). As shown in Figure 31, the 120k mi SCR catalyst combined with a lowmileage DOC returned NOx performance to the $50 \mathrm{k}$ mi level.

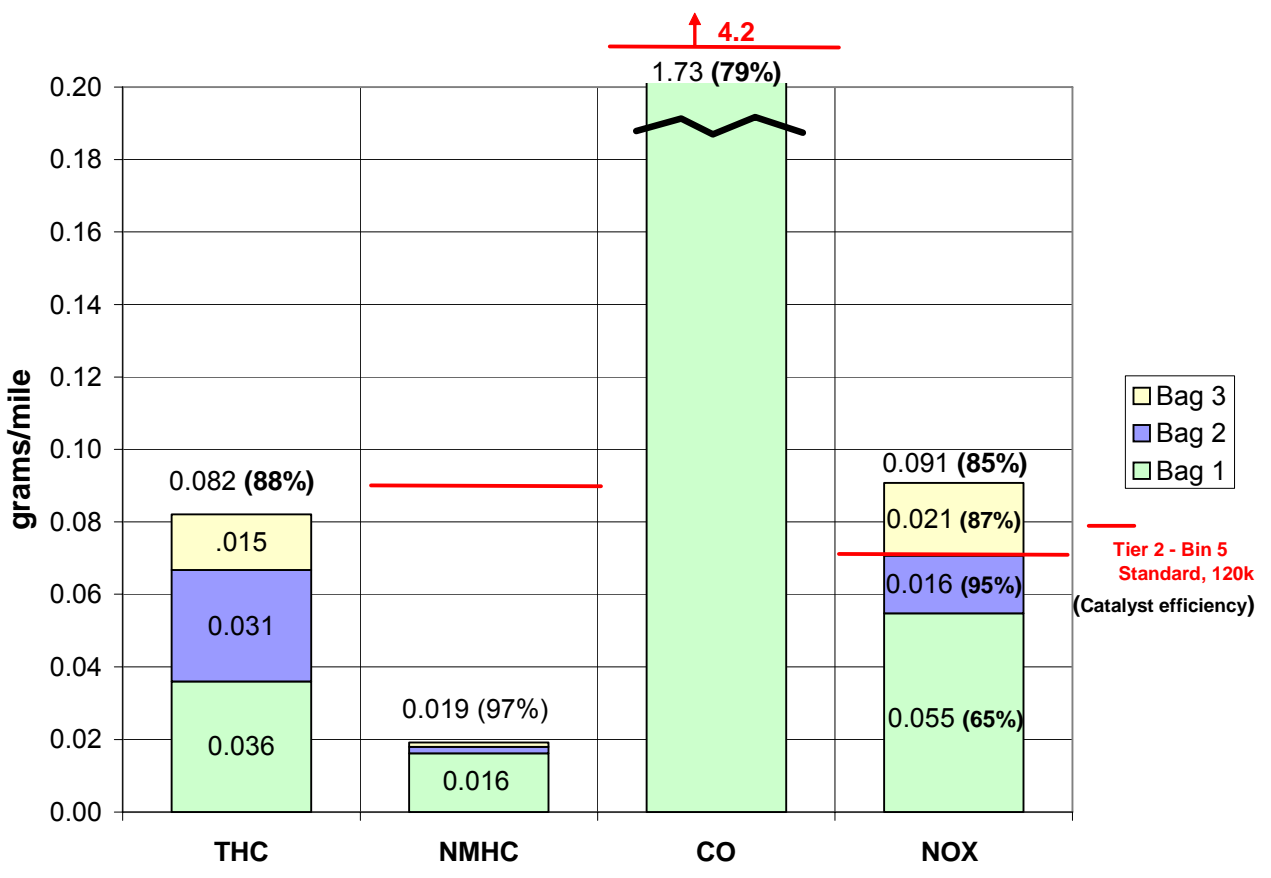

Figure 31. FTP-75 performance with 4k DOC and 120k mi aged SCR catalyst on the 6000 lbs LDT.

These results indicated that the DOC was responsible for most of the deterioration in NOx performance through the durability testing. Several tests were conducted to measure the $\mathrm{NO}_{2}$ produced by the DOC. The low-mileage DOC oxidized $40 \%$ of engine-out $\mathrm{NO}$ to $\mathrm{NO}_{2}$ averaged over the FTP-75. At $50 \mathrm{k} \mathrm{mi}$, the DOC oxidized $14 \%$ of the total NO. During the final testing with the DOC aged to $120 \mathrm{k} \mathrm{mi}$, the DOC oxidized $30 \%$ of total $\mathrm{NO}$ to $\mathrm{NO}_{2}$. Most of the $\mathrm{NO}$ oxidation occurred during portions of the test cycle where space velocities were low, primarily idle periods. Use of post injection or downstream fuel injection during cold start strongly suppressed the NO oxidation, and the effect continued throughout the test cycle even after the $\mathrm{HC}$ addition was ended. Under these conditions, the molar ratio of $\mathrm{NO}_{2} / \mathrm{NOx}$ on average ranged from $5 \%$ to $15 \%$.

During the durability phase ash was removed from the CDPF three times. Accumulation of an excess quantity of ash was indicated by an increase in exhaust restriction and a corresponding decrease in filter loading time. Following filter regeneration, the filter was removed from the exhaust system and weighed. Ash was forced from the filter by flowing compressed air in the direction opposite of the exhaust flow, and then the filter was reweighed to determine the mass of ash by difference. The first ash removal was somewhat less aggressive than the second and third, as shown in Table 6. 


\section{RESULTS AND DISCUSSION (CON'T)}

Table 6: Ash removed from CDPF.

\begin{tabular}{|c|c|c|}
\hline Dynamometer Hours & Equiv. Mi & Ash (g) \\
\hline 940 & $44 k$ & 112 \\
\hline 1688 & $79 k$ & 419 \\
\hline 2375 & $112 k$ & 388 \\
\hline
\end{tabular}

The third ash sample was analyzed by $x$-ray fluorescence spectroscopy (XRF) and Xray diffraction (XRD). XRF was used to determine the concentration of elements present in the ash. Major elements were $\mathrm{Ca}, \mathrm{S}, \mathrm{Zn}$, and $\mathrm{P}$. Minor elements, with concentrations less than $1 \%$, were $\mathrm{Fe}, \mathrm{Mo}, \mathrm{Si}$, and $\mathrm{Cu}$. Several additional trace elements were measured in concentrations less than $0.1 \%$. XRD was used to identify and quantify crystalline compounds present in the ash. Calcium sulfate $\left(\mathrm{CaSO}_{4}\right)$ and two forms of calcium zinc phosphate $\left(\mathrm{Ca}_{19} \mathrm{Zn}_{2}\left(\mathrm{PO}_{4}\right)_{14}\right.$ and $\left.\mathrm{CaZn}{ }_{2}\left(\mathrm{PO}_{4}\right)_{2}\right)$ were identified.

An ammonia sensor was aged along with the other aftertreatment components for the $120 \mathrm{k}$ mi durability testing. Vehicle testing demonstrated that the sensor was still operational and responded to $\mathrm{NH}_{3}$, but with reduced sensitivity. When the $120 \mathrm{k} \mathrm{mi}$ evaluations were complete, the sensor was coated with a layer of soot. After the soot was removed, most of the sensitivity to $\mathrm{NH}_{3}$ was recovered and response time was improved. The NOx sensors also survived the $120 \mathrm{k}$ mi, with NOx calibrations remaining within specified tolerances.

\section{VEHICLE EVALUATION OF IMPROVED SCR CATALYST}

A full-sized sample of improved SCR catalyst (B) described in Figure 18 was aged at $670^{\circ} \mathrm{C}$ under lean conditions for $64 \mathrm{~h}$, simulating time spent at high temperature during the CDPF regenerations that would occur for $120 \mathrm{k}$ mi on the vehicle. This catalyst was installed on the LDT and tested with both the low-mileage DOC (Figure 32) and the dynamometer-aged DOC (120k mi, Figure 33 ). Selectivity to $\mathrm{N}_{2} \mathrm{O}$ was $12 \%$ with the fresh DOC and $16 \%$ with the aged DOC. With the more active DOC, this catalyst met the Tier 2 Bin 5 limit even without an engine capable of running a rapid warm-up strategy. 


\section{RESULTS AND DISCUSSION (CON'T)}

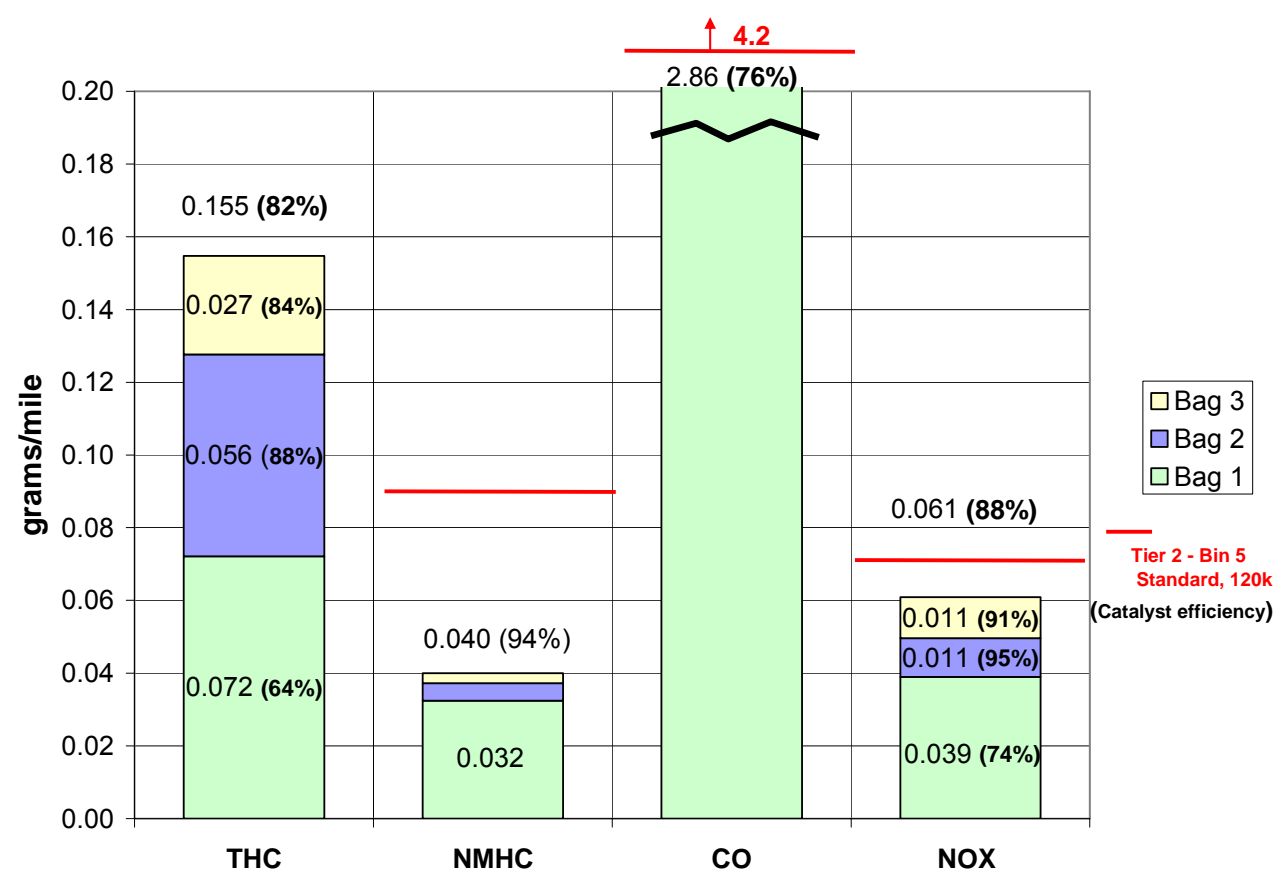

Figure 32. FTP-75 performance with $4 \mathrm{k} \mathrm{mi} \mathrm{DOC} \mathrm{and} \mathrm{improved} \mathrm{SCR} \mathrm{catalyst} \mathrm{B} \mathrm{on} \mathrm{the} 6000 \mathrm{lbs}$ LDT.

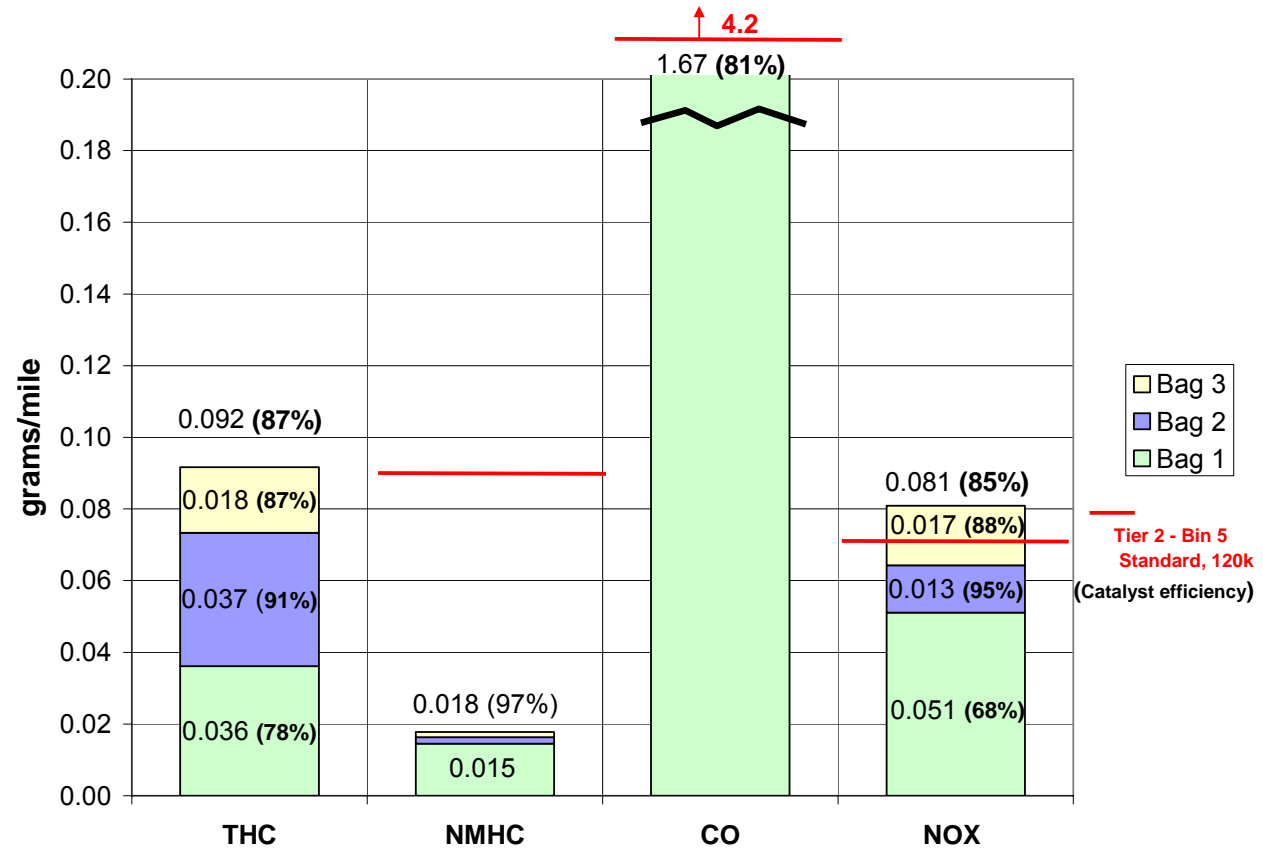

Figure 33. FTP-75 performance with 120k mi DOC and improved SCR catalyst B on the $6000 \mathrm{lbs}$ LDT. 


\section{RESULTS AND DISCUSSION (CON'T)}

\section{DOC MODEL DEVELOPMENT AND RESULTS}

A mathematical model of the chemical performance of the DOC was developed based on the SIMTWC framework. As shown in Figure 34, the model was a combination of (1) first principles description of heat transfer and energy balances in the catalyst, (2) phenomenological explanation of adsorption and desorption of hydrocarbons in the zeolite pores within the catalyst washcoat, (3) empirical catalyst performance maps for each species (i.e., $\mathrm{CO}, \mathrm{HC}$, and $\mathrm{NO}$ ) to estimate reaction conversion from catalyst temperature, and (4) experience based correlations to describe the effect of reaction rate inhibition due to competition among species for active sites. This unique combination of information from diverse sources obviated the need for a complete understanding of all the physical and chemical details of the complex catalytic system; but at the same time afforded an easy-to-use, computationally inexpensive, predictive model with which one can exploit the laboratory data to make critical business decisions. Another key advantage of this approach was that it enabled model extension with new information, as and when they are available, through the various "information hooks" - mathematical equations, experimental data, statistical correlations, expert knowledge etc.

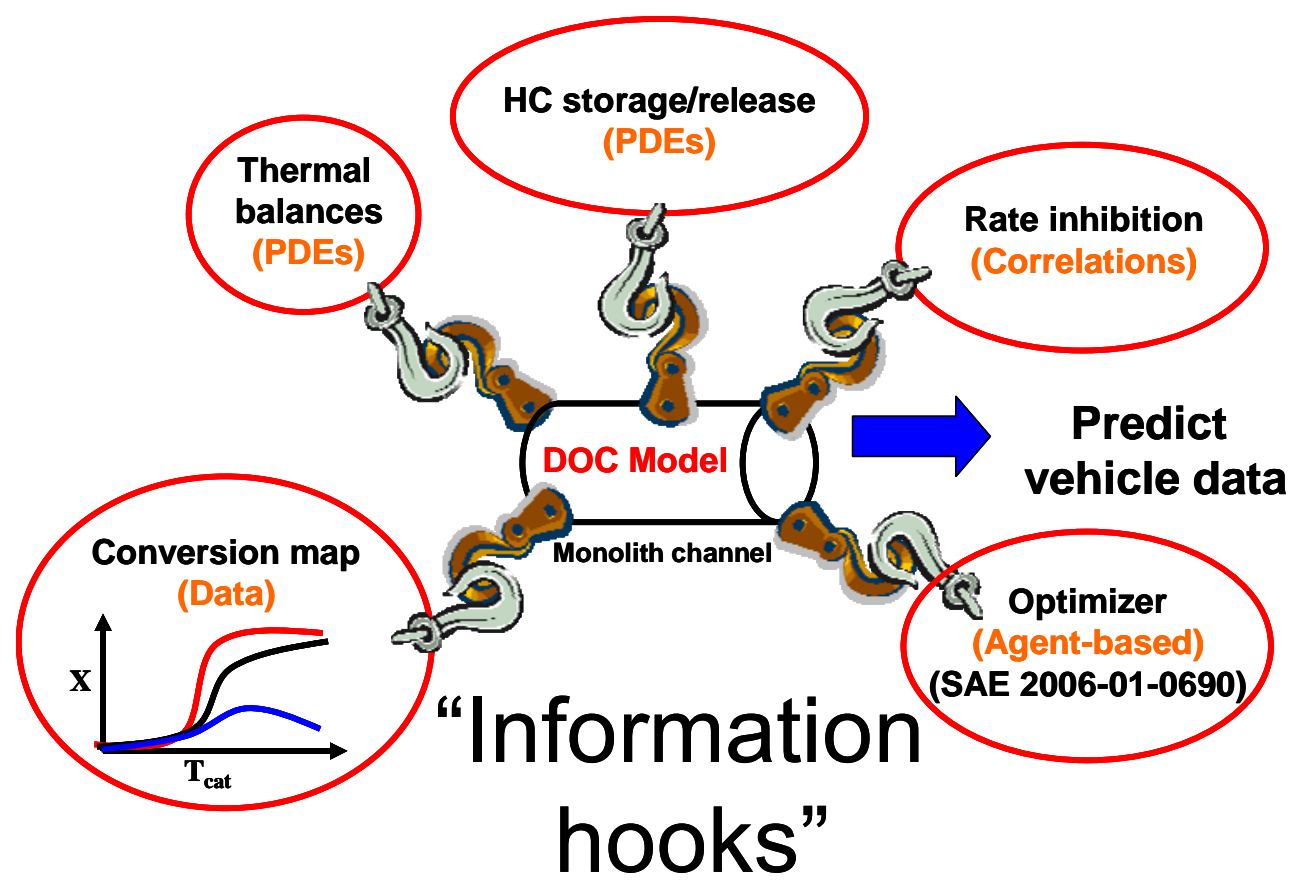

Figure 34. Schematic of the SIMTWC based DOC model.

One of the key inputs to the model was a reaction map obtained from the pulsator reactor data. As shown in Figure 35, this map provided the reaction conversion values for the oxidation of $\mathrm{CO}, \mathrm{HC}$ and $\mathrm{NO}$ at various temperatures. $\mathrm{CO}$ was converted at high 


\section{RESULTS AND DISCUSSION (CON'T)}

efficency at a lower temperature compared to that of $\mathrm{HC}$. Methane in the combustion gases that enter the catalyst did not get oxidized completely. This was believed to be the reason for the $<100 \%$ conversion values of HCs. NO light-off took place at a much higher temperature compared to that of $\mathrm{CO}$ and $\mathrm{HC}$. At lower temperatures NO oxidation to $\mathrm{NO}_{2}$ was controlled by the kinetic rate and at higher temperatures thermodynamic equilibrium limited the amount of $\mathrm{NO}_{2}$ formed.

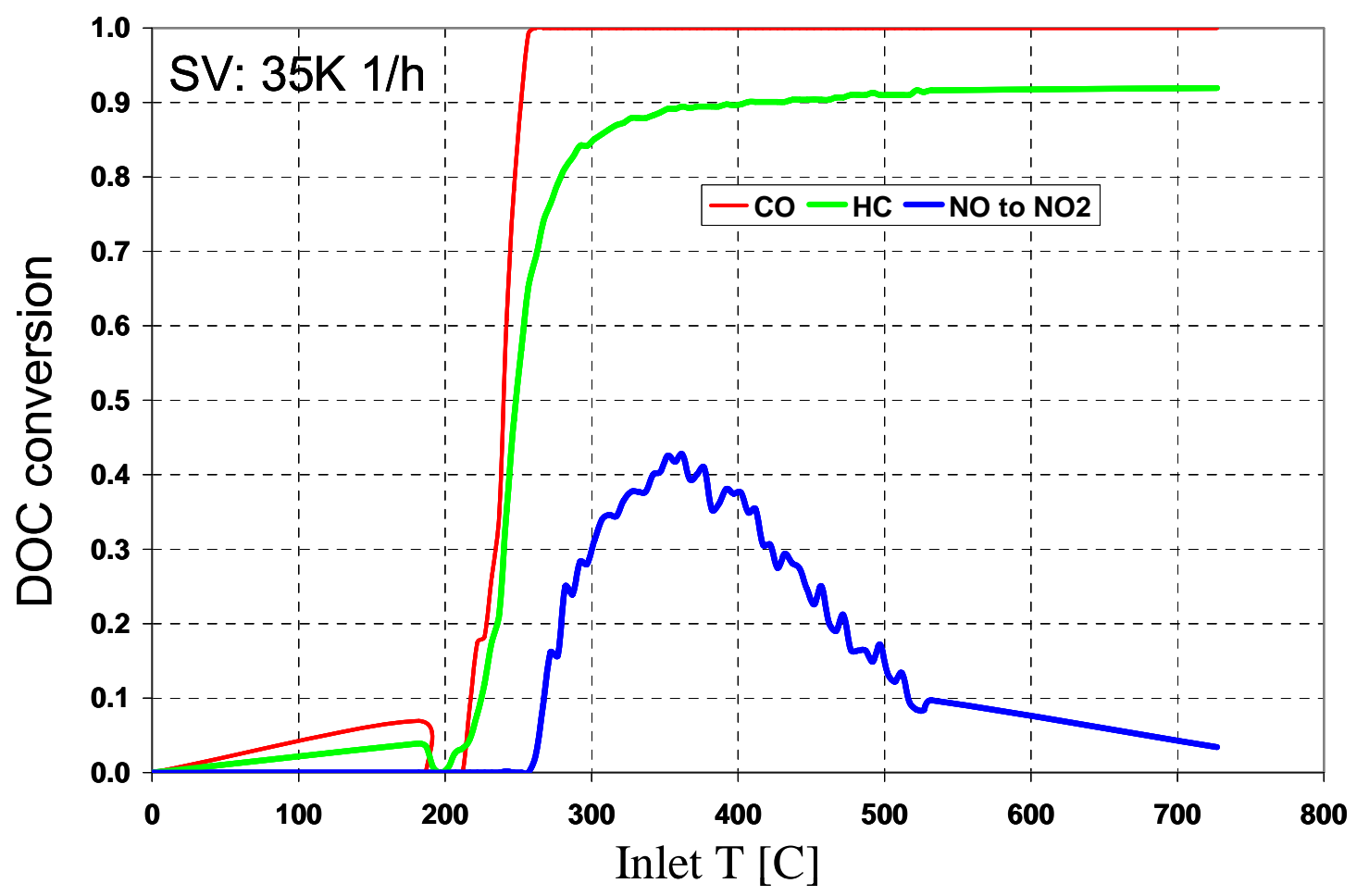

Figure 35. A typical pulsator generated DOC reaction map.

The DOC model was calibrated to the data discussed above. Zeolites are typically added to the DOC washcoat in order to store $\mathrm{HC}$ at low temperatures. Lower diesel engine operation temperatures and long chain $\mathrm{HC}$ in unburnt diesel fuel increased the probability of $\mathrm{HC}$ storage, thus reducing cold start $\mathrm{HC}$ emissions. In order to simulate this behavior, a HC storage-release experiment was carried out in the pulsator. Initially, $\mathrm{HC}$ in the gas was stored in the zeolite washcoat pores. As the inlet gas temperature was ramped up, the adsorbed $\mathrm{HC}$ desorbed and this was seen (dots in Figure 36) as the negative conversion data during the initial periods of the experiment. The temperature reached a level where the catalyst lit-off, and the HC was oxidized. This phenomenon was seen as the steep increase in conversion at the later stages of the experiment. As seen from the close fit between the solid line (model prediction) and the dotted experimental values, the model explained the data reasonably well with the set of estimated parameters. 


\section{RESULTS AND DISCUSSION (CON'T)}

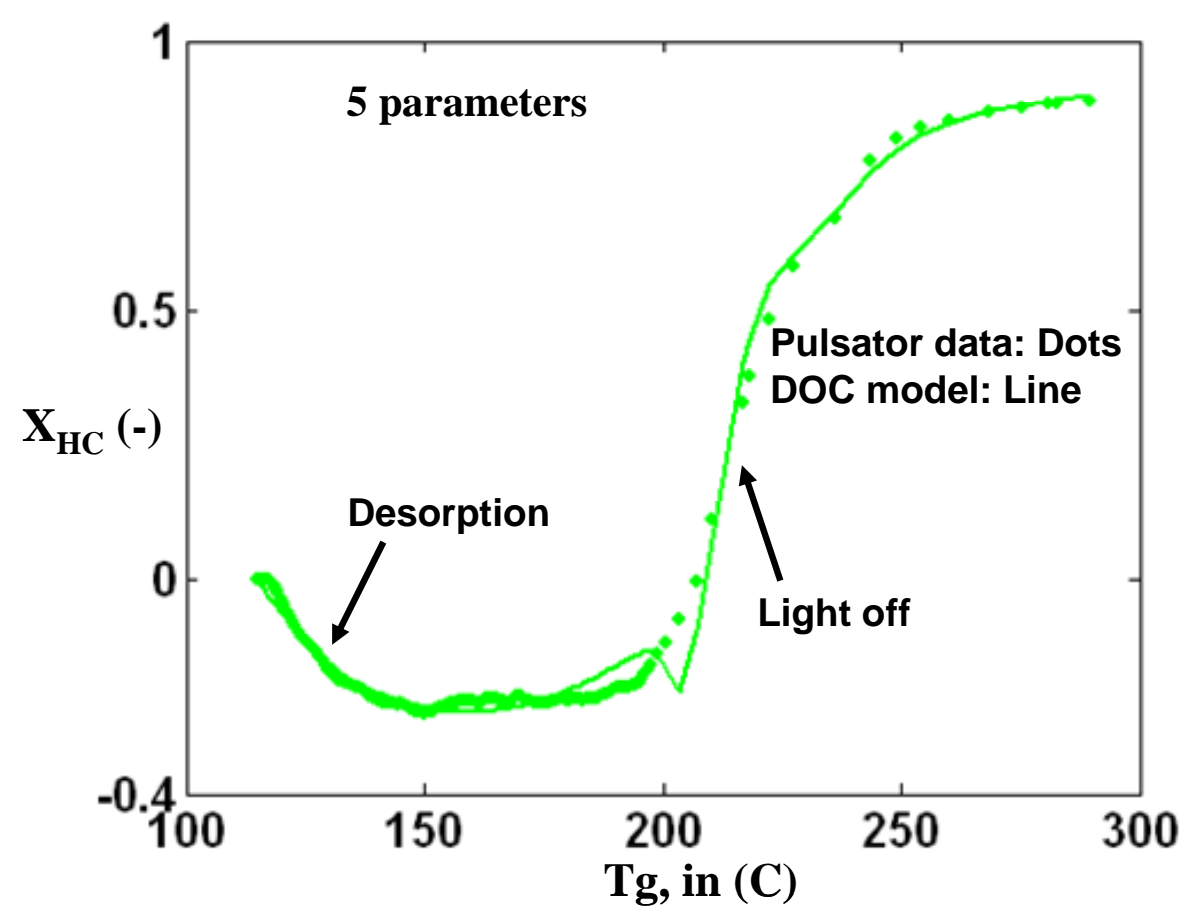

Figure 36. Model data match in a typical HC light-off experiment.

One of the key utilities of the DOC model was to predict the amount of $\mathrm{NO}_{2}$ generated by the DOC. Some portion of $\mathrm{NO}_{2}$ has been shown to be helpful for improved SCR performance at low temperatures [9]. The calibrated DOC model was used to predict $\mathrm{NO}_{2}$ downstream of the DOC over an FTP-75 test with the LDT as shown in Figure 37. As seen from the $\mathrm{NO}_{2}$ data, the $\mathrm{DOC}$ did not produce any $\mathrm{NO}_{2}$ during the first $200 \mathrm{~s}$ of the FTP-75 test. The model assumed that all the input NOx to the DOC was only NO, and any $\mathrm{NO}_{2}$ generated by the engine was ignored. This was probably one the reasons for underestimation of the $\mathrm{NO}_{2}$ generated by the DOC.

$\mathrm{NO}_{2}$ generated by the $\mathrm{DOC}$ is strongly inhibited by $\mathrm{CO}$ and $\mathrm{HC}$, probably due to increased competition for active sites, especially at higher concentrations of $\mathrm{CO}$ and $\mathrm{HC}$ that prevented $\mathrm{NO}$ from adsorbing and hence oxidizing to $\mathrm{NO}_{2}$. Figure 38 shows that the $\mathrm{NO}_{2}$ generation was reduced by up to $75 \%$ due to a $50 \%$ increase in $\mathrm{HC}$. The data was obtained from three different FTP-75 tests over the $120 \mathrm{k} \mathrm{mi} \mathrm{DOC} \mathrm{catalyst.} \mathrm{The}$ model predictions as shown in the solid line qualitatively explained the inhibiting effect of $\mathrm{HC}$ on $\mathrm{NO}_{2}$ generation. 


\section{RESULTS AND DISCUSSION (CON'T)}

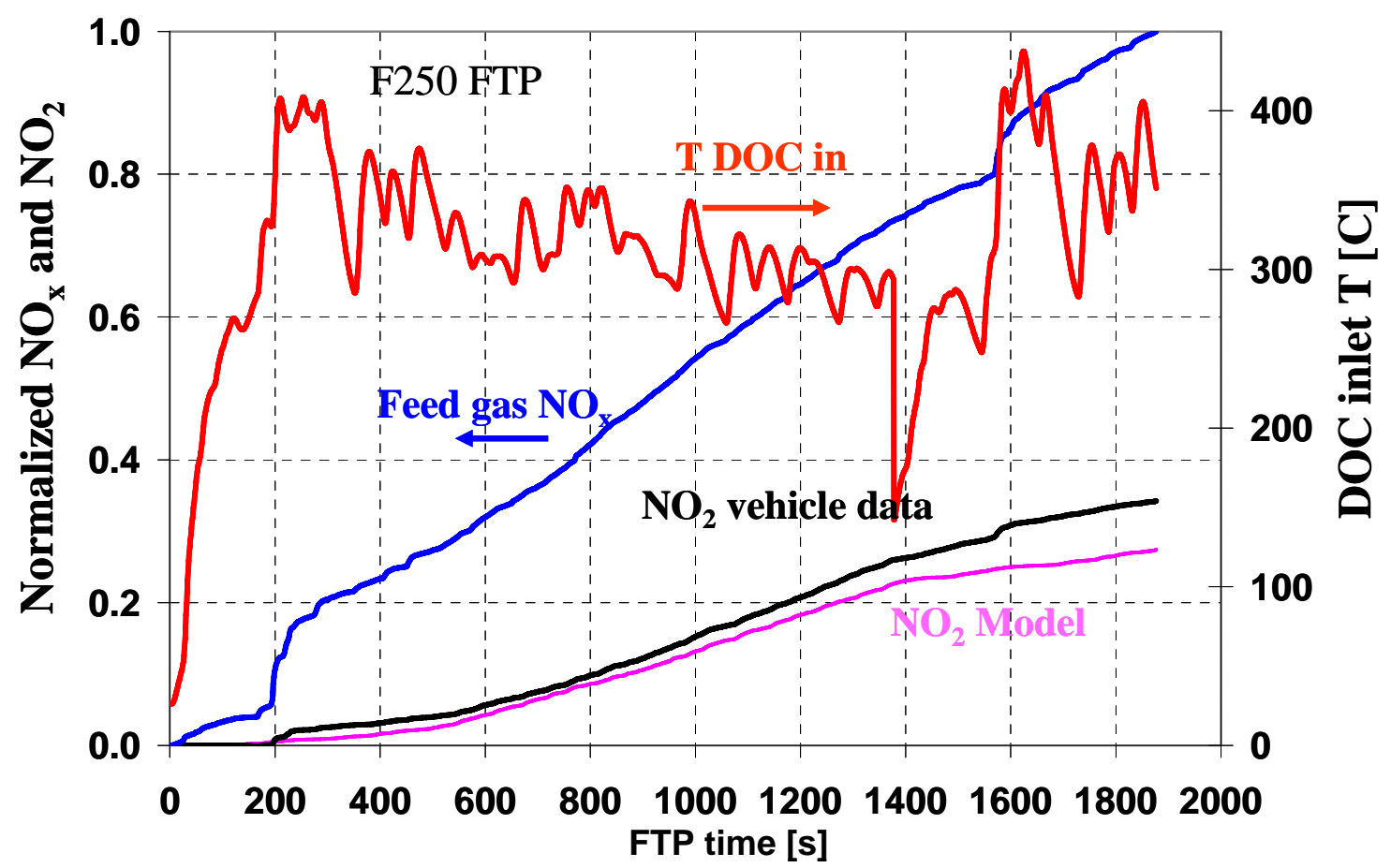

Figure 37. DOC model prediction and data showing DOC out $\mathrm{NO}_{2}$ over an FTP-75 test. The DOC out $\mathrm{NO}_{2}$ during the first $200 \mathrm{~s}$ is negligible.

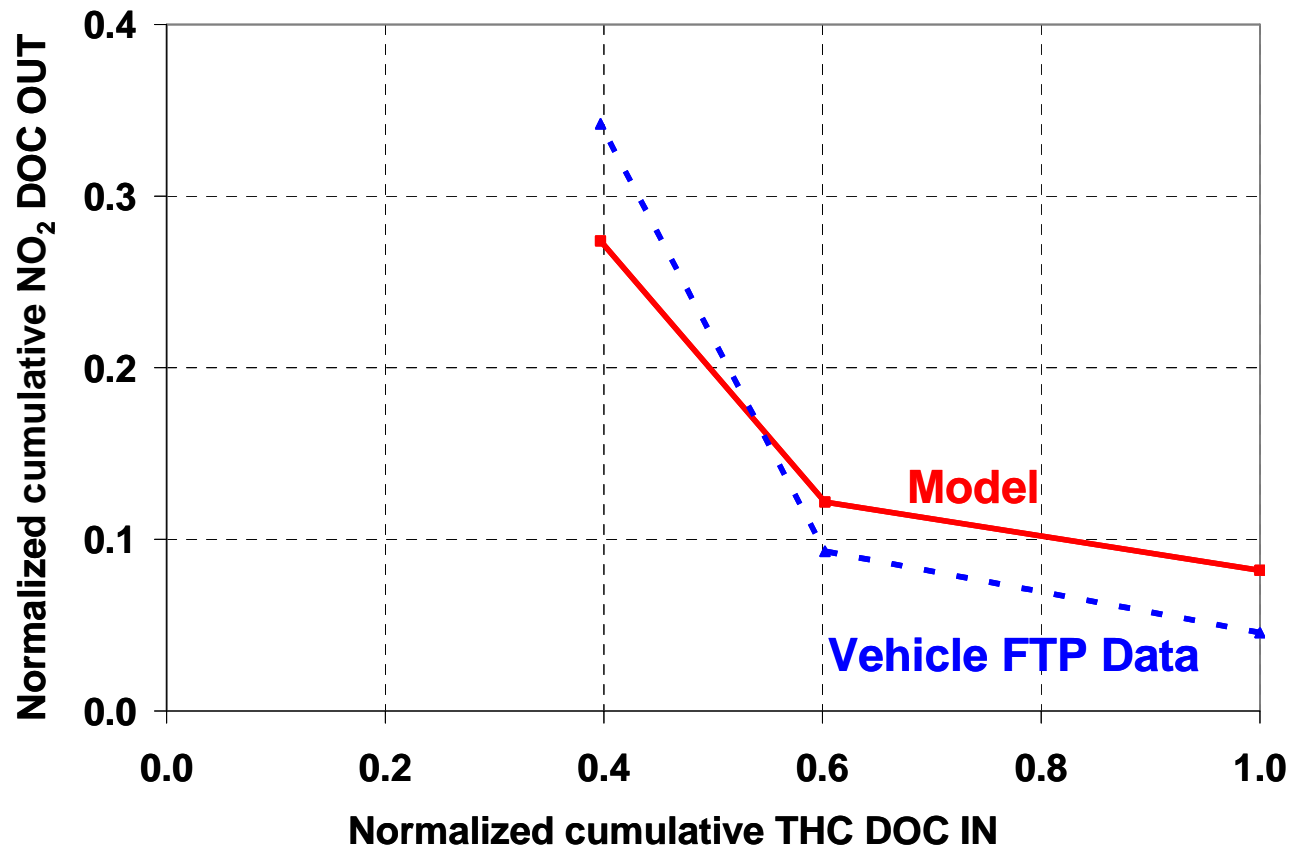

Figure 38. Inhibition effect of $\mathrm{HCs}$ on the $\mathrm{DOC}$ generation of $\mathrm{NO}_{2}$. 


\section{RESULTS AND DISCUSSION (CON'T)}

A DOC+SCR system model (Figure 39) was developed to predict NOx conversion. The SCR model was also based on the semi-empirical SIMTWC approach and assumed that (1) the catalyst was saturated with $\mathrm{NH}_{3}$ at every point during the FTP-75 test, (2) urea injected was completely converted to $\mathrm{NH}_{3}$, and that (3) flow and temperature distribution across the face of the SCR catalyst was uniform. A representative reaction map for $\mathrm{NOx}+\mathrm{NH}_{3}$ was used as shown in Figure 40. This data were obtained in a flow reactor by measuring the NOx conversion after saturating the catalyst with $\mathrm{NH}_{3}$ at any given temperature. SCR NOx conversion increased considerably due to the presence of $\mathrm{NO}_{2}$, especially at lower temperatures, as discussed previously.

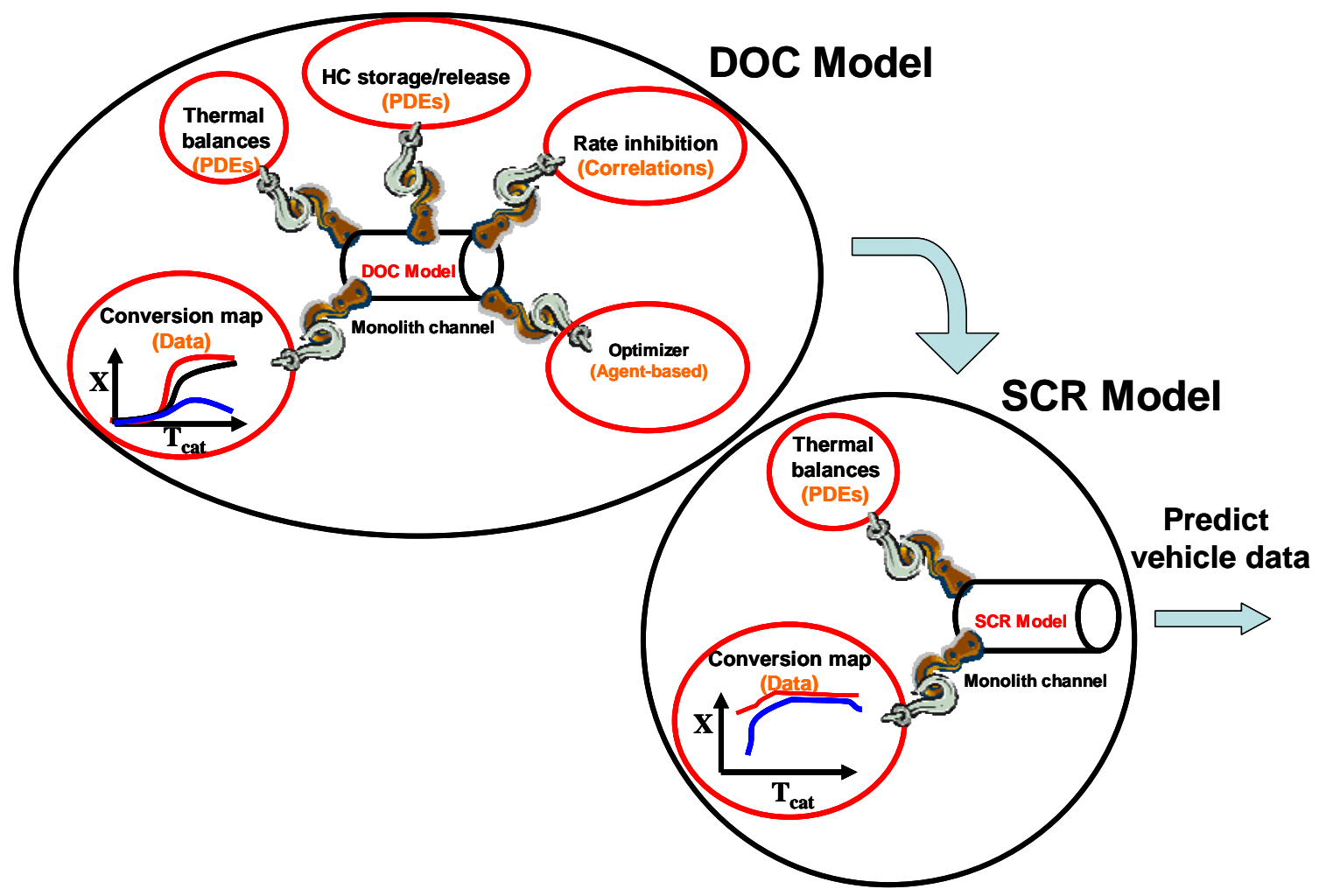

Figure 39. Semi-empirical model of the DOC+SCR system.

In order to show the importance of $\mathrm{NO}_{2}$ generated in the $\mathrm{DOC}$ for the NOx performance of the SCR, the DOC model was exercised to simulate (Figure 41) three cases of the DOC generating (1) only $\mathrm{NO}$ (worst case), (2) $\mathrm{NO}_{2}=\mathrm{NO}\left(50 \% \mathrm{NO}_{2} / \mathrm{NOx}\right.$, best case), and (3) an intermediate value of $\mathrm{NO}_{2}\left(20 \% \mathrm{NO}_{2} / \mathrm{NOx}\right)$. These three $\mathrm{NO}_{2}$ levels were used as the inputs to the SCR model to predict the dependence of $\mathrm{NO}_{x}$ conversion on the $\mathrm{NO}_{2}$ input. 


\section{RESULTS AND DISCUSSION (CON'T)}

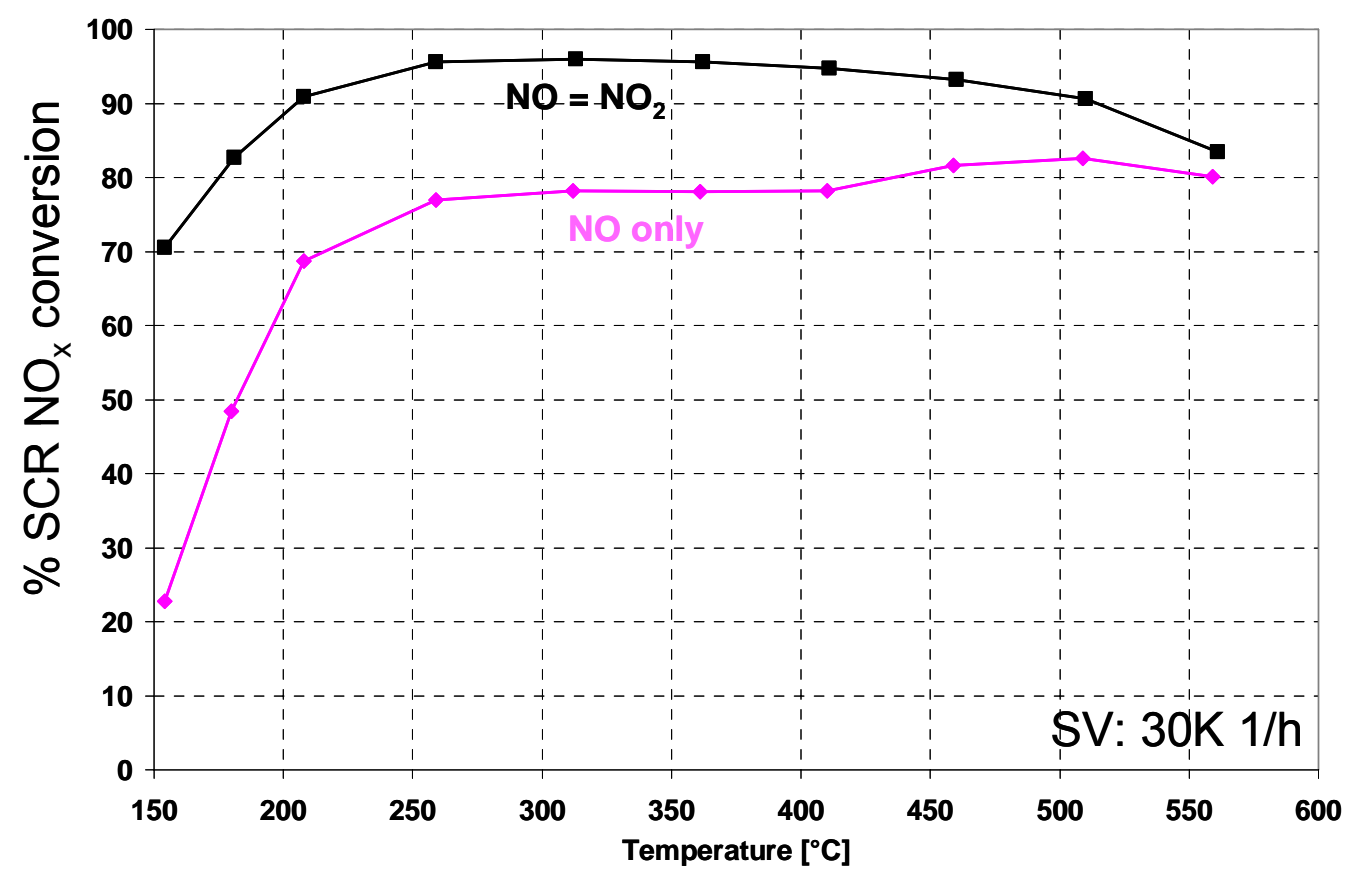

Figure 40. Representative SCR reaction map showing the effect of $\mathrm{NO}_{2}$ on SCR performance.

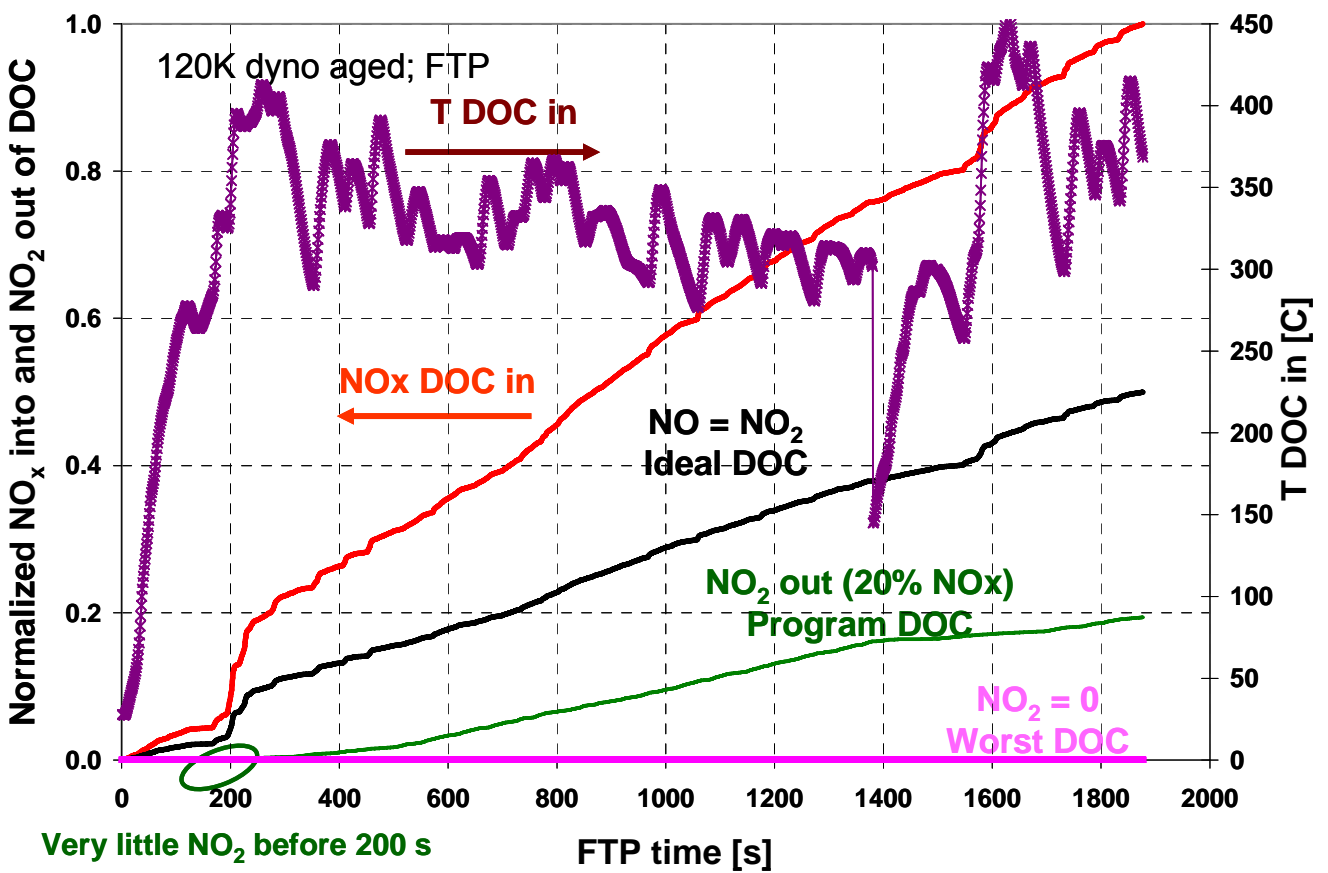

Figure 41. Amount of $\mathrm{NO}_{2}$ generated from three different DOC formulations - (1) no $\mathrm{NO}_{2},(2) 50 \%$ $\mathrm{NO}_{2} / \mathrm{NOx}$ and (3) $20 \% \mathrm{NO}_{2} / \mathrm{NOx}$ - to study the effect of $\mathrm{NO}_{2}$ on SCR performance. 


\section{RESULTS AND DISCUSSION (CON'T)}

Tailpipe NOx levels downstream of the SCR catalyst were predicted using the three different $\mathrm{NO}_{2}$ levels as input (Figure 42). The difference in the model prediction vs the experimental data especially after the cold start was probably related to the model assumption that the catalyst was saturated with $\mathrm{NH}_{3}$ at all times. This was probably not true as the adsorption and desorption of $\mathrm{NH}_{3}$ was governed by the amount of $\mathrm{NH}_{3}$ in the gas phase available for adsorption, catalyst temperature, and the level of $\mathrm{NH}_{3}$ already adsorbed on the surface of the catalyst. Nevertheless, the simple SCR model illustrated the effect of $\mathrm{NO}_{2}$ on improved operation of the SCR catalyst.

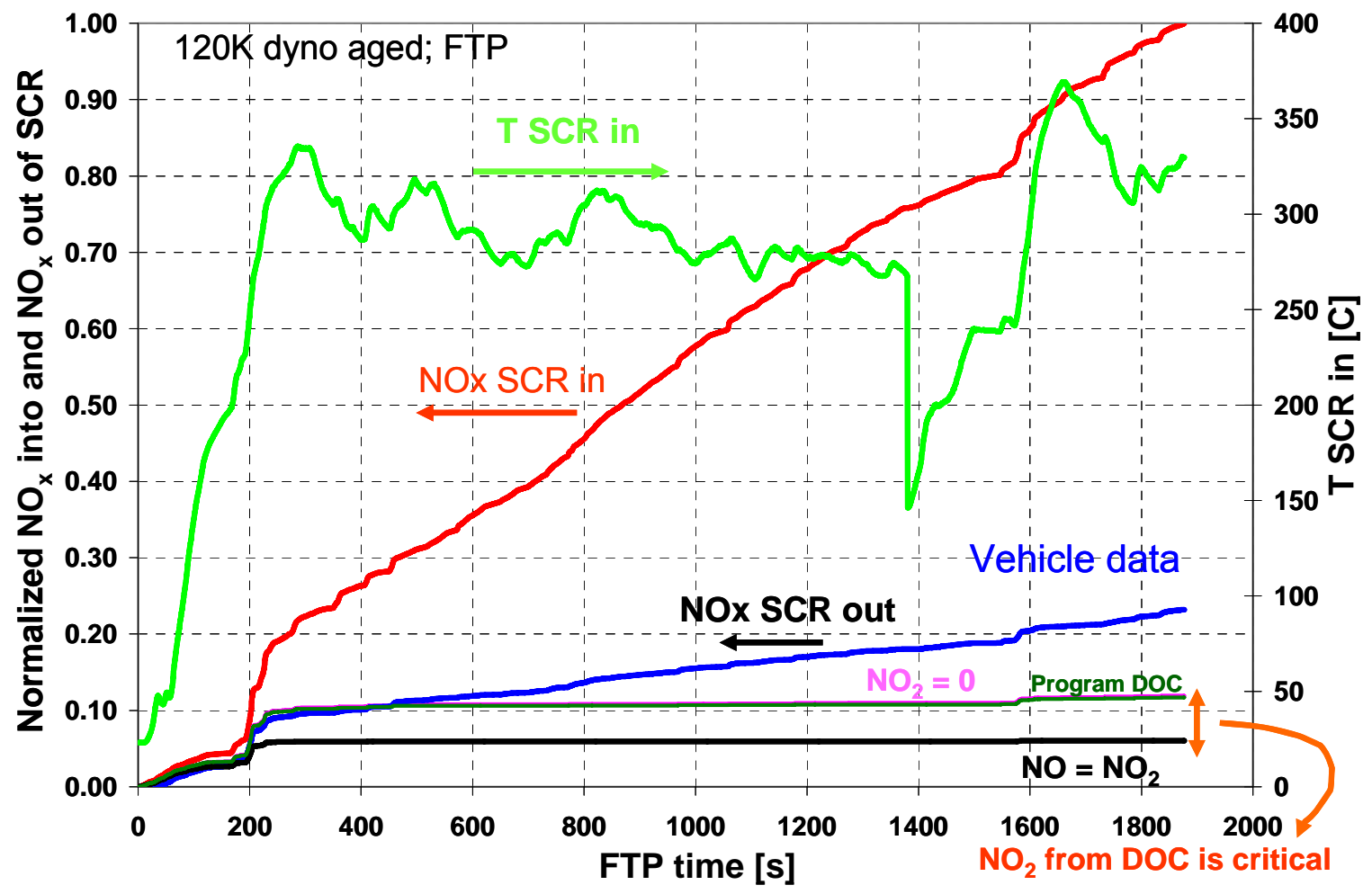

Figure 42. Model predictions over an FTP-75 test showing that SCR performance is better when a DOC that produces $50 \% \mathrm{NO}_{2} / \mathrm{NO}_{\mathrm{x}}$ is placed upstream of the SCR as compared to that the DOC that produces no $\mathrm{NO}_{2}$.

The DOC model was used to study the effect of formulation and volume on the amount of $\mathrm{NO}_{2}$ generated and the resulting SCR NOx conversion (Figure 43). As seen previously in Figure 42, the SCR NOx performance increased with the amount of $\mathrm{NO}_{2}$. The program DOC (AB) produced the most amount of $\mathrm{NO}_{2}$ among all the other formulations studied during this program. 


\section{RESULTS AND DISCUSSION (CON'T)}

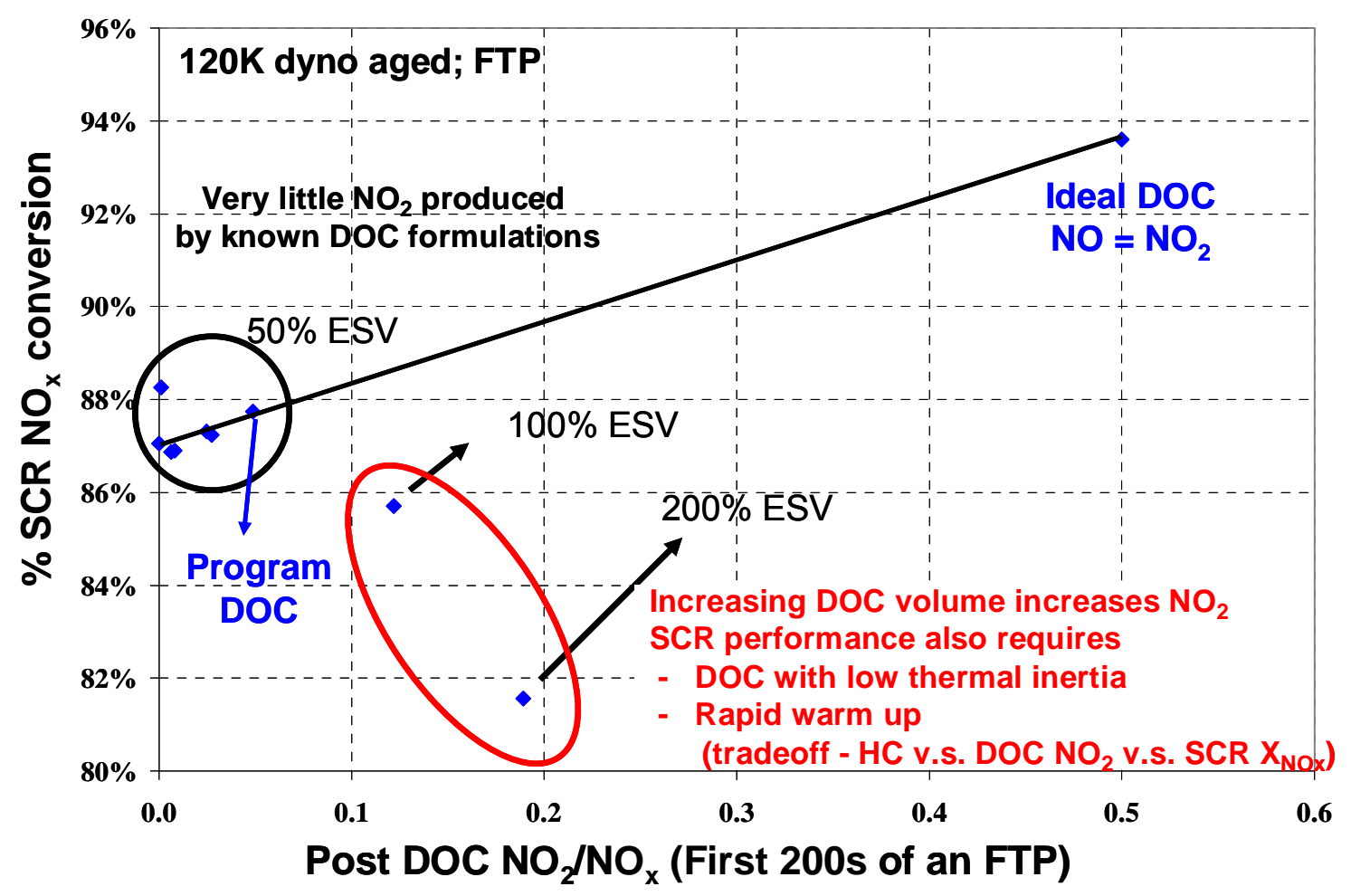

Figure 43. Trade-off between using a larger $\mathrm{DOC}$ to produce more $\mathrm{NO}_{2}$ and reduced SCR performance due to lower SCR input temperatures.

Increasing the DOC size from $50 \%$ to $100 \%$ and further to $200 \%$ ESV increased the amount of $\mathrm{NO}_{2}$ generated but at the same time reduced the NOx performance. This was because the extra thermal inertia associated with the increased DOC volume reduced the SCR input temperature and thus reduced its NOx performance. Thus increasing the DOC volume without managing its thermal inertia was found to be counterproductive.

In summary, a semi-empirical DOC model was developed based on the SIMTWC framework. The model was calibrated using the pulsator reactor data and was used to predict $\mathrm{NO}_{2}$ generated by the DOC. The model was able to explain the inhibition effect of $\mathrm{HCs}$ on $\mathrm{NO}_{2}$ production. The DOC model was used along with an SCR model to explain (1) the importance of $\mathrm{NO}_{2}$ generated in the DOC for the increased SCR performance, and (2) the trade-off between increasing the size of the catalyst to generate more $\mathrm{NO}_{2}$ and the reduction of SCR performance due to the reduced SCR input temperatures. 


\section{RESULTS AND DISCUSSION (CON'T)}

\section{CALIBRATION AND VEHICLE VALIDATION OF SCR MODEL}

A more detailed SCR model was developed that considered energy and mass balances with the description of $\mathrm{NH}_{3}$ algorithms, $\mathrm{NH}_{3}$ oxidation as well as several selective $\mathrm{NH}_{3}$ reactions with NOx.

The mass and energy balances for the bulk gas phase were:

$$
\begin{aligned}
& \frac{\partial T_{g}}{\partial t}=-u \frac{\partial T_{g}}{\partial x}-\frac{h_{i n} G S A_{i n}}{\varepsilon \rho_{g} C p_{g}}\left(T_{g}-T_{s}\right) \\
& \frac{\partial C_{g, N H 3}}{\partial t}=-u \frac{\partial C_{g, N H 3}}{\partial x}-\frac{G S A k_{m}}{\varepsilon_{w}}\left(C_{g, N H 3}-C_{s, N H 3}\right)
\end{aligned}
$$

The corresponding equations for the surface were:

$$
\begin{aligned}
& \frac{\partial T_{s}}{\partial t}=\frac{k_{\text {cond }}}{\rho_{s} C p_{s}} \frac{\partial^{2} T_{s}}{\partial x^{2}}+\frac{h_{\text {in }} G S A_{\text {in }}}{\left(1-\varepsilon_{w}\right) \rho_{s} C p_{s}}\left(T_{g}-T_{s}\right)-\frac{h_{\text {out }} G S A_{\text {out }}}{\left(1-\varepsilon_{w}\right) \rho_{s} C p_{s}}\left(T_{s}-T_{\text {amb }}\right)-\frac{W_{\text {loading }} G S A}{\left(1-\varepsilon_{w}\right) \rho_{s} C p_{s}} \sum\left(R_{j} \Delta H_{j}\right) \\
& \frac{\partial C_{s, i}}{\partial t}=\frac{G S A_{i n} k_{m}}{\left(\varepsilon-\varepsilon_{w}\right)}\left(C_{g, i}-C_{s, i}\right) \pm \frac{W_{\text {lodding }} G S A}{\left(\varepsilon-\varepsilon_{w}\right)} \sum \text { Rate }_{i, j}
\end{aligned}
$$

$\mathrm{NH}_{3}$ adsorption/desorption and consumption were expressed as follows,

$$
\begin{aligned}
& \frac{\partial C_{s, N H 3}}{\partial t}=\frac{G S A k_{m}}{\left(\varepsilon-\varepsilon_{w}\right)}\left(C_{g, N H 3}-C_{s, N H 3}\right)-\frac{1}{\left(\varepsilon-\varepsilon_{w}\right)}\left[\text { Rate }_{a d} C_{s, N H 3}\left(1-\theta_{N H 3}\right)-\text { Rate }_{\text {des }} \theta_{N H 3}\right] \\
& \Omega_{N H_{3}} \frac{\partial \theta_{\mathrm{NH} 3}}{\partial t}=\left[\text { Rate }_{a d} C_{s, \mathrm{NH} 3}\left(1-\theta_{\mathrm{NH} 3}\right)-\text { Rate }_{\text {des }} \theta_{\mathrm{NH} 3}\right]-\frac{W_{\text {loading }} G S A}{\left(\varepsilon-\varepsilon_{w}\right)} \sum \text { Rate }_{i}\left(C_{s, \mathrm{NH} 3}, C_{s, i} T_{s}\right)
\end{aligned}
$$

Where, $\quad$ Rate $_{a d}=k_{a d} \exp \left(-\frac{E_{a d s}}{R T_{s}}\right)$, and $\quad$ Rate $_{\text {des }}=k_{\text {des }} \exp \left(-\frac{E_{\text {des }}}{R T_{s}}\left(1-\beta \theta_{\mathrm{NH} 3}\right)\right)$

The following reaction pathways were selected for the model:

$$
\begin{aligned}
& 4 \mathrm{NH}_{3}+4 \mathrm{NO}+\mathrm{O}_{2} \rightarrow 4 \mathrm{~N}_{2}+6 \mathrm{H}_{2} \mathrm{O} \\
& 4 \mathrm{NH}_{3}+2 \mathrm{NO}+2 \mathrm{NO}_{2} \rightarrow 4 \mathrm{~N}_{2}+6 \mathrm{H}_{2} \mathrm{O} \\
& 4 \mathrm{NH}_{3}+3 \mathrm{O}_{2} \rightarrow 2 \mathrm{~N}_{2}+6 \mathrm{H}_{2} \mathrm{O} \\
& 4 \mathrm{NH}_{3}+4 \mathrm{O}_{2} \rightarrow 2 \mathrm{~N}_{2} \mathrm{O}+6 \mathrm{H}_{2} \mathrm{O}
\end{aligned}
$$




\section{RESULTS AND DISCUSSION (CON'T)}

$$
\begin{aligned}
& 2 \mathrm{NH}_{3}+2 \mathrm{NO}_{2} \rightarrow \mathrm{N}_{2} \mathrm{O}+\mathrm{N}_{2}+3 \mathrm{H}_{2} \mathrm{O} \\
& 4 \mathrm{NH}_{3}+4 \mathrm{NO}_{2}+3 \mathrm{O}_{2} \rightarrow 4 \mathrm{~N}_{2} \mathrm{O}+6 \mathrm{H}_{2} \mathrm{O} \\
& 2 \mathrm{NO}+\mathrm{O}_{2} \leftrightarrow 2 \mathrm{NO}_{2}
\end{aligned}
$$

The model considered $\mathrm{NH}_{3}$ and NOx reactions $(7-$ standard SCR) and ( 8 - fast SCR) as well as $\mathrm{NH}_{3}$ oxidation (9) and $\mathrm{N}_{2} \mathrm{O}$ generation (10) - (12). Oxidation of $\mathrm{NO}$ was also considered (13). Reactions (7) - (13) were expressed as the following general form:

$$
\text { Rate }_{j}=k_{j} \exp \left(-E_{j} / R T_{s}\right) C_{a} C_{b} C_{c}
$$

where $j$ represented the $j^{\text {th }}$ species. Adopting a standard Eley-Rideal rate mechanism, constants $a, b$ and $c$ were determined based on reactions (7) - (13). Assuming that reaction (7) occurred between adsorbed ammonia and NO, the rate equation (7) became:

$$
\text { Rate }_{j}=k_{j} \exp \left(-E_{j} / R T_{s}\right) C_{s, N O} C_{s, N H 3} C_{s, O 2}
$$

where $K$ and $E$ values were obtained from the model calibration based on the laboratory data.

The values of heat and mass transfer coefficients in Equation (1) through (5) were obtained from Nusselt and Sherwood numbers, which were correlated with Reynolds, Prandtl and Schmidt numbers.

Equations (1) - (6) were solved simultaneously by discretization of the spatial and time derivatives. The system of partial differential equations were converted to a set of coupled ordinary differential equations, using mixed with first order accurate backwards difference and second order accurate central difference schemes for the spatial derivatives. The Euler backward scheme was applied to discretize the time derivative, which was absolutely stable for relatively large time steps. The resulting set of coupled ordinary differential equations was solved by the double precision version of the ordinary differential equation solver DDASSL.

A sample of improved SCR catalyst B described previously was used to calibrate the model for the characteristics of $\mathrm{NH}_{3}$ adsorption and desorption onto the base metal. Equations (1) - (6) were solved simultaneously without considering any reactions between $\mathrm{NH}_{3}$ and $\mathrm{NOx}, \mathrm{NH}_{3}$ oxidation or $\mathrm{NO}$ oxidation reactions, to estimate six kinetic parameters, including the total $\mathrm{NH}_{3}$ adsorption capacity, $\Omega_{\mathrm{NH} 3}$, over the specific SCR sample. The laboratory measured data from the $\mathrm{NH}_{3}$ adsorption and desorption with TPD (Temperature Programmed Desorption) were used to determine the kinetic parameters. 


\section{RESULTS AND DISCUSSION (CON'T)}

The model was calibrated for $\mathrm{NH}_{3}$ adsorption and desorption characteristics of degreened and oven aged (simulating $120 \mathrm{k} \mathrm{mi}$ ) catalyst $\mathrm{B}$ as shown in Figure 44. Upon addition of $\mathrm{NH}_{3}$ at time $=0 \mathrm{sec}$, the $\mathrm{NH}_{3}$ outlet concentration slowly increased with time, approaching the $\mathrm{NH}_{3}$ inlet concentration (typically $350 \mathrm{ppm}$ ). A similar behavior was shown at $\mathrm{NH}_{3}$ shutoff ( $\mathrm{t} \approx 1200$ seconds): the outlet $\mathrm{NH}_{3}$ concentration slowly decreased with time due to desorption of previously adsorbed $\mathrm{NH}_{3}$. Complete desorption of $\mathrm{NH}_{3}$ was achieved with subsequent heating of the catalyst sample (TPD). Very good agreement between model predictions and measured laboratory data were found for both degreened and aged samples. This implied that the rate expression for the non-activated adsorption, $E_{\text {ads_ } 0}=0$, and a linear decrease of the activation energy for desorption with the $\mathrm{NH}_{3}$ surface coverage in Equation (5) and (6) were sufficient conditions to describe the characteristics of the $\mathrm{NH}_{3}$ adsorption and desorption processes.

The successful estimates of the kinetic parameters led to the predicted results shown in Figure 44 and allowed the model to proceed to the next level. The model was updated with reactions (7) - (13), which included another 14 kinetic parameters to calibrate. The model calibration was performed, based on the measured data from the series of NOx performance tests.

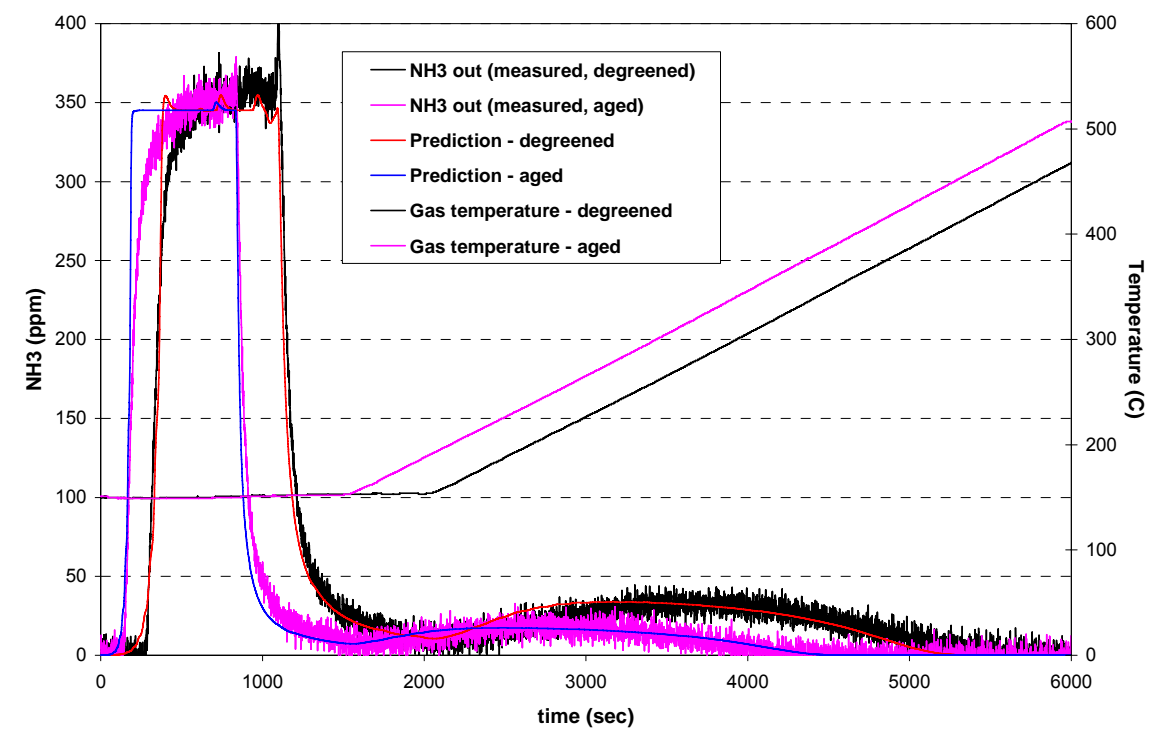

Figure 44. Comparison of the predicted and measured data for $\mathrm{NH}_{3}$ adsorption/desorption at a beginning temperature of $150^{\circ} \mathrm{C}$ (Sample B).

Model calibration results were compared to the measured data from various test conditions. Each result represented the model calibration for specific reaction kinetics. 


\section{RESULTS AND DISCUSSION (CON'T)}

The $\mathrm{NH}_{3}$ oxidation rate was estimated as a function of SCR inlet temperature (Figure 45). Complete oxidation of $\mathrm{NH}_{3}$ was observed above $500^{\circ} \mathrm{C}$. Kinetic parameters for standard SCR, expressed in reaction (7) and fast SCR as in reaction (8) were obtained from the measured data shown in Figure 46 and Figure 47, respectively. The effect of oxygen level on NOx performance of SCR sample B was also studied (Figure 48). Based on the measured NOx performance changes with various amount of oxygen, the following formula was obtained and implemented into the model:

$$
\text { Effect of } \mathrm{O}_{2} \approx\left(\frac{\left[\mathrm{O}_{2}\right]}{\left[2 \% \mathrm{O}_{2}\right]}\right)^{0.6}
$$

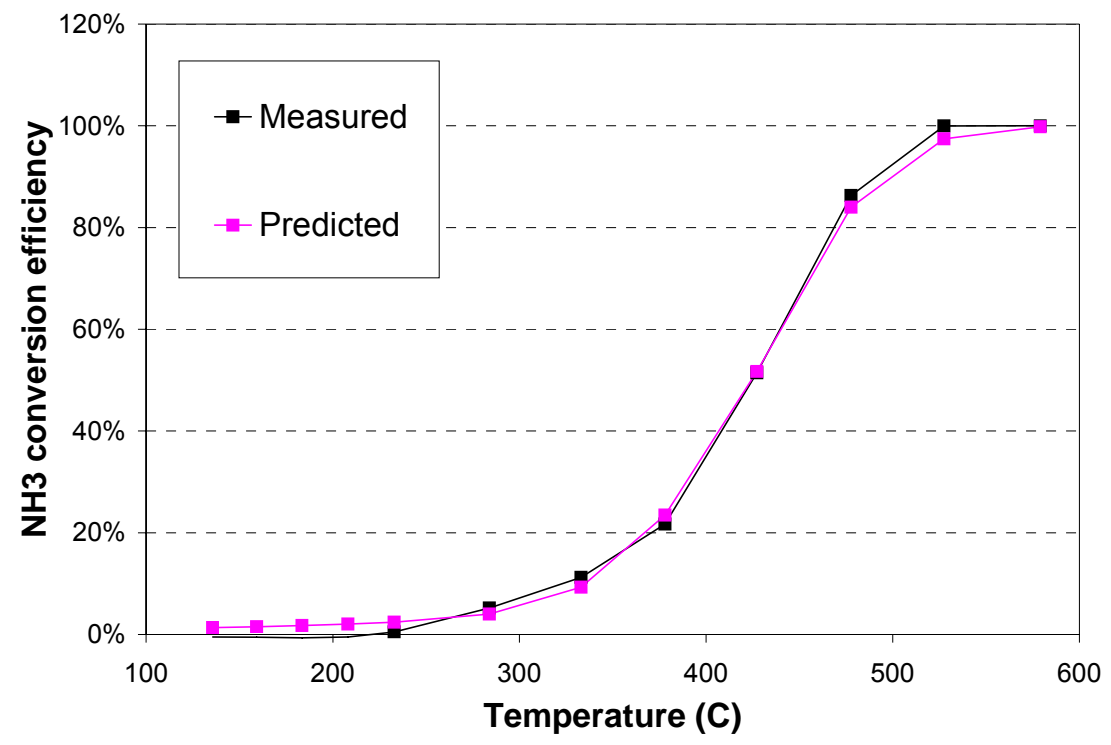

Figure 45. Comparison of the measured data for $\mathrm{NH}_{3}$ oxidation $\left(\mathrm{NH}_{3}=350 \mathrm{ppm}\right.$, space velocity $=$ $30 \mathrm{k} \mathrm{h}^{-1}, \mathrm{O}_{2}=14 \%$ ). 


\section{RESULTS AND DISCUSSION (CON'T)}

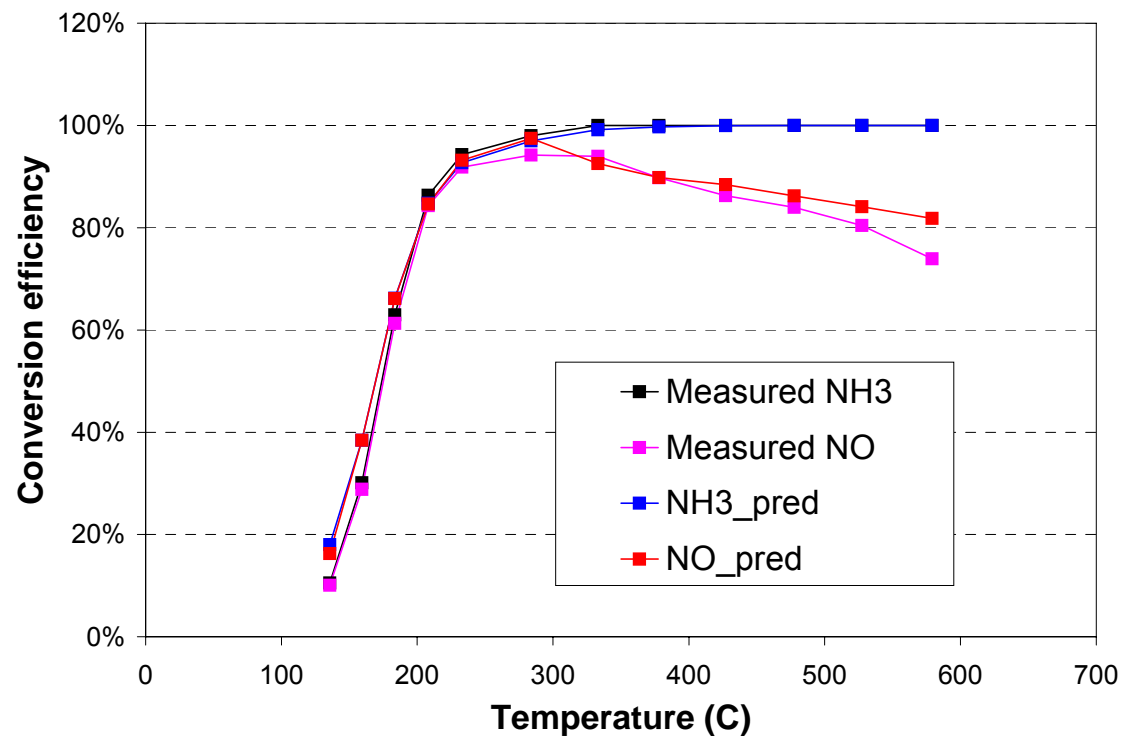

Figure 46. Comparison of the measured data $\left(\mathrm{NH}_{3}=350 \mathrm{ppm}\right.$ and $\mathrm{NO}=350 \mathrm{ppm}$, space velocity $=$ $\left.30 \mathrm{~K} \mathrm{~h}^{-1}, \mathrm{O}_{2}=14 \%\right)$.

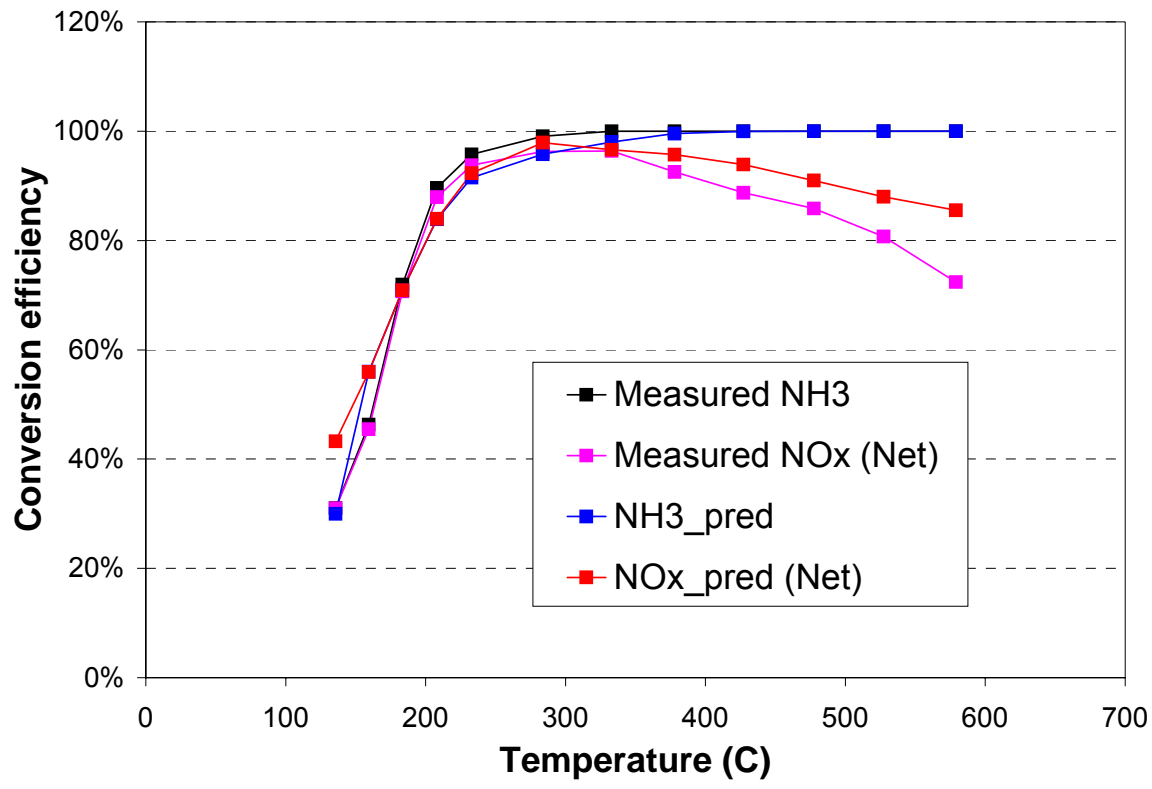

Figure 47. Comparison of the measured data $\left(\mathrm{NH}_{3}=350 \mathrm{ppm}, \mathrm{NO}=280 \mathrm{ppm}\right.$ and $\mathrm{NO}_{2}=70 \mathrm{ppm}$, space velocity $=30 \mathrm{k} \mathrm{h}^{-1}, \mathrm{O}_{2}=14 \%$ ). 


\section{RESULTS AND DISCUSSION (CON'T)}

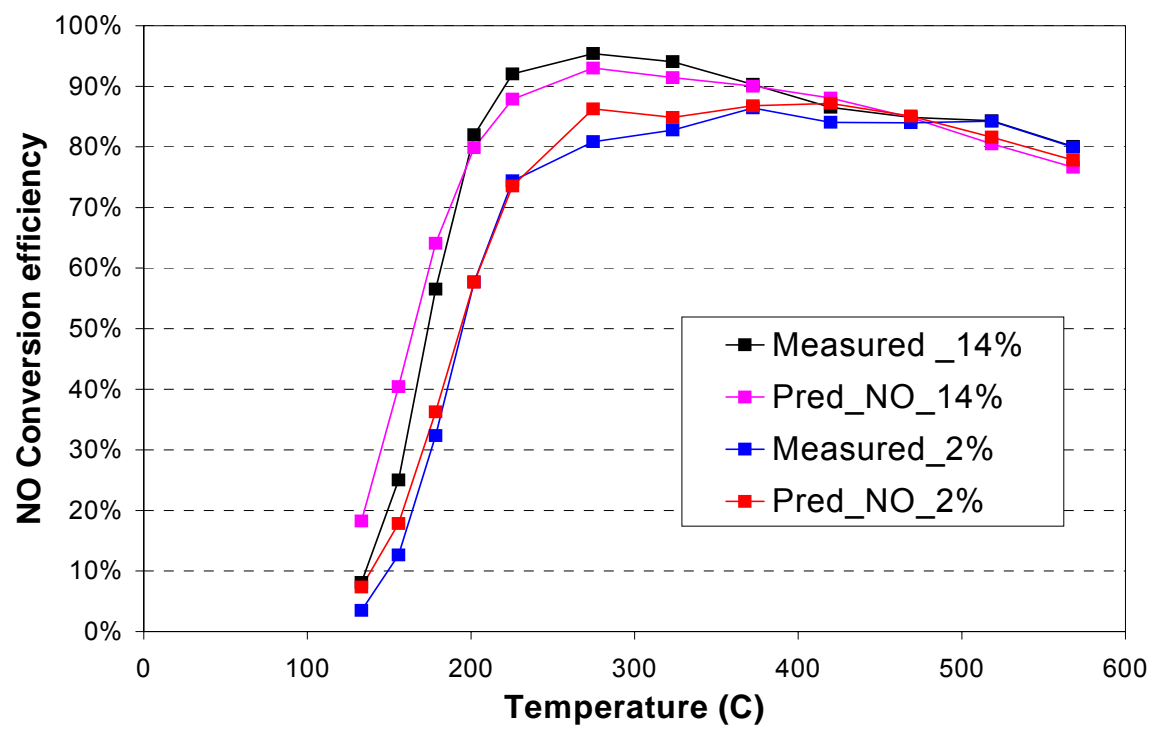

Figure 48. Comparison of the measured data $\left(\mathrm{NH}_{3}=350 \mathrm{ppm}\right.$ and $\mathrm{NO}=350 \mathrm{ppm}$, space velocity $=$ $30 \mathrm{k} \mathrm{h}^{-1}$ ).

After the kinetic parameters were calibrated, validation of the model was performed using vehicle data obtained from the previously described system with $120 \mathrm{k} \mathrm{mi}$. Exhaust gas temperatures and composition measured before the SCR catalyst during FTP-75 testing were used to generate model predictions. In the next four figures, the model results are compared to gas temperature, $\mathrm{NOx}, \mathrm{NH}_{3}$ slip and the amount of $\mathrm{N}_{2} \mathrm{O}$ measured after the SCR. Exhaust composition results are shown at various levels of urea efficiency, which is defined as:

\section{Urea efficiency $=$ (efficiency of urea conversion to $\left.\mathrm{NH}_{3}\right) \times$ (mixing efficiency).}

Comparison of the model results and the measured results in Figure 50 suggests that the urea efficiency was approximately $80 \%$ in the vehicle exhaust. Note that in Figure 51 the predicted $\mathrm{NH}_{3}$ slip occurs $60 \sim 70$ seconds later than the measured slip. This implies that there was $\mathrm{NH}_{3}$ pre-adsorbed on the SCR before the test. The measured $\mathrm{N}_{2} \mathrm{O}$ generation in Figure 52 started at the beginning of test cycle, while the predicted $\mathrm{N}_{2} \mathrm{O}$ generation started at about 190 seconds. Since the source of $\mathrm{N}_{2} \mathrm{O}$ generation is mainly $\mathrm{NH}_{3}$, this serves as further confirmation of the pre-adsorbed $\mathrm{NH}_{3}$ before the test. 


\section{RESULTS AND DISCUSSION (CON'T)}

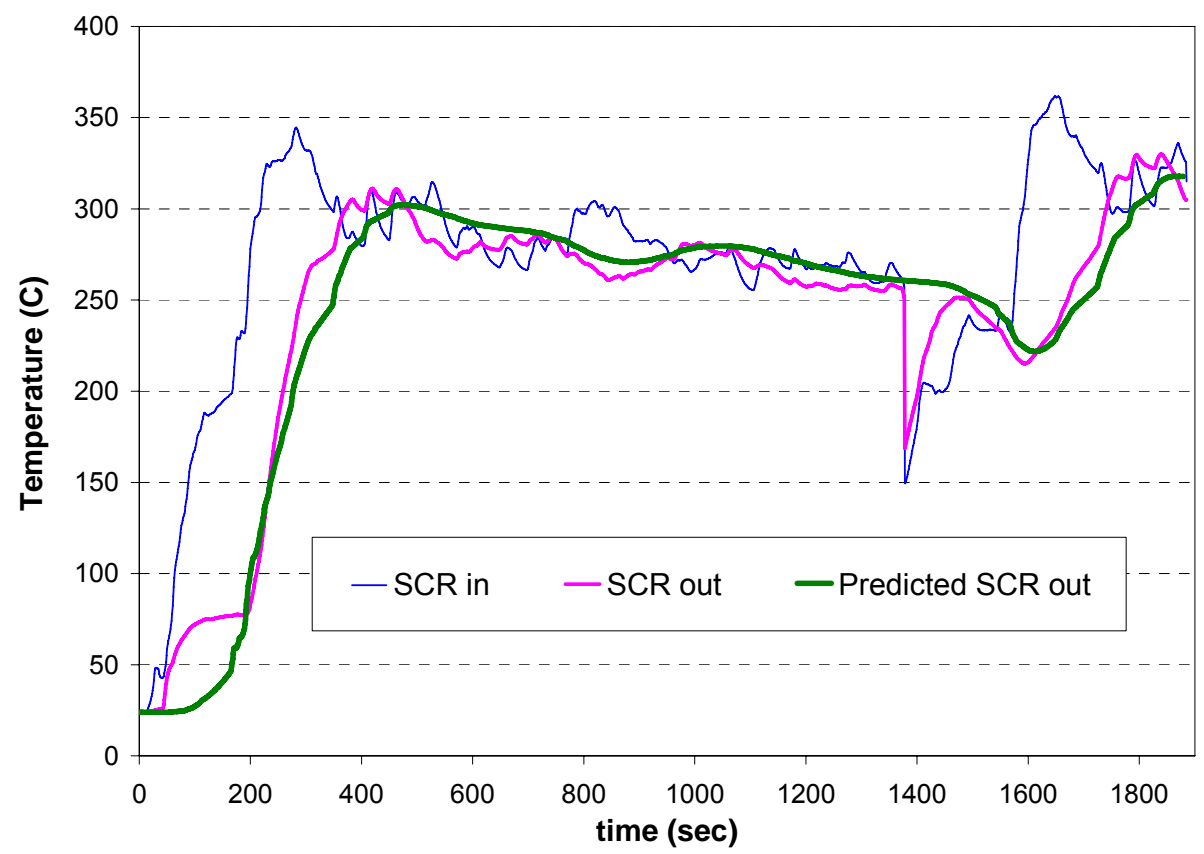

Figure 49. SCR outlet gas temperature prediction during the FTP-75.

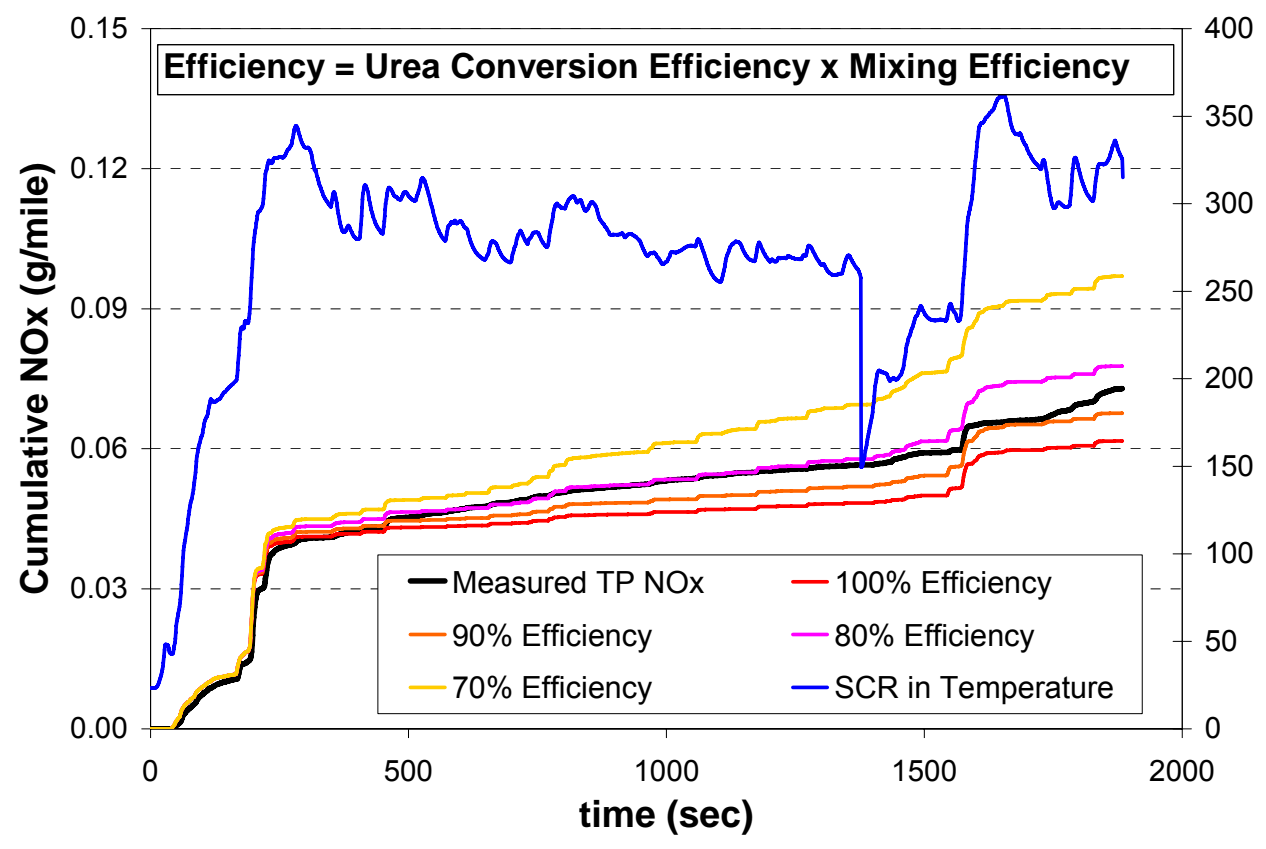

Figure 50. Cumulative NOx comparison of the model prediction with measured data during the FTP-75. 


\section{RESULTS AND DISCUSSION (CON'T)}

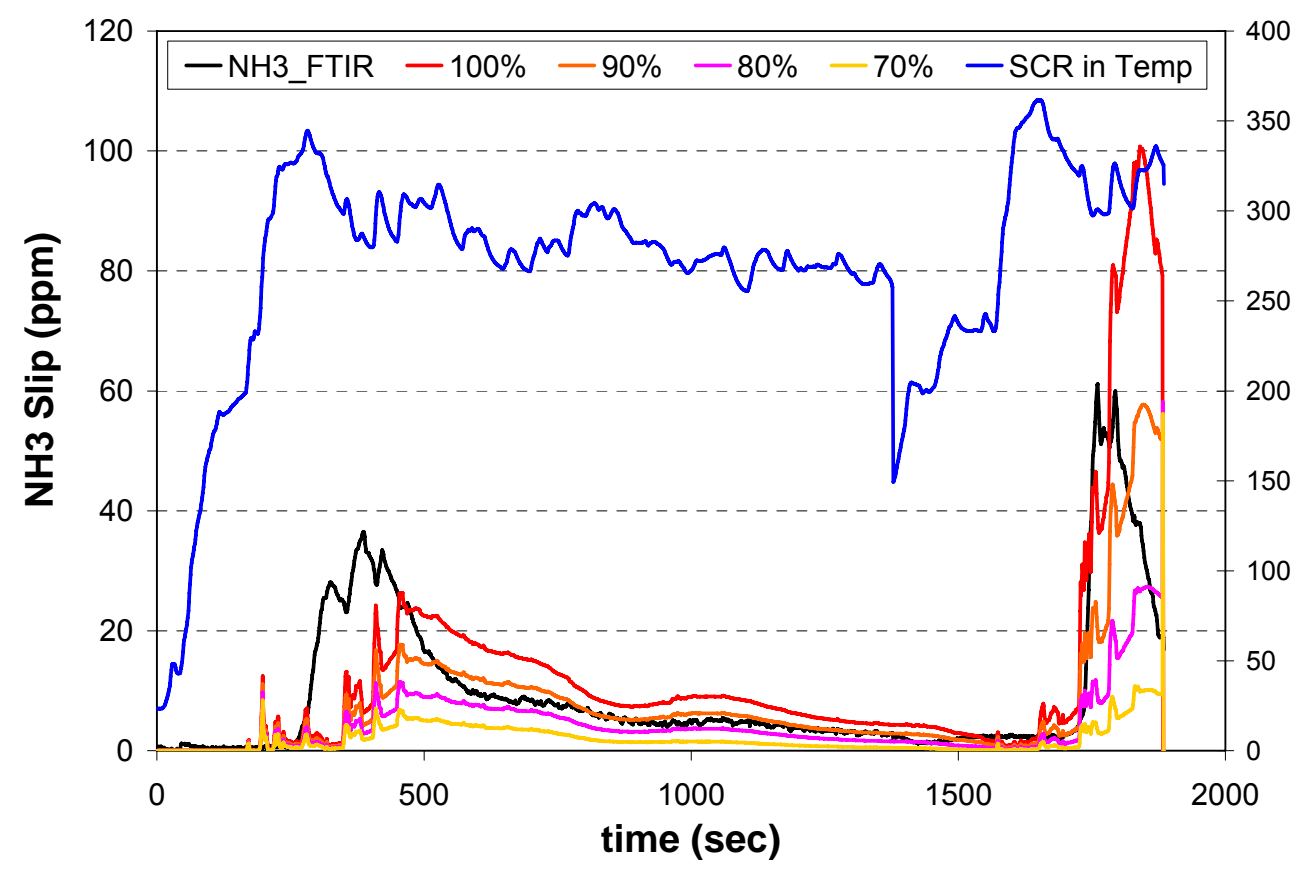

Figure 51. Comparison of $\mathrm{NH}_{3}$ slip prediction with measured data during the FTP-75.

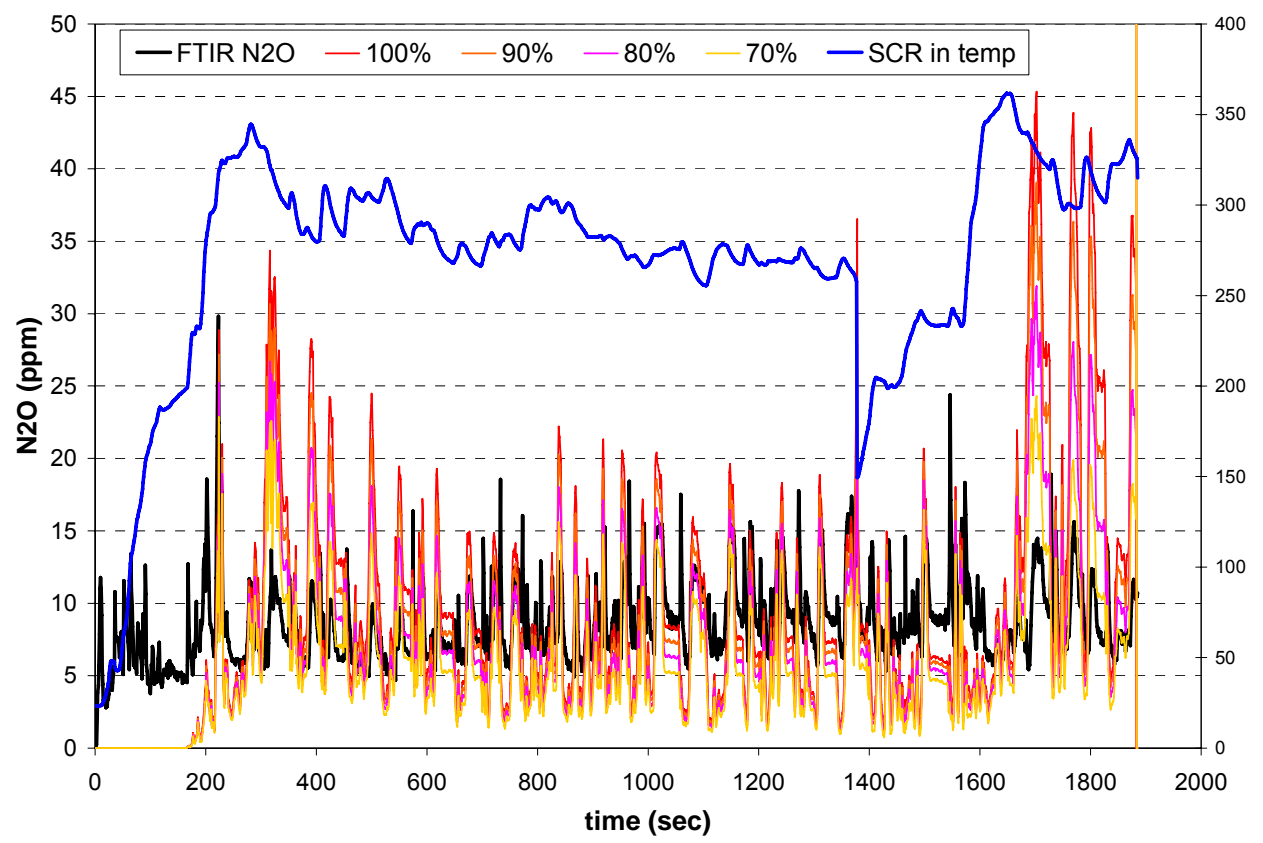

Figure 52. Comparison of $\mathrm{N}_{2} \mathrm{O}$ prediction vs measured data during the FTP-75. 


\section{RESULTS AND DISCUSSION (CON'T)}

Overall the model prediction results agreed well with the measured data. The successful development of the SCR model will guide the study of several key design factors for SCR systems and aid in the development of urea control strategy for maximum NOx reduction with minimum $\mathrm{NH}_{3}$ slip.

\section{UREA INFRASTRUCTURE STUDY}

Urea solutions were evaluated for the optimum mixture, a prototype dispenser was developed for diesel fuel and aqueous urea, and the business case for an aqueous urea infrastructure for LD vehicles in the US was studied. Major dispenser and nozzle manufacturers provided assistance with the urea co-fueling equipment. A $32.5 \mathrm{wt} \%$ blend of urea and water was used as this has the lowest freezing point $\left(12^{\circ} \mathrm{F}\right)$ of any aqueous urea solution. Potential freeze point depressants were investigated at ExxonMobil and prime candidates were tested at Ford. Any organic additive had significant negative impact on $\mathrm{NO}_{x}$ conversion over the base metal/zeolite SCR catalyst [12]; therefore, heaters were suggested for colder climates.

Making the use of urea completely transparent to the customer would facilitate introduction. A way to do this is through the use of a concentric nozzle that "co-fuels" urea and diesel fuel simultaneously [13]. A prototype dispenser was fabricated using a modern diesel dispenser and off-the-shelf parts as shown in Figure 53. A major nozzle manufacturer developed and supplied the coaxial, co-fueling nozzle. A meter and display were added to the dispenser to show the amount of urea delivered. Aqueous urea was stored in a stainless steel tank mounted on the side of the dispenser. The dispenser functioned properly at ambient temperatures down to minus $20^{\circ} \mathrm{F}$. Heaters kept the urea solution temperature between 35 and $50^{\circ} \mathrm{F}$. Urea and fuel were delivered simultaneously to either a Ford F350 truck fitted with the appropriate filler neck and onboard tanks or a fueling cart fitted with similar equipment. Prolonged testing indicated a small, intermittent leak of urea $(0.5 \mathrm{vol} \%)$ into the fuel within the nozzle/insert seal. A second, improved version of the nozzle was tested and found to have a reduced leak rate of less than $0.1 \mathrm{vol} \%$. Cross contamination of urea into diesel remained a concern for the co-axial design due to urea line connection within the diesel re-fueling stream. 


\section{RESULTS AND DISCUSSION (CON'T)}

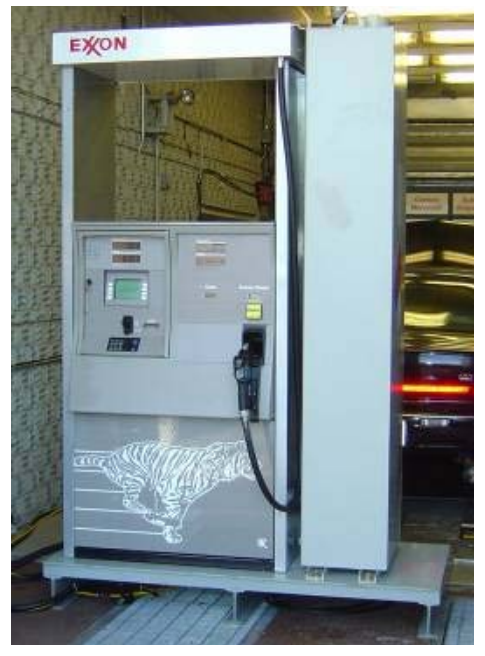

Figure 53. Prototype co-fueling dispenser.

An economics study was conducted to understand the costs associated with providing aqueous urea to LD diesel vehicle customers. The economics model followed similar logic to two previous, similar studies on urea usage [14-15]. Model inputs were derived from existing data when possible. The number of service stations used in the model matched the current number of about 167,571 stations in the US, with approximately $1 / 3$ selling diesel fuel. Trends in LD diesel vehicle population growth and fuel consumption were derived from DOE's Energy Information Administration 2003 Annual Energy Outlook [16], and vehicle distribution and mileage accumulation by age came from EPA's MOBILE6 model [17]. It was assumed that a solution of $32.5 \mathrm{wt} \%$ urea in deionized water would have a wide usage among HD diesel vehicles with an established pathway from the manufacturing plant to distribution facilities. The capital payout period for the investment in co-fueling dispensers was assumed to be three years, at a $15 \%$ rate of return. The urea consumption was assumed to be $2 \%$ of the diesel fuel consumption on average. Results did not include profit markup or taxes, and all estimates were in constant dollars.

\section{Estimated Urea Cost at the Service Station}

The cost of aqueous urea to the customer at the service station was calculated by the following equation:

Estimated Urea Cost at the Service Station $\mathbf{( \$ / g a l )}=($ Manufacture + Distribution Cost) + Storage Cost + Delivery Cost + Service Station Costs

These costs, except for service station costs, are quantified in Table 7. 


\section{RESULTS AND DISCUSSION (CON'T)}

Table 7: Urea cost estimates for manufacture, distribution, storage and delivery.

\begin{tabular}{|l|l|}
\hline Item & $\begin{array}{l}\text { Est. Cost } \\
\mathbf{( \$ / g a l )}\end{array}$ \\
\hline Manufacture + Distribution & 0.60 \\
\hline Bulk Urea Storage & 0.14 \\
\hline Bulk Urea Delivery & 0.46 \\
\hline Total (without Service Station Costs) & 1.20 \\
\hline
\end{tabular}

Service station costs included the capital investment and operating expenses divided by the urea volume throughput for that station:

Service Station Cost $=($ Annualized Capital Cost + Annual Operating Expense $) /$ Annual Urea Volume Throughput per Station

The urea volume throughput was a function of the total urea demand divided by the number of stations with urea. The total urea demand depended on diesel consumption and urea-to-diesel ratio. Diesel consumption was based on the total number of Urea SCR vehicles, their fuel economy and annual mileage accumulation. The number of Urea SCR vehicles depended on Urea SCR vehicle sales and scrap rates.

The capital cost of a single co-fueling dispenser was estimated to be $\$ 26,500$ as shown in Table 8, and the annual operating expenses were $\$ 1,777 / \mathrm{yr}$ as shown in Table 9.

Table 8: Estimated capital cost of a single co-fueling dispenser with complete heating.

\begin{tabular}{|l|l|}
\hline Item & $\begin{array}{l}\text { Est. Cost } \\
\mathbf{( \$ )}\end{array}$ \\
\hline Dispenser & 6,000 \\
\hline Urea pumping system with heaters & 4,500 \\
\hline Urea tank (140 gallon) with heaters & 3,500 \\
\hline Hoses, nozzles, electronic level/signal & 3,000 \\
\hline Freight \& taxes (8\%), utilities upgrade & 3,500 \\
\hline Installation and startup & 3,500 \\
\hline Administrative costs (permitting, $\sim 10 \%)$ & 2,500 \\
\hline Total & $\mathbf{2 6 , 5 0 0}$ \\
\hline
\end{tabular}




\section{RESULTS AND DISCUSSION (CON'T)}

Table 9: Estimated annual operating cost of single co-fueling dispenser.

\begin{tabular}{|l|l|}
\hline Item & Est. Cost (\$/yr) \\
\hline Maintenance & 1,100 \\
\hline Property taxes (2\% of capital) & 220 \\
\hline Utilities & 457 \\
\hline Total & $\mathbf{1 , 7 7 7}$ \\
\hline
\end{tabular}

$\underline{\text { Urea Infrastructure Economics - Study Findings }}$

Scenario 1: Introduction of Co-fueled Urea in 2007: If co-fueling is introduced beginning in 2007, when more stringent Tier 2 and LEVII standards are phased-in, the estimated cost of urea is approximately $\$ 42 /$ gal. This high cost results from the assumption that all current service stations that sell diesel fuel to light-duty vehicles would install one new co-fueling dispenser and expect a three year payout on the capital investment in the dispenser, at a time when the number of light-duty diesel vehicles needing urea is expected to be very low $(608,000)$. The total capital investment is estimated at $\$ 1.47$ billion. After the capital recovery period, or in 2010, the urea cost would drop to approximately $\$ 3.76 /$ gal and steadily continue to decrease as urea SCR vehicle volume increases. The long-term cost is estimated to be $\$ 2 /$ gal in this scenario.

Scenario 2: Introduction of Bottled Urea in 2007 and Co-fueled Urea in 2010: The use of bottled urea will reduce costs during the introduction of urea SCR vehicles in 2007 . The cost of bottled aqueous urea as delivered to the service station is estimated at $\$ 3.66$ per gallon.

Table 10: Estimated costs for bottled urea to the retail location.

\begin{tabular}{|l|l|}
\hline Item & $\begin{array}{l}\text { Est. Cost } \\
\mathbf{( \$ / g a l )}\end{array}$ \\
\hline Manufacture + Distribution & 0.60 \\
\hline Bottling & 2.11 \\
\hline Delivery & 0.95 \\
\hline Total & $\mathbf{3 . 6 6}$ \\
\hline
\end{tabular}

If co-fueling is introduced beginning in 2010, when the Tier 2 light-duty diesel vehicle volume is projected to grow to 2.6 million, the cost of co-fueled urea during the capital payout period is estimated to be $\$ 18 /$ gal. After the capital recovery period (2013), the cost would drop to approximately $\$ 2.75 /$ gal, with a long-term cost stabilizing at $\$ 2 /$ gal. 


\section{RESULTS AND DISCUSSION (CON'T)}

The LD diesel population needed to make co-fueled urea cost competitive with bottled urea in 2010 is 20 million vehicles, or roughly $9 \%$ of the entire US PC and LDT population that existed in 2001 [18]. Based on predicted LD vehicle growth rates, it will be well after 2025 before widespread co-fueled urea could compete with bottled urea.

Scenario 3: Introduction of Bottled Urea in 2007 and Co-Fueled Urea Phase-in Starting 2010: The previous scenarios have shown that the lowest supply costs are achieved by using bottled urea starting in 2007 and that wide-scale introduction of urea co-fueling is more costly in any near term time scale. In 2010, the lowest cost scenario for co-fueling is to install preferentially at only the highest throughput light-duty diesel stations. In this scenario co-fueling would be introduced at less than $1 \%$ of stations, and long-term cofueled urea costs are expected to be $\$ 1.50 /$ gal. Note that the decision to install cofueling equipment is based entirely on the economics at the service station, and the decision of owners to increase co-fueling installations would be made on a station-bystation basis. 


\section{CONCLUSION}

The following conclusions emerge from this study:

With a baseline urea SCR and CDPF emission control system, over $80 \%$ NOx reduction was achieved on a $6000 \mathrm{lbs}$ light-duty truck on the FTP-75 cycle, and tailpipe NOx was below the Tier 2 Bin 8 emission standard $(0.2 \mathrm{~g} / \mathrm{mi} \mathrm{NOx})$. Good mixing of aqueous urea in the exhaust gas was essential for full utilization of the reductant by the SCR catalyst, thus improving NOx conversion. Through modeling, rapid warm-up of the exhaust system during cold-start was found to be critical to achieve the $90+\%$ NOx conversion required to meet the light-duty Tier 2 Bin 5 standards.

The components of the baseline SCR and CDPF system were improved in the laboratory. $\mathrm{DOC}$ sample $\mathrm{AB}$ had the highest $\mathrm{NO}_{2}$ production after aging, although it was not the best catalyst for low temperature $\mathrm{HC}$ conversion. Long-chain $\mathrm{HC}$ such as those present in diesel fuel were found to suppress NO oxidation. In the laboratory flow reactor, the program SCR catalyst A3 withstood temperatures in excess of those typically associated with CDPF regeneration, and NOx conversion was high assuming the upstream oxidation catalyst had some activity for $\mathrm{NO}_{2}$ production. SCR catalyst aging with sulfur and hydrocarbons was studied in greater detail and any poisoning effects were found to be reversible. New SCR catalysts were developed that have improved NOx conversion after $120 \mathrm{k}$ mi equivalent aging. Long-term hydrothermal aging at $670^{\circ} \mathrm{C}$ decreased the ability of base metal/zeolite SCRs to store ammonia. SCR catalysts were used downstream of reduced size LNTs with favorable results, although the system cost and fuel penalty were higher than for urea SCR. Laboratory and vehicle testing of pre-production $\mathrm{NOx}$ and prototype $\mathrm{NH}_{3}$ sensors was successful. The NOx sensor behavior in diesel exhaust and its cross-sensitivity with $\mathrm{NH}_{3}$ was understood, and initial results with a prototype $\mathrm{NH}_{3}$ sensor onboard the vehicle were favorable. Nearly complete regeneration of a CDPF was achieved within ten minutes, or less time than one FTP-75 cycle.

The objective of $0.07 \mathrm{~g} / \mathrm{mi}$ NOx and $0.01 \mathrm{~g} / \mathrm{mi} P M$ on an engine dynamometer over the FTP-75 was met with an improved fresh emission control system of Urea SCR and a CDPF. System improvements were required to lower engine-out NOx and enable rapid exhaust system warm-up. The improved Urea SCR and CDPF system was aged successfully on the engine dynamometer for the equivalent of $50 \mathrm{k} \mathrm{mi}$ on the Ford High Speed Cycle. Evaluation of the aged system on the LDT resulted in HC, CO \& PM emissions that met Tier 2 Bin 5 standards at 50k mi. However, NOx emissions were $0.09 \mathrm{~g} / \mathrm{mi}$ and were predicted to be $0.05 \mathrm{~g} / \mathrm{mi}$ (Bin 5) if rapid warm-up during cold-start was functional.

The improved Urea SCR and CPDF system was aged successfully for another $70 \mathrm{k} \mathrm{mi}$ on the engine dynamometer using the same aging cycle, bringing the total aging time to about 2500 engine hours or an equivalent total mileage of $120 \mathrm{k} \mathrm{mi}$. The CDPF was regenerated a total of 643 times, with each regeneration typically lasting ten minutes, including six minutes with the SCR at high temperature (over $600^{\circ} \mathrm{C}$ ). In all, the SCR 


\section{CONCLUSION (CON'T)}

spent approximately $64 \mathrm{~h}$ at high temperature during the durability phase, similar to the lab aging time. PM, NMOG and CO emissions were within Tier 2 Bin 5 limits, but Bag 1 NOx emissions were higher than expected due to the lack of a reliable rapid warm-up strategy during cold start. Overall FTP-75 NOx conversion was $74 \%$ conversion with $0.128 \mathrm{~g} / \mathrm{mi}$ at the tailpipe, exceeding the Tier 2 Bin 5 standard at $120 \mathrm{k} \mathrm{mi} \mathrm{of} 0.07 \mathrm{~g} / \mathrm{mi}$ NOx. This result was improved by using a fresh DOC upstream of the $120 \mathrm{k}$ mi SCR $(0.091 \mathrm{~g} / \mathrm{mi})$; therefore, the durability of the DOC had a significant impact on SCR performance. An improved SCR catalyst (B) was oven-aged and tested with the 120k mi DOC resulting in $0.08 \mathrm{~g} / \mathrm{mi} \mathrm{NOx}$, and $0.06 \mathrm{~g} / \mathrm{mi} \mathrm{NOx}$ with a fresh DOC. Again the importance of DOC durability for long-term NOx reduction was shown.

A semi-empirical DOC model was developed based on the SIMTWC framework. The model was calibrated using the pulsator reactor data and was used to predict $\mathrm{NO}_{2}$ generated by the DOC. The model was able to explain the inhibition effect of HCs on $\mathrm{NO}_{2}$ production. The DOC model was used along with an SCR model to explain (1) the importance of $\mathrm{NO}_{2}$ generated in the DOC for the increased SCR performance, and (2) the trade-off between increasing the size of the catalyst to generate more $\mathrm{NO}_{2}$ and the reduction of SCR performance due to the reduced SCR input temperatures.

A more detailed SCR model was developed that considered energy and mass balances with the description of $\mathrm{NH}_{3}$ algorithms, $\mathrm{NH}_{3}$ oxidation as well as several selective $\mathrm{NH}_{3}$ reactions with NOx. Overall the model prediction results agreed well with the measured data. The successful development of the SCR model will guide the study of several key design factors for SCR systems and aid in the development of urea control strategy for maximum $\mathrm{NOx}$ reduction with minimum $\mathrm{NH}_{3}$ slip.

An infrastructure for aqueous urea delivery to light-duty diesel vehicles appears feasible. The urea solution will need to be heated in colder climates $\left(<12^{\circ} \mathrm{F}\right)$. A cofueling dispenser for urea and diesel fuel was tested successfully to minus $20^{\circ} \mathrm{F}$, and a potential nozzle durability issue was discovered. The cost of aqueous urea for LD diesel vehicles was high in the short-term during introduction. Costs were minimized when bottled urea was used initially and co-fueling was phased in gradually. The longterm cost of co-fueled aqueous urea was $\$ 1.50$ to $\$ 2$ per gallon. Cross contamination of urea into diesel remained a concern for co-axial design due to urea line connection within the diesel re-fueling stream. 


\section{REFERENCES}

1. R.M. Heck and R.J. Farrauto, Catalytic Air Pollution Control, Van Nostrand Reinhold, NY, 1995.

2. H. Luders, R. Backes, G. Huthwohl, D.A. Ketcher, R.W. Horrocks, R.G. Hurley, and R.H. Hammerle, "An Urea Lean NOx Catalyst System for Light Duty Diesel Vehicles," SAE 952493.

3. P. Tennison, C. Lambert and M. Levin, "NOx Control Development with Urea SCR on a Diesel Passenger Car," SAE 2004-01-1291.

4. W. Held, A. Konig, T. Richter, L. Puppe, "Catalytic NOx Reduction in Net Oxidizing Exhaust Gas," SAE 900496.

5. W.R. Miller, J.T. Klein, R. Mueller, W. Doelling, J. Zuerbig, "The Development of Urea-SCR Technology for US Heavy Duty Trucks," SAE 2000-01-0190.

6. W. Mueller, H. Ölschlegel, A. Schäfer, N. Hakim and K. Binder, "Selective Catalytic Reduction - Europe's NOx Reduction Technology," SAE 2003-01-2304.

7. P. Laing, et al. "A Simplified Approach to Modeling Exhaust System Emissions: SIMTWC," SAE 1999-01-3476.

8. Christine Lambert, Robert Hammerle, Ralph McGill, Magdi Khair and Christopher Sharp, "Technical Advantages of Urea SCR for Light-Duty and Heavy-Duty Vehicle Applications," SAE 2004-01-1292.

9. G. Madia, M. Koebel, M. Elsener, A. Wokaun, "The Effect of an Oxidation Precatalyst on the NOx Reduction by Ammonia SCR", Industrial \& Engineering Chemistry Research, 41 (2002) 3512.

10. L. Castoldi, I. Nova, L. Lietti and P. Forzatti, "Study of the effect of Ba loading for catalytic activity of $\mathrm{Pt}-\mathrm{Ba} / \mathrm{Al}_{2} \mathrm{O}_{3}$ model catalysts," Catalysis Today, Vol. 96, Issues 12, 1 October 2004, Pages 43-52.

11. C-H. Wu and R. Hammerle, "An On-board Reductant Delivery System for Diesel Aftertreatment," SAE 2001-01-3622.

12. C. Lambert, C. Montreuil, J. Vanderslice, "Application of Organic Freeze-point Depressants in Aqueous Urea Solutions: Effect on NOx Reduction", SAE 2003-010775. 


\section{REFERENCES (CON'T)}

13. M.B. Levin, R.E. Baker, "Co-fueling of Urea for Diesel Cars and Trucks," SAE 200201-0290.

14. S. Fable, F. Kamakate, S. Venkatesh, "Selective Catalytic Reduction Urea Infrastructure Study," AD Little report to NREL, July 2002.

15. "SCR-Urea Infrastructure Implementation Study Final Report," TIAX report to the Engine Manufacturers Association, July 30, 2003.

16. "Annual Energy Outlook 2003 With Projections to 2025," DOE Energy Information Administration, January 2003, http://www.eia.doe.gov/oiaf/archive/aeo03/index.html

17. MOBILE6 Vehicle Emission Modeling Software, US EPA, http://www.epa.gov/otaq/m6.htm

18. http://www.bts.gov 


\section{BIBLIOGRAPHY}

1. Christine K. Lambert, Paul M. Laing, and Robert H. Hammerle, "Using Diesel Aftertreatment Models to Guide System Design for Tier 2 Emission Standards," SAE 2002-01-1868.

2. David Kubinski, Richard Soltis, Jacobus Visser and Michael Parsons, "Detection of $\mathrm{NH}_{3}$ using a YSZ-based potentiometric sensor with a tungsten oxide electode." Proceedings of Electrochem. Soc. Meeting, San Fran., CA, Sept. 2-7, 2001.

3. R. E. Soltis, K. E. Nietering, D. Kubinski, "Non-ideal behavior of zirconia-based NOx sensors under reducing conditions", 9th International Meeting on Chemical Sensors in Boston, July 7-10, 2002.

4. R. Hammerle, "Urea SCR and DPF System for Diesel Sport Utility Vehicle Meeting Tier 2 Bin 5", 2002 DEER Conference.

5. C. Lambert, C. Montreuil, J. Vanderslice, " Application of Organic Freeze-point Depressants in Aqueous Urea Solutions: Effect on NOx Reduction", SAE 2003-010775 .

6. A. K. Prasad, P. I. Gouma, D. J. Kubinski, J. H. Visser, R. E. Soltis and P. J. Schmitz, "Reactively Sputtered $\mathrm{MoO}_{3}$ Films for Ammonia Sensing", Thin Solid Films, 436 (1) 2003, pp 46-51. Also presented at the 2002 Semiconducting Gas Sensor Conference, Ustron, Poland in September, and at the 2003 American Ceramic Society Meeting, Nashville in April.

7. A. K. Prasad, D. J. Kubinski and P. I. Gouma, "Comparison of Sol-gel and Ion Beam Deposited $\mathrm{MoO}_{3}$ Thin Film Gas Sensors for Selective Ammonia Detection", Sensors and Actuators B: Chemical, 93 (1-3) 2003, pp 25-30. Also presented at the 2002 International Meeting on Chemical Sensors, Boston (July).

8. D. Kubinski, R. Novak and R. Soltis, "H-ZSM5 zeolite gas sensors: Temperature Dependence of the Ammonia Sensitivity", 2002 International Meeting on Chemical Sensors, Boston (July).

9. Christine Lambert, Robert Hammerle, Ralph McGill, Magdi Khair and Christopher Sharp, "Technical Advantages of Urea SCR for Light-Duty and Heavy-Duty Vehicle Applications," SAE 2004-01-1292.

10. C. Lambert, et al., "Urea SCR and DPF System for Diesel Sport Utility Vehicle Meeting Tier 2 Bin 5", 2003 DEER Conference.

11. C. Lambert, et al., "Urea SCR and DPF System for Diesel LDT/SUV Meeting Tier 2 Bin 5", 2004 DEER Conference. 


\section{BIBLIOGRAPHY (CON'T)}

12. C. Lambert, "Ford/DOE SCR Program Update," $8^{\text {th }}$ CLEERS Workshop, May 19 , 2005, Dearborn, MI.

13. C. Lambert, et al., "Urea SCR and DPF System for Diesel LDT/SUV Meeting Tier 2 Bin 5", 2005 DEER Conference.

14. C. Lambert, "Ford/DOE SCR Program Update," $9^{\text {th }}$ CLEERS Workshop, May 3, 2006, Dearborn, MI. 


\section{LIST OF ACRONYMS AND ABBREVIATIONS}

$\begin{array}{ll}\text { CDPF } & \text { Catalyzed Diesel Particulate Filter } \\ \text { CFD } & \text { Computational Fluid Dynamics } \\ \text { CIDI } & \text { Compressed Ignition Direct Injection } \\ \text { CO } & \text { Carbon Monoxide } \\ \mathrm{CO}_{2} & \text { Carbon Dioxide } \\ \text { DDASSL } & \text { Double-precision Differential Algebraic System SoLver } \\ \text { DOC } & \text { Diesel Oxidation Catalyst } \\ \text { EMRE } & \text { ExxonMobil Research \& Engineering } \\ \text { FTIR } & \text { Fourier Transform Infra-Red } \\ \text { FTP-75 } & \text { Federal Test Procedure for LD vehicles } \\ \text { HC } & \text { Hydrocarbons } \\ \text { LD } & \text { Light-Duty } \\ \text { LDT } & \text { Light-Duty Truck } \\ \text { LNT } & \text { Lean NOx Trap } \\ \mathrm{N}_{2} & \text { Nitrogen } \\ \text { NMOG } & \text { Non-Methane Organic Gases } \\ \text { NOx }\left(N O, \mathrm{NO}_{2}\right) & \text { Oxides of Nitrogen (Nitrogen Oxide, Nitrogen Dioxide) } \\ \mathrm{N}_{2} \mathrm{O} & \text { Nitrous Oxide } \\ \text { NH } & \text { Ammonia } \\ \mathrm{O}_{2} & \text { Oxygen } \\ \text { PC } & \text { Passenger Car } \\ \text { PM } & \text { Particulate Matter } \\ \text { SCR } & \text { Selective Catalytic Reduction } \\ \text { SFTP } & \text { Supplemental Federal Test Procedure } \\ \text { SIMTWC } & \text { Ford proprietary aftertreatment model } \\ \text { SOx } & \text { Sulfur Oxides (SO }{ }_{2}, \mathrm{SO}_{3} \text { ) } \\ \text { THC } & \text { Total Hydrocarbon } \\ \text { TPD } & \text { Temperature Programmed Desorption } \\ \text { VERL } & \text { Vehicle Emissions Research Laboratory } \\ \text { YSZ } & \text { Yttria-Stabilized Zirconia } \\ & \end{array}$

